\title{
2. WUNDER UND AUTORITÄTEN
}

Guiberts Deutung von Ereignissen als Wunder und seine Reflexion über Rahmenbedingungen für Wunder sind durch Traditionen und autoritative Texte geprägt. Deutungen von Ereignissen als Wunder sind aber auch Gegenstand von Diskussionen über diese Phänomene in einem aktuellen gesellschaftlichen Zusammenhang, die sich wiederum in Texten niederschlagen. In Guiberts Texten findet sich eine große Spannweite von Wundern: Von klerikal kontrollierten Wundern, Schreinswundern, die am Grab von Heiligen geschehen, über ungebundene, direkte Wunder von Heiligen, bis zu solchen Wundern, die in Zusammenhang stehen mit Kulten, die nicht akzeptiert werden können und in die Nähe der Häresie rücken. Guibert berichtet von vielen Marienwundern, die sich unabhängig von einem Schrein ereignen, auch von Wundern, die Gott ohne heilige Mittler direkt wirkt.

In einem ersten Schritt soll Guiberts Deutungsarbeit von Ereignissen als Wunder und seine Kriterien dieser Deutungsarbeit im Zentrum stehen. Der Umgang Guiberts mit dem Wunder wird dabei in Zusammenhang gesetzt mit seiner Auseinandersetzung mit der Tradition, aber auch mit Vorfällen in seiner Umgebung. Ausgangspunkte für die Analyse der Deutungsarbeit Guiberts sind sowohl dessen Begrifflichkeit als auch die Reflexion über Wunder, die Guibert im ersten Buch seiner Reliquienkritik im Zusammenhang mit dem Reliquienkult liefert. Auch in den anderen Schriften Guiberts sind Hinweise auf seine Wunderkonzeption faßbar. Deshalb soll der Frage nachgegangen werden, in welche Zusammenhänge diese Wunderkonzeption einzuordnen ist. In diesem ersten Teilkapitel geht es darum, besser fassen zu können, welche Ereignisse mit welchen Deutungsschemata als Wunder erfaßt werden ${ }^{1}$. Um die Deutungsschemata besser verstehen zu können, muß erst der Frage nach den intellektuellen Traditionen nachgegangen werden. Dabei interessieren vor allem Bezüge von Guiberts Text zu anderen Texten und zu Autoritäten.

Am Anfang der Deutungsarbeit stehen zumeist regionale und relativ aktuelle Ereignisse ${ }^{2}$, die Guibert als sinnhaft in seine Schriften einfügt. Auf dem Weg eines Ereignisses zur Wundererzählung interessiert hier der Punkt, an dem diesem Ereignis sinnhafter Charakter zugesprochen wird ${ }^{3}$.

Guibert konzentriert seine Überlegungen jedoch nicht auf die Deutung von Ereignissen als Wunder. Er verlagert seinen Blick vielmehr vom Inhalt eines

1 In diesem ersten Teilkapitel soll der erste Schritt des von BoEsch Gajano, Verità e pubblicità, S. 372, genannten Weges der Wunder beleuchtet werden: Vom Ereignis zu dessen Zuordnung mirakulösen Charakters.

2 Siehe dazu unten, Kap. 3.

${ }^{3}$ Die Deutungsproblematik ist zweischichtig: Neben die Deutung von Ereignissen als Wunder tritt die Deutung der Wunderzeichen in ihrem Bedeutungsgehalt für die Umgebung. Dieser zweite Deutungsschritt steht im Zentrum des vierten Kapitels. 
wunderbaren Ereignisses auf die Rahmenbedingungen, die ein Wunder überhaupt erst ermöglichen. Deren drei können gesehen werden: Einerseits ist der Betroffene des Wunders Gegenstand der Betrachtung. Andererseits ist der Mittler und dessen Kult für die Beurteilung des Ereignisses wichtig. Die dritte Rahmenbedingung, die Bezeugung des Ereignisses, wird in Kapitel 3 ausführlich diskutiert.

Im zweiten Teil des Kapitels verschiebt sich der Blickwinkel auf Guiberts soziales Umfeld. Dabei steht Umgang kirchlicher Autoritätspersonen mit dem Wunder im Zentrum der Betrachtung. Das Problem, in dessen größerem Zusammenhang die Beschäftigung mit dem Wunder steht, ist in diesem Umfeld Guiberts aktuell: Die Heiligsprechung und das Urteil über konformen oder häretischen Kult. Guiberts Beschäftigung mit dem Wunder ist also auch in einen institutionellen Diskurs eingebunden. Schon in der augustinischen Wunderkonzeption spielt die institutionelle Verankerung der Anerkennung von Wundern für deren Glaubwürdigkeit eine große Rolle 4 . Auch Guibert äuBert diese Forderung wiederholt. Daher steht hier im Zentrum des Interesses, wo in Guiberts Umfeld entschieden wird, ob ein Ereignis als Wunder anerkannt werden soll oder nicht. Stehen im ersten Teil die Deutungsschemata einer Einzelperson, Guiberts, im Zentrum, wird im zweiten Teil der Blick auf eine Gruppe in Guiberts sozialem Umfeld gelenkt. Kurz bevor das Papsttum das Kanonisationsverfahren entwickelt und sich als dessen Instanz durchsetzt, befaßt sich diese Gruppe als kirchliche Autorität in mehr oder weniger formalisierten Verfahren mit der Anerkennung von Ereignissen als Wunder.

Ob die konkrete Beschäftigung mit dem Wunder in Guiberts Umfeld zu einer theoretischen Beschäftigung Guiberts mit dem Problem des Wunders führt oder ob diese Beschäftigung als Folge von Guiberts exegetischer Tätigkeit betrachtet werden kann, läßt sich nicht festmachen. Eine Wechselwirkung ist aber augenfällig. Diese findet Niederschlag in der Reliquienkritik, zeigt sich aber auch in Erzählungen in anderen Werken Guiberts.

${ }^{4}$ DCD 21, 6, S. 397 (Bibliothèque augustinienne 37). 


\subsection{Was ist ein Wunder?}

\subsubsection{Gelehrte Zurückhaltung}

Die Diskussion über Wunder im Mittelalter wurde von der Forschung meist im Zusammenhang mit dem Heiligen- und Reliquienkult geführt. Auch in den mittelalterlichen Quellen stehen diese Bereiche oft in engem Zusammenhang. So entwickelt auch Guibert seinen Exkurs über Wunder im Kontext seiner Reflexion über die Reliquienverehrung. Darüber hinaus versucht er aber, die Reliquienverehrung in den größeren Zusammenhang der Glaubenspraxis zu stellen. Dabei deutet er an, daß der Bereich der Heiligenverehrung und somit auch der damit verbundenen Wunder nicht durch Autoritäten geregelt sei5. Dies im Gegensatz zum Bereich der Sakramente. Für Taufe und Eucharistie gäbe es Schriften, die deren Praxis regeln würden. Taufe und Eucharistie, zentrale Glaubensinhalte, könnten daher überall gleich praktiziert werden. Dagegen zählt Guibert den Reliquienkult, ähnlich wie das Fasten und das Singen von Psalmen, nicht zu den verbindlich geregelten Vorgaben, sondern zu den Bräuchen der Christenheit. Gläubige könnten ein gottgefälliges Leben auch ohne deren Praxis verbringen. Er unterscheidet also Bereiche, die in der Glaubensgemeinschaft praktiziert und gelehrt wurden, das heißt, worüber es einen theologischen Diskurs und autoritative Schriften gab, von solchen, die nicht durch autoritative Schriften geregelt waren und die so Probleme der Interpretation und Ausführung bereiten konnten.

Guibert unterscheidet also Taufe und Eucharistie, wovon die Lehre auf Autoritäten beruht, von der Heiligenverehrung, die nicht von Schriften geregelt wird. Gerade die Wunder werden aber einerseits im Bereich der autoritativen Schriften thematisiert (Guibert bezeichnet die jungfräuliche Geburt Jesu als Wunder) und sind andererseits mit dem zweiten Bereich der Heiligen- und Reliquienverehrung untrennbar verbunden. So sind es die von den Saint-Médardenser Mönchen festgehaltenen Wunder einer Christusreliquie, des Milchzahns Christi, die Guiberts Mißfallen erregen. Dies, da die Reliquie als Teil

5 Guibert de Nogent, Quo ordine, P, I, S. 86f., Z. 60-65: Preterea sunt quaedam quae, etsi inter summe necessaria saluti nostrae, de quibus agimus, non computantur, sine quibus vivi recte non potest, tamen et tenentur et in ecclesiis predicantur, sine quorum plane usu et presentia multi vitas bene transegerunt et transigunt, ut sunt cadavera sanctorum, ut pignera de iis videlicet, quae fuerunt in usibus ipsorum. »Außerdem gibt es gewiße Dinge, die, wenn sie zwar nicht zu dem in höchstem Maße zum Heil Notwendigen, ohne das nicht richtig gelebt werden kann, gehören, an denen aber doch festgehalten wird und die in den Kirchen gepredigt werden. Allerdings haben viele ohne deren Gebrauch und Vorhandensein ihr Leben gut verbracht und verbringen es noch immer. Dazu gehören die Leiber der Heiligen, in ihrer Eigenschaft als Unterpfänder, die in deren Gebrauch waren.« Dazu Srock, Implications, S. 245; Snoek, Medieval Piety, S.353f.; Lobrichon, Culte, rire, triomphe, S. 108. Auch Röckelein, Pragmatik, S. 226, Anm.7, macht darauf aufmerksam, daß die Hagiographie nicht zu den autorisierten Schriften zählt und somit anfechtbar ist. 
des irdischen Körpers Christi durch ihre Herkunft den geregelten Bereich berührt, in ihrem aktuellen Gebrauch durch die Mönche von Saint-Médard aber zum nicht geregelten Bereich der Reliquienverehrung gehört. Die Anerkennung der Körperreliquie Christi bereitet Schwierigkeiten, da sie mit der heiklen Frage der Realpräsenz in engem Zusammenhang steht ${ }^{6}$.

Überlegungen zum Reliquienkult wurden immer wieder angestellt. Diese sind in Zusammenhang zu stellen mit Forderungen nach institutionell anerkannter Heiligkeit und geregeltem Kult. Sie sind in erster Linie in der Spätantike, in der Karolingerzeit und um die Jahrhundertwende vom 11. zum 12. Jahrhundert aktuell und vor allem im kirchenrechtlichen Bereich faßbar: In Konzilsbeschlüssen wurden Richtlinien der Heiligenverehrung formuliert? Wenn in anderen Textsorten Vorbehalte gegen den Reliquienkult formuliert wurden, betrafen diese eher Mißbräuche durch den Klerus oder Diskussionen von Einzelfällen als eine grundsätzliche Erörterung oder gar kritische Reflexion der Heiligenverehrung, wie dies Guibert in seinem Traktat leistet ${ }^{8}$. Eine Ausnahme davon bilden die Reaktionen auf die Stellungnahmen des Claudius von Turin gegen Bilder- und Reliquienverehrung durch Dungal von Saint-Denis und Jonas von Orléans in der ersten Hälfte des 9. Jahrhunderts9.

6 Der Milchzahn ist insofern problematisch, als er als menschlicher Überrest eigentlich hätte auf Erden verbleiben können. Dazu ANGENENDT, Corpus incorruptum, S. 345. GuiberT DE Nogent, Quo ordine, Einleitung, S. 16. Zu dieser Überlegung auch RuBENSTEIN, Guibert of Nogent, S. 139. Die Hypothese von BENTON, Self and Society, S. 29f., daß Guibert wegen einer allgemeinen Abscheu vor Körperlichkeit Körperreliquien Christi nicht akzeptieren könne, ist auf der Basis moderner psychohistorischer Ansätze entwickelt worden und bezieht die theologischen Überlegungen Guiberts zu wenig ein.

7 So wurden beispielsweise im 3. Konzil zu Karthago im Jahr 401 Bedingungen für die Verehrung von Märtyrern formuliert: Die Reliquien und die lokale Tradition sollten überprüft werden, die Entscheidungsgewalt über die Verehrung beim lokalen Bischof liegen: Can. 15: Item placuit ut de altaribus quae passim per agros aut vias tanquam memoriae martyrum constituuntur, in quibus nullum corpus aut reliquiae martyrum conditae probantur, ab episcopis, qui iisdem locis praesunt, si fieri potest, evertantur. Si autem hoc per tumultus populares non sinitur, plebes tamen admoneantur, ne illa loca frequentent, ut qui recte sapiunt, nulla ibi superstitione devincti teneantur. Et omnino nulla memoria martyrum probabiliter acceptetur, nisi ubi corpus aut aliquae reliquiae sunt, aut origo alicuius habitationis, vel passionis fidelissima origine traditur. Nam quae per somnia et per inanes quasi revelationes quorumlibet hominum ubicumque constituuntur altaria, omnimodo improbentur. Concilia Africae, S. 359. Siehe dazu unten, Kap. 2.2.2.; Delehaye, Sanctus, S. 172f.; Kemp, Canonization and Authority, S. 15.

8 So kritisiert Agobard von Lyon, Epistola ad Bartholomäum, nur das Verhalten des Klerus. Siehe Geary, Furta sacra, S. 32. Weitere Beispiele bei Schreiner, Discrimen veri ac falsi.

9 So nennt GEaRY, Furta sacra, S. 32 für die Karolingerzeit als kritische Stellungnahme zum Reliquienkult einzig diejenige des Claudius von TuRIN, der sich in seinen ikonoklastischen Stellungnahmen Apologeticum atque rescriptum Claudii episcopi adversus Theutmirum abbatum, ed. Ernst Dümmler, MGH Epp. Karol. IV, Berlin 1985, S. 610-613, ablehnend zur Bilder- und Reliquienverehrung und den Wallfahrten äußert. Dieser ablehnenden Haltung wird darauf von Dungal von Saint-Denis in der Responsa contra perversas Claudii Taurinensis episcopi sententias und von Jonas von Orléans in seiner Widerlegung de cultu imaginum widersprochen. Dazu siehe BrunHölzL, lateinische Literatur, Bd. 1, S. 305f. bzw. 406. 
Auch zeitgenössische größere Abhandlungen über Reliquien und Heiligenverehrung sind, jenseits von Randbemerkungen in hagiographischen Texten, an der Wende vom 11. zum 12. Jahrhundert selten. Zu Beginn des 12. Jahrhunderts verfaßte Thiofrid von Echternach die Flores epyitaphii sanctorum, eine Abhandlung über den Reliquienkult ${ }^{10}$. Obwohl zwischen dieser Abhandlung und Guiberts Reliquienkritik thematische Parallelen gezogen werden können, sind sie von unterschiedlichem Charakter und legen andere Schwerpunkte ${ }^{11}$. Thiofrid konzentriert sich in seiner Abhandlung auf die Reliquien als Gefäße, durch welche Gott seine Wunder tut. Seine Schrift liest sich als Typologie von Reliquien und konzentriert sich auf anerkannte Reliquien ${ }^{12}$. Guibert hingegen versucht im Laufe seiner Kritik der Mißbräuche von Reliquien, Kriterien für die Anerkennung von Heiligen zu finden. Daß er im Laufe dieser Argumentation ausführlichere Überlegungen zum Wunder anstellt als Thiofrid ${ }^{13}$, ist auch im Werk angelegt. Obwohl auch Thiofrid den Vergleich zwischen Eucharistie und Reliquienkult zieht ${ }^{14}$, nimmt dieses Thema bei Guibert, der das Konzept der Körperreliquien Christi angreift, einen gewichtigeren Stellenwert ein. Thiofrid konzentriert sich auf Reliquien von Heiligen, während Guibert eine breiter angelegte Abhandlung bietet. Ob Guibert Thiofrids Schrift gekannt hat, ist nicht bekannt. Einerseits scheint er auf gewisse von Thiofrid erwähnte Punkte eine Replik zu bieten, andererseits besteht kein Anhaltspunkt, $\mathrm{da} B$ er eine Kopie der Schrift, die in zwei Handschriften aus Echternach überliefert ist, gesehen haben könnte ${ }^{15}$.

Überlegungen zu Heiligen oder Reliquien sind jedoch im anglonormannischen Bereich belegt, vor allem in hagiographischen und liturgischen Quellen. Lanfranc, 1070 als Erzbischof von Canterbury eingesetzt, griff regulierend in die Verehrung angelsächsischer Heiliger ein, indem er beispielsweise Veränderungen am Festkalender vornahm ${ }^{16}$. Diese Überlegungen sind in die kirchlichen Neuordnungen nach der normannischen Eroberung 1066 einzuordnen ${ }^{17}$. In diesen Zusammenhang ist auch die Diskussion von Lanfranc und Anselm über die Heiligkeit ihres Vorgängers auf dem erzbischöflichen Stuhl in Canterbury, Elfegus ( $† 1012$ ), zu stellen. Guibert bezieht sich in der Reliquienkritik auf diese Diskussion, sie ist aber auch in der Vita des heiligen

10 Thiofrid Abbatis Echternachensis, Flores epytaphii, S. IX zur Datierung des Werkes zwischen 1098 (1102) und 1104/1105.

11 Zum Aufbau von Thiofrids Werk: Ibid. S. LVIII-LIX.

12 Ferrari, Lemmata, S. 219. Eine Zusammenfassung des Inhalts von Thiofrids Abhandlung bei Thiofridi AbBatis Echternachensis, Flores epytaphii, S. XX-XXXV.

13 Für eine kurze Überlegung zur Natur von Wundern bezieht sich Thiofrid im dritten Buch der Flores auf Augustinus' Reflexion in DCD, Buch 22. Thiofridi AbBatis EchTERNACHENSIS, Flores epytaphii, III, 7, S. 78, siehe dazu auch S. XLV.

14 Ferrari, Lemmata, S. 223.

15 Ibid. S. 225.

16 Diese Veränderungen sind in den Decreta Lanfranci, S. 55-67, ersichtlich. Siehe dazu RubEnStein, Liturgy, S. 283f.; Gibson, Lanfranc, S. 170-173.

17 Siehe dazu auch unten, S. 86. 
Anselm, geschrieben von Eadmer, belegt ${ }^{18}$. Eadmer, ein Schüler Anselms, verfaßte zudem einen kurzen Traktat über die Heiligenverehrung in der monastischen Gemeinschaft ${ }^{19}$. Auch in seinen weiteren hagiographischen Schriften sind Reaktionen auf die Reformen Lanfrancs zu sehen. Dies gegen dessen Bemühungen, der Verehrung von Christus und der Eucharistie einen höheren Stellenwert gegenüber der Verehrung von Heiligen und deren körperlichen Resten zu geben ${ }^{20}$. Auf die Beziehungen Guiberts zu diesem angelsächsischen Kreis von gelehrten Mönchen und hohen geistlichen Würdenträgern wird später genauer eingegangen.

Auch im Zusammenhang des ersten Kreuzzugs wurde über eine Reliquie diskutiert: Um die Auffindung der heiligen Lanze wurde heftig gestritten. Es ging dabei aber eher um die konkrete Anerkennung dieser Auffindung als um grundsätzliche Reflexionen über den Reliquienkult ${ }^{21}$.

Kritische Bemerkungen zu Körperreliquien Christi finden sich nicht erst in Guiberts Reliquientraktat. Schon im Wunderbuch der Mönche aus St. Médard ist ein Einwand gegen den Milchzahn Christi formuliert. Dort werden Äußerungen von Zweiflern eingeführt, die gegenüber den Mönchen feststellen, daß nach der Auferstehung keine Überreste Christi auf Erden zurückgeblieben seien. Der Einwand wird im Wunderbuch schließlich durch ein Wunder entkräftet ${ }^{22}$. Dieses Zeugnis zeigt, daß die Überlegungen, die in theoretischen Traktaten wie denjenigen des Guibert oder des Thiofrid formuliert werden, verbreiteter waren, als dies die handschriftliche Überlieferung dieser Traktate vermuten lassen könnte ${ }^{23}$, oder auch, daß solche Überlegungen nicht so singulär waren, wie es diese außergewöhnlichen Schriften vermuten lassen.

Abhandlungen, deren hauptsächlicher Gegenstand die Erörterung des Phänomens Wunder ist, sind mir keine bekannt. So wird auch für die Wende vom 11. zum 12. Jahrhundert von einer Konzeption von Wundern ausgegangen, die von augustinischem und gregorianischem Gedankengut geprägt ist. Während bei Augustin eine philosophisch-theologische Konzeption des Wunders zu erkennen ist, charakterisiert die Abwesenheit definitorischen Bemühens das Werk Gregors des Großen ${ }^{24}$.

18 Die Diskussionen um Elfegus sind bei GuiberT DE Nogent, Quo ordine, S. 88 und in der Vita Sancti Anselmi des Eadmer bezeugt. Siehe unten, S. 72, Anm. 181.

19 Sententia de memoria sanctorum quo veneraris, ed. André WILMART, in: Revue des sciences religieuses 15 (1935), S. 190f., zit. aus Rubenstein, Guibert of Nogent, S. 127.

20 Rubenstein, Liturgy, S. $304 \mathrm{f}$.

21 Siehe dazu Giese, Lancea Domini, Flori, Encore l'usage.

22 Miracula SS. Gregorii et Sebastiani, S. 238. Siehe dazu unten, Kap. 5.1.

23 Die systematische Untersuchung von Vorworten zu Mirakelsammlungen würde hier sicher vertiefte Erkenntnisse bringen.

24 Boesch Gajano, Proposta, S. 646f. und Anm. 128 mit Literaturhinweisen. Boglioni, Miracle et nature, S. 72-75 zu den Definitionen Augustins und der bewußten Nicht-Definition bei Gregor. 
Daß nur wenige Traktate bekannt sind, die sich auf grundsätzlicher Ebene mit Heiligen, Reliquienkult und Wundern auseinandersetzen, läßt sich vielleicht dadurch erklären, daß die Heiligenverehrung im zweiten, nicht durch Schriften geregelten Bereich des christlichen Kultes angesiedelt ist. Als sekundäres Phänomen der religiösen Praxis gehörte diese nicht zu den zentralen Glaubensgegenständen, die in Auseinandersetzung mit Nichtchristen und häretischen Gruppierungen seit der Spätantike immer wieder verhandelt werden mußte. Diskussionen über die Verehrung von Heiligen, bei denen Wunder eine Rolle spielten, wurden aber im Zuge von Reformen des Kultes sehr wohl geführt.

\subsubsection{Deutungsmuster bei Guibert de Nogent}

Die Bezeichnung und Einordnung von Ereignissen als Wunder spielt aber nicht nur im Zusammenhang mit Heiligen- und Reliquienkult eine Rolle. Wenn der Wunderglaube mit Michael Rothmann als Deutungs- und Verstehensparadigma verstanden werden soll, öffnet sich die Breite der Interpretation ${ }^{25}$. Wunder als Zeichen Gottes werden in verschiedenen Kontexten beobachtet und als solche gedeutet. Daher muß im folgenden nach Deutungsmustern und Konzeptionen gefragt werden, die Guiberts Wunderverständnis geprägt haben. Um diesem näher zu kommen, soll das Augenmerk als erstes auf eine von Guibert selbst erlebte Begebenheit gelenkt werden, die er als Wunder eingeordnet hat: ein Heilungswunder am Altar des heiligen Leodegar.

Guibert gibt an, daß er dieses Wunder in seiner Kindheit selbst erlebt habe. Es ist das einzige selbst erlebte Wunder, das Guibert erzählt. Er fügt die Erzählung am Schluß des dritten Buches der Monodiae ein. Das Wunder ist aus der Perspektive der Monodiae allerdings kein aktuelles Ereignis, sondern ein Kindheitserlebnis, das Guibert im Alter von ungefähr sechzig Jahren beschreibt:

Er erinnere sich noch sehr gut daran, wie er als kleiner Junge an heftigem Fieber erkrankt sei. Seine Mutter habe veranlaßt, daß er mit zwei Klerikern in einer Kirche der heiligen Leodegar und Macutus eine Nacht vor dem Altar des heiligen Leodegar verbringe. Diese Kirche, so erwähnt Guibert in einer Nebenbemerkung, habe zum Gut seiner Mutter gehört ${ }^{26}$. Die Vorgänge während der Nacht in der Kirche werden anschaulich geschildert:

25 Rothmann, Zeichen und Wunder, S. 347.

26 GuiberT DE Nogent, Autobiographie, III, 20, 464: Leodegarium martyrem, signis egregium, ad subventiones alacrem non nescimus. Ego enim, adhuc pusio, optime tamen horum memor, sub matre agens diebus pascalibus febre quotidiana atrociter aestuabam. Sub oppido autem erat ecclesia sub nomine sanctorum Leodegarii et Machuti, cui continuum olei lumen mater mea fide humili ministrabat. Cum ergo quicquid pene est victuum fastidirem, evocatis ipsa duobus clericis, capellano suo et magistro meo, sub eorum custodia eo me de. ferri praecipit. Juxta pravitatem vero veteris usus, ecclesia illa ad jus ejus pertinebat. Zum Problem der Eigenkirchen und ihrem Verhältnis zu den Pfarrkirchen siehe Avrıl, Églises paroissiales. Siehe zu dieser Episode auch Rubenstern, Principled passion, S. 140f. 
»Die Kleriker begaben sich also dorthin und ordneten an, daß für diese Nacht ihnen und mir vor dem Altar ein Bett aufgestellt werde. Mitten in der Nacht begann innerhalb der Kirche die Erde wie durch ein Hämmern zu zittern, mehrmals wurden die Schlösser der Truhen mit großem Lärm aufgerissen, und hin und wieder konnte man über diesen Truhen ein Rascheln wie von Zweigen hören. Die Kleriker, vom Lärm aus dem Schlaf gerissen, fürchteten sehr, mein Zustand könne sich vor Angst verschlimmern. Was weiter? Als sie flüsterten, hörte ich $\mathrm{zu}$, aber da sie mir nahe waren und eine Lampe, die in meiner Nähe leuchtete, mir Zuversicht gab, fürchtete ich mich nur wenig. Nachdem ich die Nacht so verbracht hatte, kehrte ich derart gesund zu meiner Mutter zurück, wie wenn ich keinerlei Unbill erlitten hätte, und während ich zuvor sogar allerfeinste Speisen verabscheut hatte, erwies ich mich jetzt der gewöhnlichen Kost zugetan, und nicht weniger auch dem Ballspiel $\aleph^{27}$.

Diese Geschichte führt Guibert damit ein, daß auch der Märtyrer Leodegar berühmt sei für seine signa und seine Schnelligkeit im Helfen. Hierbei handelt es sich wohl um die übliche Art, ein Wunder zu erleben: Im Falle einer Krankheit wurde der Altar eines Heiligen aufgesucht und betend die Nacht im Kirchenraum verbracht. Unerklärliche, unheimliche Wahrnehmungen von Geräuschen wurden als zum Wundervorgang gehörig beschrieben, der am nächsten Morgen abgeschlossen war. Das Erlebnis, das Guibert in der Nacht, in der Grauzone zwischen Wachen und Schlaf in fiebrigem Zustand hatte, wird auf ähnliche Weise wie eine Intervention von Dämonen beschrieben ${ }^{28}$. $\mathrm{Da}$ das persönliche Wundererlebnis in den Monodiae berichtet wird, stimmt mit der Ausrichtung des Werkes überein. Dieser Umstand zeigt deutlich, daß Guibert de Nogent Wunder nicht nur als distanzierter Analytiker betrachtet, sondern diese für ihn durchaus gelebte Realität sein können.

Pierre André Sigal stellte für die von ihm untersuchten Mirakelbücher fest, daß selbst erlebte Wunder von Hagiographen selten erwähnt werden. In zwei Fällen werden solche Vorfälle aber als Schreibanlaß für eine Wundersammlung genannt ${ }^{29}$. Auch bei diesen handelt es sich um Heilungswunder, um eine Fieberheilung und eine Befreiung von einer plötzlichen Lähmung. Das von Guibert erlebte Wunder, die Heilung eines Kindes von Fieber, würde in heutigem medizinischen Verständnis natürlichen Ursachen zugeschrieben.

Um Guiberts Deutungsmustern näher zu kommen, muß im folgenden das Augenmerk erst auf die Begrifflichkeit gelenkt werden, mit denen Wunder

27 GuIBERT DE Nogent, Autobiographie, III, 20, 464 466: Venientes ergo illuc clerici, stratum ante altare sibi et mihi nocte illa fieri imperarunt. Ecce nocte media intra eandem ecclesiam coepit terra quasi malleis concuti, aliquotiens serae arcarum cum multo strepitu circumvelli, crepitus aliquando quasi virgarum super arcas audiri. Clerici vero, a sonitu experrecti, coeperunt multum ne timor in deterius me verteret formidare. Quid plura? Eis mussitantibus subaudivi; tamen, ex eorum contubernio, et lampadis praelucentis solatio, parce timui. In his noctem transiens, ita sospes ad matrem redii, acsi nihil incommodi pertulissem, et qui pridem lautissima horrueram, communem jam promptus ad cibum, non minor sum repertus ad pilam.

28 Dazu Paul, Le démoniaque et l'imaginaire; siehe auch WITTMER-Butsch, Schlaf und Traum. Zu den Träumen Guiberts siehe auch Schmiтt, Les rêves de Guibert de Nogent.

29 Sigal, Travail, S. 157. 
bezeichnet werden. Dann muß nach Modellfiguren oder -situationen und Deutungshilfen gesucht werden, anhand derer Guibert Ereignisse als Wunder einordnet. Für die Deutung von Ereignissen als Wunder spielen die biblischen Bücher und die Vätertexte eine wichtige Rolle. Gerade Guibert läßt aber erkennen, daß diese Deutungsarbeit nicht immer eindeutig war und Zweifel an der Beurteilung von Phänomenen als Wunder bestanden. Um erklärungsbedürftige Vorfälle in seiner Umgebung einzuordnen, wurden diese mit anerkannten Wundern aus autoritativen Texten in Parallele gesetzt. Besonders problematisch war immer wieder die Beurteilung der zeitgenössischen Wunder. Diese waren oft nur mit Mühe mit den traditionellen Deutungsschemata in Parallele zu bringen. Die grundsätzlichen Vorbehalte Guiberts gegen diese zeitgenössischen Wunder sind jedoch ebenfalls in Übereinstimmung mit der theologischen Reflexion über diese Phänomene zu sehen, die bei Augustin und Gregor dem Großen bezeugt ist ${ }^{30}$.

\section{Signa und miracula}

$\mathrm{Da}$ es Wunder als Zeichen des Herrn gibt, ist für Guibert als mittelalterlichen Menschen unbestritten. Zeichen müssen aber gedeutet werden. Diese Deutung von Zeichen ist jedoch problematisch, ja auch schon die begriffliche Fassung von Zeichen uneindeutig.

Signum ist in Guiberts Werken der breiteste Begriff, womit wunderbare Ereignisse bezeichnet werden können. Im Traktat Contra judaizantem et Judaeos, einer Streitschrift gegen die Juden in der Gegend von Soissons, definiert Guibert Zeichen am explizitesten. Dies im Zusammenhang mit den jüdischen Argumenten gegen die jungfräuliche Geburt Christi. Die Geburt besitze Zeichencharakter, müsse also gegen den gewöhnlichen Lauf der Natur geschehen sein: Si autem signum est, contra usum naturae est ${ }^{31}$. Die Bedeutung des hebräischen Begriffs halma könne daher in bezug auf Maria nicht breit mit »junges Mädchen« übersetzt werden, wie die Juden behaupten würden, sondern müsse mit »Jungfrau« übersetzt werden ${ }^{32}$. Guibert variiert in bezug auf die jungfräuliche Geburt die Begrifflichkeit. Im Marienlob situiert er den Vorgang der jungfräulichen Geburt praeter naturam ${ }^{33}$. Aus diesen Situierun-

30 Zur ablehnenden Haltung Augustins zum zeitgenössischen Wunder, die sich gegen Ende seines Lebens änderte siehe Vooght, Miracles, S. 5-16; Vooght, Théologie du miracle, S. 197-222. Zur Einstellung Gregors des Großen zu zeitgenössischen Wundern in den Dialogi und in seinen anderen Schriften siehe BogLIONI, Miracle et nature, S. 11-13.

31 GuiberT de Nogent, Contra judaizantem, S. 334. In seinem Brief De bucella judae data bezeichnet er das Stück Brot des Judas ebenfalls als Zeichen, aber nur als Zeichen des Verräters, nicht als Zeichen des Sakramentes. RubensteIN, Guibert of Nogent, S. 137.

32 PL 156, 502B. Siehe dazu Rubenstein, Guibert of Nogent, S. 116.

33 GuiberT De Nogent, De laude, Sp. 540: [...] ita et in matre, exolescente Filio, et propalante per doctrinam et signa quod erat, quidquid in ea praeter naturam factum nesciebatur, apparuit. "...so erschien, während der Sohn heranwuchs und durch die Lehre und Zeichen verkündete, was er war, auch in der Mutter, was in ihr, ohne daß man es wußte, außerhalb der Natur gemacht war." 
gen der jungfräulichen Geburt können jedoch keine weitergehenden Reflexionen Guiberts zu Wundern in bezug auf die Natur abgeleitet werden. Diese Stellen sind die einzigen, an denen er das Verhältnis von Wundern zur Natur thematisiert. Guibert interessiert sich nicht für die philosophische Situierung von Wundern, es geht ihm vielmehr um die Verteidigung des Dogmas der jungfräulichen Geburt. Contra usum nature und praeter naturam situieren das Ereignis auf recht unscharfe Art jenseits der gewohnten Funktionsweise der Natur ${ }^{34}$. Somit steht Guibert ganz in der dogmatischen Tradition Augustins, die zumindest bis zur Scholastik die mittelalterliche Konzeption des Wunders als Eingriff Gottes geprägt hatte. Augustin setzt die jungfräuliche Geburt in seiner Genesis-Exegese De Genesi ad litteram in Parallele zur Schaffung Evas aus Adams Seite ${ }^{35}$. Um das Problem der Erschaffung Evas zu lösen, greift er auf weitere biblische Wunder als Eingriffe Gottes in den normalen Lauf der Natur zurück. Diese geschahen laut dem Kirchenvater contra naturae usitatum cursum $^{36}$. Als biblische Beispiele nennt er das Aufblühen des Stabes Aarons (Num. 17, 8), die Fruchtbarkeit der alten und unfruchtbaren Sarah (Gen. 18, 11 u. 21, 2), den sprechenden Esel des Bileam (Num. 22, 22-28) und die Verwandlung von Wasser in Wein in Kana (Ioh. 2, 1-12) ${ }^{37}$. Das Beispiel des sprechenden Esels des Bileam verwendet Guibert ebenfalls im Zusammenhang mit Wundern: sowohl im Marienlob bei der Erörterung über die jungfräuliche Geburt als auch in der Reliquienkritik bei der Diskussion von Wundern, die ohne Zutun von Mittlern geschehen ${ }^{38}$.

Eine der augustinischen ähnliche Überlegung findet sich in konziser Form auch im Kapitel 11 des Werkes De conceptu virginali et de originali peccato, verfaßt von Anselm von Bec/Canterbury ( $† 1109$ ), dem Lehrer Guiberts ${ }^{39}$. Er setzt die Erschaffung Adams und Evas ebenfalls in Parallele zur jungfräulichen Geburt Christi ${ }^{40}$. Auch er nennt parallele biblische Wunder wie den Durchzug des Volkes Israel durch das Rote Meer, die Erweckung von Toten und die Verwandlung von Wasser in Wein, die außerhalb des gewohnten Laufs der Schöpfung oder des Willens der Geschöpfe geschehen ${ }^{41}$. Dann teilt er den

34 Dies in Parallele zu Thiofrid, der die Begriffe synonym verwendet. Thiofridi Abbatis ECHTERNACHENSIS, Flores epytaphii, S. XXXVII, Anm. 112.

35 Augustinus Aurelius, De genesi, 9, 16, S. 290, siehe Vooghr, Notion philosophique, S. 334. Weitere Belege aus Sermones und Briefen: Vooght, Théologie du miracle, S. 209, Anm. 58.

36 Augustinus Aurelius, De genesi, 6, 14, S. 189.

37 Siehe dazu Vooght, Notion philosophique, S. 339.

38 Guibert de Nogent, De laude, Sp. 547; Guibert De Nogent, Quo ordine, S. 91, Z. 170f., dazu siehe unten, S. 57.

39 Der Traktat ist ediert in Anselm von Canterbury, Opera Omnia, S. 136-173. Dazu siehe BYNum, Wonder, S. 8.

40 Siehe Anselm von CANTERBury, Opera Omnia, Kap. 11, S. 153: [...] sed deus propria potestate et voluntate fecit virum unum de limo et alterum de sola femina, et feminam de solo viro. 41 Ibid. Kap. 11, S. 153: Solius quippe voluntatis dei opus est, cum mare siccum iter intra se populo praebet, cum mortui resurgunt, cum aqua subito in vinum convertitur, [...], cum alia multa fiunt, quae nec creatura nec eius voluntas per usitatum cursum suum operaretur. 
Lauf der Dinge in drei Arten auf: mirabilis, naturalis, voluntarius. Dem »wunderbaren « Bereich sind die direkten Eingriffe Gottes in den Lauf der Natur, so auch bei der Geburt Christi aus einer Jungfrau ${ }^{42}$, zugeordnet.

Guiberts Interpretation der zentralen Mysterien des christlichen Glaubens als signa ist durchaus traditionell. Darüber hinaus ist auch die Wahl paralleler Beispiele für Eingriffe Gottes als signa traditionell. In Guiberts Marienlob ist auch die Überleitung vom göttlichen Zeichen der jungfräulichen Geburt zu aktuellen Zeichen Mariens in der Begründung augustinischer Tradition verpflichtet. Durch Wundertaten erbaut Maria die Menschen im Glauben und wärmt erstarrte Herzen wieder auf, signa dienen zur Erbauung und Bestärkung des Glaubens ${ }^{43}$. Hier wirkt der Diktion nach allerdings nicht Gott die Wunder, sondern Maria selbst ${ }^{44}$.

In den Monodiae, einem im Gegensatz zum Marienlob in der Aktualität verankerten Werk, können signa auf breiter Basis Zeichen verschiedener Herkunft sein. Der Begriff wird jedoch relativ selten verwendet: Die Strafe des Teufels kann dem Sünder Zeichen seines Unrechts $\operatorname{sein}^{45}$, wie auch Heilige für ihre Wunderzeichen berühmt sein können ${ }^{46}$. Auch in der Reliquienkritik läßt sich kein spezifischer Gebrauch des Begriffs festmachen.

Der Begriff der virtus eröffnet im Werk Guiberts ein breites semantisches Feld, in ähnlicher Weise, wie dies William McCready für Gregor den Großen und Martin Heinzelmann für Gregor von Tours gezeigt haben ${ }^{47}$. So können damit in biblischer Begrifflichkeit Wundertaten gemeint sein, wie das Zitat von Matth. 7,22: Domine, nonne in nomine tuo prophetavimus, demonia eieci-

42 Ibid. Kap. 11, S. 154: Cum igitur omnia quae fiunt, si diligenter considerentur, fiant aut sola voluntate dei, aut natura secundum vim illi a deo inditam, aut voluntate creaturae; et ea quae nec natura creata nec voluntas creaturae sed solus deus facit, semper miranda sint: apparet quia tres sunt cursus rerum, scilicet mirabilis, naturalis, voluntarius. [...] Quoniam ergo propagatio viri de sola virgine ita non est naturalis aut voluntaria sed mirabilis, [...].

43 Zu dieser Begründung bei Augustin siehe HeinzelmanN, Funktion, S. 45.

44 GuiberT De Nogent, De laude, Sp. 564: Quia enim hodie non est praedicator qui mutiat, ipsa seipsam quaeri debere, seque etiam non rogatam opitulari velle signis enuntiat. Igitur quoniam quanta sit, quantumque veteribus portensa praeconiis significare voluimus, dignum est etiam ut quae nostra aetate peregit intexamus. »Denn da es heute keinen Prediger gibt, der auch nur ein wenig seinen Mund auftäte, verkündet sie selbst, daß sie selbst aufgesucht werden müsse, und daß sie, auch wenn sie nicht gefragt werde, mit Wunderzeichen helfen wolle. Und da ich zu verstehen geben wollte, wie groß sie ist, und wie sie seit alters durch Ruhmestitel geoffenbart worden ist, ist es denn würdig, daß ich auch das einflechte, was sie zu unserer Zeit vollendet hat."

45 GuiberT De Nogent, Autobiographie, S. 198: [...] diabolum tandem fuisse credidit, qui hoc signo suum opus in homine denotavit.

46 Ibid. S. 462: Et sanctus Witonus apud urbem Wintonium se in signis hucusque praebuit efficacem; S. 464 [...] Leodegarium martyrem, signis egregium, ad subventiones alacrem non nescimus.

47 McCready, Signs of Sanctity, S. 90f.; Heinzelmann, Funktion, S. 55-57, dessen Zusammenstellung der Belegstellen für virtus bei Gregor von Tours die kritischen Bemerkungen von MCCREADY, ibid. Anm. 29, S. 92 etwas entkräftet. 
mus, virtutes multas fecimus? im Vorwort zur Reliquienkritik zeigt ${ }^{48}$. Damit kann auch die göttliche Kraft bezeichnet werden, die wie in den Monodiae hinter einem Strafwunder stehen kann ${ }^{49}$. In der Reliquienkritik wird virtus im Singular für ein Wunder verwendet ${ }^{50}$.

Dann wird, ebenfalls in den Monodiae, im Zusammenhang der Beschreibung eines Kampfes um die Seele eines Sterbenden zwischen guten und schlechten Kräften (altercatio diversarum potestatum) der Begriff im Plural ebenfalls als Umschreibung von Dämonen verwendet (contrarii virtutes) ${ }^{51}$.

Die Begriffe signum und virtus sind nur in einem Teil ihres semantischen Feldes mit wunderspezifischen Bedeutungen belegt, was auch mit der Unschärfe oder Flexibilität der Wunderkonzeption in Parallele gesetzt werden kann. So kann Gott traditionellerweise nicht nur jenseits der Naturgesetze Zeichen setzen, sondern auch innerhalb derselben. Ein Beispiel dafür ist die Interpretation von Naturereignissen wie Blitzen, Unwettern oder Himmelserscheinungen als Zeichen Gottes ${ }^{52}$. Auch ist die Mehrdeutigkeit von virtus als Tugend, Wunderkraft und Wundertat in der Hagiographie häufig ${ }^{53}$.

Mit dem Begriff miraculum wird die Reaktion der Rezipienten auf das göttliche Zeichen ins Zentrum gesetzt. Zumeist werden mit miracula sowohl in den Monodiae als auch in der Reliquienkritik Wundertaten Gottes bezeichnet, die oft durch Heilige gewirkt werden. In den Monodiae zeichnet sich aber eine Nuancierung der Begrifflichkeit ab. In der so umschriebenen Bedeutung wird der Begriff im zweiten und dritten Buch verwendet. So wird im zweiten Buch, worin die Geschichte des Klosters Nogent im Zentrum steht, berichtet, daß die Kirche von alters her durch Wunder, miracula, ausgezeichnet wurde ${ }^{54}$. Im dritten Buch geschehen miracula anläßlich der Reliquienreise der Kleriker von Laon. Hier sind es zumeist Heilungen, die als miracula bezeichnet werden. Zudem wird die Unversehrtheit des Körpers des heiligen Edmund als miraculum behandelt ${ }^{55}$.

Im ersten Buch hingegen stehen die persönliche Entwicklung Guiberts, aber auch persönliche Erlebnisse im Zentrum. Der Begriff wird dort im Zusammenhang mit Visionen verwendet. Einerseits für »sich wundern« im Sinne von »staunen« im Laufe einer Vision, andererseits für den Anlaß einer Vision.

48 GUibert DE Nogent, Quo ordine, S. 83.

49 Guibert de Nogent, Autobiographie, III, 18, S. 438: In hac ipsa Novigenti cui, Deo autore, servimus ecclesia miles quidam rapinam fecerat, fratrum scilicet bobus abduxerat, Calniacumque castrum deveniens, unum de boves comedendum a se, ut putabat, complicibusque decoxerat. Ad primum ergo quod de carnibus illis ori intulit, divina virtute percutitur (Hervorhebung K. F.), et uterque ei inter masticandum oculus a fronte et ab ore lingua expromitur, sicque eo damnato, vellet nollet, residua praeda reducitur.

50 Siehe unten, S. 149.

51 Guibert de Nogent, Autobiographie, III, 19, S. 448.

52 Siehe unten, S. 55.

53 Boesch Gajano, Proposta, S. 640.

54 Guibert de Nogent, Autobiographie, II, 2, S. 224.

55 Ibid. III, 12-13, S. 376-390 (Reliquienreise), III, 20, S. 460 (Eadmundus). 
In diese Ereignisse sind die Mutter Guiberts, ihr Gutsverwalter, sein Lehrer und er selbst involviert. Der Verwalter der mütterlichen Güter hatte eine Vision, in der er sah, daß die Mutter wieder heiraten werde. Dies habe bei den Umstehenden großes Verwundern und Erstaunen erzeugt ${ }^{56}$. Guibert beschreibt auch Visionen seiner Mutter und seines Lehrers, die den beiden durch Gottes Wundertat, tuo miraculo, enthüllt wurden ${ }^{57}$. Schließlich wird ein unerklärliches Ereignis als miraculum bezeichnet ${ }^{58}$. In der Reliquienkritik wird der Begriff nur für Wundertaten von Heiligen verwendet, wie beispielsweise im dritten Buch in Zusammenhang mit denjenigen, die im Wunderbuch von Saint-Médard de Soissons festgehalten sind.

Miraculum scheint in Guiberts Schriften der spezifischste Begriff in bezug auf Heilige und deren Wundertaten zu sein. Gleichzeitig wird dieser Begriff oft in Zusammenhang mit dem Publikmachen der wunderbaren Intervention verwendet. So in einer Erzählung aus der Reliquienkritik, worin die fama die Kunde eines Wunders weitherum verbreitet ${ }^{59}$ oder in einer Erzählung aus den Monodiae, die berichtet, daß eine Narbe von einem Wunder zeugt und die Kunde davon auf diese Weise verbreitet ${ }^{60}$, oder als die Kleriker von Laon anläßlich eines Wunders, das während ihrer Mittagspause geschieht, ad theatrum tanti miraculi eilen ${ }^{61}$. Diese Wortwahl betont den Aspekt des Staunens, das durch die göttlichen Eingriffe bewirkt wird, zeigt aber auch, wie wichtig es war, daß das Geschehen in der Öffentlichkeit sichtbar vonstatten ging ${ }^{62}$. Anläßlich der Reliquienreise der Kleriker aus Laon nimmt Guibert eine Klassifizierung von Wundern vor: Heilungswunder bezeichnet er als miracula consuetudinaria, im Gegensatz zu miracula insolita ${ }^{63}$. Als miracula insolita werden

56 Ibid. I, 14: [...] quae res liberis ejus, amicis ac parentibus miraculum et stuporem maximum generaret.

57 Ibid. I, 16, S. 124: quia tuo miraculo eis tantum, qui me diligebant, detegebatur [...].

58 Ibid. I, 24, S. 194. Siehe dazu unten, S. 54.

59 GuIBERT DE NOGENT, Quo ordine, P, I, Z. 289: [...] non intra rus idem miraculi fama ses cohibuit, sed in remotas regiones virtus isti tempori prorsus inusitata circuntulit.

60 Guibert De Nogent, Autobiographie, III, 19, S. 448: quod cicatrix evidens et insignis illi remansit in gutture, quae miraculum circumferret [...].

61 Ibid. III, 13, S. 386. In der Historia dedicationis ecclesiae S. Remigii apud Remos, die von der Dedikation dieser Kirche durch Leo IX. 1049 handelt, wird in bezug auf ein Heilungswunder von spectaculum gesprochen, das sich alle anschauen wollen. ARNulfus MetTENsIs, Historia Dedicationis, col. 1418: Haec videns fratrum conventus divinas ingeminat laudes, et qui in vicino positi ea audiunt, ad tam jucundum spectaculum confluunt alacres. Dieser Bericht ist nach 1056 verfaßt von Anselm, Mönch aus Saint-Rémi de Reims. BHL 4825, siehe dazu Falkenstein, Art. »Anselm von Saint-Remi«.

62 Siehe dazu auch EAdMER, Vita Sancti Anselmi, S. 156, der in seiner Zusammenstellung der Wunder des heiligen Anselm nach dem Bericht von zwei Visionen den Unterschied von Visionen und sichtbaren Interventionen macht und dann von mehreren Heilungen berichtet: Haec interim de visis dicta sunt. Ad ea quae manifeste facta sunt hinc veniemus, nichil unde animum nostrum vel levis dubitatio mordeat, ulla ratione scripturi.

63 GuiberT de Nogent, Autobiographie, III, 13, 388: Igitur prospere devecti ad Anglos, cum ad Wintoniensem venissent urbem, plurima inibi miracula claruerunt. Apud Essecestri- 
dann göttliche Eingriffe aufgezählt, die schlechtes Verhalten strafen und gutes belohnen, die daher geeignet sind, eine moralische Botschaft zu transportieren.

Guibert spricht auch in der Reliquienkritik in Bezug auf die Skrofelheilung seines Königs Ludwig VI. von einem prodigium consuetudinarium ${ }^{64}$. Guibert scheint diesen Ausdruck nicht nur für den spezifischen Kontext der Skrofelheilungen zu verwenden, sondern diese Begrifflichkeit kann eher dahingehend interpretiert werden, daß Guibert einfache Heilungswunder als weniger aufsehenerregend einstuft, aber auch geringer schätzt als die Wunder, die aufgrund von Tugenden, Buße oder Reue geschehen oder aber Fehlverhalten strafen ${ }^{65}$.

Hinweise, daß alltägliche Wunder nicht berichtet werden, oder daß nur außergewöhnliche Wunder niedergeschrieben werden, finden sich auch in hagiographischen Texten ${ }^{6}$. Die Unterscheidung im Sinne Guiberts ist etwas abweichend vom augustinischen Konzept, das eher natürliche wunderbare Ereignisse von direkten Eingriffen Gottes in den Lauf der Natur trennt. Miracula insolita stehen bei Augustin im Gegensatz zum ständigen Wunder der Natur ${ }^{67}$.

Die vergleichende Betrachtung der Verwendung der Begriffe signum, virtus und miraculum zeigt, daß diese alle ein relativ breites Bedeutungsfeld eröffnen und teilweise synonym verwendet werden können. Dies ist durchaus in Übereinstimmung mit der Begrifflichkeit der Bibel zu sehen. Hieronymus verwendet in seiner Übersetzung die Begriffe virtutes, signa und miracula, aber auch andere Begriffe wie prodigia, portenta oder ostenta $^{68}$. Dies zeigt auch eine Stelle aus der Kreuzzugschronik, dem historiographischen Werk Guiberts. Zu Beginn des zweiten Kapitels beschreibt er das Grab Urbans II., desjenigen Papstes, der zum ersten Kreuzzug aufgerufen hatte. Hier verwen-

am quoque non disparia contigerunt, causasque plurimorum munerum effecerunt. Taceamus consuetudinarias aegritudinem medicinas: insolita attingamus.

64 Guibert de Nogent, Quo ordine, P, I, Z. 158.

65 BLoch, Die wundertätigen Könige, S. 68 interpretiert das Adjektiv consuetudinarius dahin gehend, daß es sich um ein »gewohntes Wunder «, also um einen schon gefestigten Brauch handelte. Consuetudinarius ist aufgrund der Nennung in den Monodiae aber eher weniger eng zu verstehen, im Sinn von alltäglich als Gegensatz zu außergewöhnlichen Gegebenheiten. Auch in der augustinischen Wunderkonzeption wird mehrmais der Akzent auf das Ungewöhnliche gelegt. Siehe dazu BogLioni, Miracle et nature, S. 72-75. Zu Heilungswundern siehe auch Demm, Zur Rolle des Wunders, S. 310 f.

66 Siehe dazu Sigal, Travail, S. 182. So wird auch im Liber Miraculorum S. Fidis, ed. Auguste BoullLET, Paris 1897, 1, $\S$ 9, S. 37, zit. ibid., S. 182, Anm. 193, unterschieden zwischen alltäglichen Heilungswundern und Wundern, die schlechtes Verhalten strafen oder sonst außergewöhnlich sind: Neque nos id damus operam, ut de his quae infirmis ibi geruntur cottidie, immensam conficiamus bibliothecam, sed quae, vel ad vindictam malorum gesta, vel quoquomodo habentur inaudita eorumdem etiam grandi parte resecta, parvum ac pre ciosum edamus volumen. WARD, Miracles, S. 13 spricht hingegen von miracula quotidiana in Zusammenhang mit Sakramenten von Eingriffen Gottes in den normalen Lauf der Natur, wohl vor allem in bezug auf die Eucharistie, nennt aber für diese Qualifizierung keine mittelalterlichen Belegstellen.

67 Dazu Heinzelmann, Funktion, S. 44.

68 Zur biblischen Begrifflichkeit siehe ibid. S. 31 . 
dete Guibert im gleichen Abschnitt drei verschiedene Begriffe für Wundertat, Wunderzeichen und Wunderkraft:

Attestatur statui mentis finis eius splendens miraculis [Hervorhebungen K. F.]. Defuncto etenim ac sepulto eo, sicut succedens ei Ostienisis scripsit episcopus, cum plurima signa iam fierent, astitit quidam sepulchro illius iuvenis et membrorum dampnum sibi imprecatus est, si per Urbani merita, qui Odo diceretur, signum umquam factum fuerit aut fieret. Necdum a loco pedem extulerat, cum, officio sermonis amisso et altero laterum paralisi intercurrente correpto, post tridie Urbani virtutum testimonia mortuus ipse perhibuit ${ }^{69}$.

Einzig der Begriff des miraculum scheint bei Guibert einen genauer definierten Bedeutungsgehalt zu besitzen und auch nuanciert zu werden, wie die Unterscheidung zwischen miracula consuetudinaria und miracula insolita zeigt.

\section{Der Exkurs über Wunder in De sanctis et eorum pigneribus}

Der Exkurs über Wunder in der Reliquienkritik steht in engem Zusammenhang mit Guiberts Argumentation über vertrauenswürdige und zweifelhafte Heilige. So stehen in dessen Argumentation vielmehr Fragen nach dem Wesen und der Lebensführung des Wunderwirkers im Zentrum als diejenigen nach der Deutung von Ereignissen als Wunder. Die Auswahl der Beispiele gibt aber sehr wohl Hinweise auf Guiberts Vorstellung der Funktionsweise wunderbarer Ereignisse.

$\mathrm{Zu}$ Beginn des Exkurses steht die Frage nach der moralischen Lebensführung von Mittlern, welche die Glaubwürdigkeit von Wundern erleichtern kann. Um zu zeigen, daß das Wunder alleine noch kein Argument für Heiligkeit ist, zitiert Guibert für analoge wunderbare Ereignisse biblische Exempla, wie auch solche aus der profanen Geschichte. Denn es gäbe solche, die verwendet würden, sowohl die Ehre der einen - der heidnischen - wie auch der anderen - der christlichen - Seite zu unterstützen ${ }^{70}$.

An erster Stelle wird das Teilen des Roten Meeres für das Volk Israel dem Zurückhalten der Pamphylischen See für Alexander den Großen gegenübergestellt: qui enim filiis Israhel Mare Rubrum, divisit Magno Alexandro Pamphilicum $^{71}$. Hinter dieser Parallelisierung steht der Theozentrismus des Wunderphänomens, der sowohl im Alten wie auch im Neuen Testament angelegt ist $^{72}$. Aber auch in der Bibel ist Gott nicht ausschlieBlicher Wundertäter: Die Schlange Aarons besiegte die Schlangen der pharaonischen Zauberer, indem sie diese auffraß (Exod. 7, 8). Dies als Zeichen der Wunderkraft Gottes, die

69 Guibert de Nogent, Dei Gesta, S. 107.

70 Guibert de Nogent, Quo ordine, P, I, Z. 147-149.

71 Ibid. P, I, Z. 149f. Zum Alexander-Exemplum siehe CARY, The Medieval Alexander, S. 126-130. Zu den alttestamentarischen Wundern siehe QuELL, Phänomen des Wunders.

72 Angenendt, Wunder, S. 97f. Ps. 72,18: »Er allein tut Wunder«; Luc. 1,37: »Denn für Gott ist nichts unmöglich«. Guibert unterscheidet auch nicht wie Gregor der Große zwischen alttestamentarischen und neutestamentarischen Wundern. Gregor charakterisiert Moses nur als Werkzeug Gottes, während Christus aufgrund seiner göttlichen Natur aus eigenem Antrieb Wunder wirke. McCready, Signs of Sanctity, S. 58. 
größer war als die Kraft der heidnischen Zauberer ${ }^{73}$. Bei Paulus ist es vor allem Gott, der Wunder tut, er gesteht aber auch Dämonen und Charismen von Menschen eine gewiße Wirkkraft zu ${ }^{74}$.

In der augustinischen Wunderkonzeption geschehen Wunder durch die Gnade Gottes ${ }^{75}$. Sie haben vor allem apologetischen Zweck und dienen der Weckung und Aufrechterhaltung des Glaubens. Erst gegen Ende seines Lebens kommen zeitgenössische Wunder von längst verstorbenen Heiligen $\mathrm{zu}$ einem breiten Wunderbegriff dazu ${ }^{76}$. In seinem apologetischen Werk De civitate Dei ordnet Augustin aber Wunder, die auf heidnischer Seite geschehen, natürlichen Wirkkräften oder Dämonen zu ${ }^{77}$. Diese gehören heilsgeschichtlich gesehen für Augustin wohl eher in die civitas terrena als in die civitas Dei und finden außerhalb der christlichen Welt, des einzigen wahren Kults, statt ${ }^{78}$. Wunder waren aber vor allem anzuerkennen, weil sie innerhalb der wahren Kirche stattfanden, nicht weil sie Wunder waren ${ }^{79}$. Das Umfeld eines Wunders sollte also über dessen Akzeptanz entscheiden. Dies begründete dann auch die wichtige Rolle der kirchlichen Autorität für die Anerkennung von Wundern 80 .

Guibert hingegen stellt in seinem Wunderexkurs Wundern aus dem christlichen Bereich Beispiele, die er aus der paganen Überlieferung nennt, gleichberechtigt gegenüber. Für ihn sind die einen wie die anderen von Gott gewirkt. Augustin hat ebenfalls Wunder auf heidnischer Seite als solche anerkannt, aber dämonischen Kräften zugeschrieben. Für Guibert ist auf beiden Seiten Gott der Wunderwirker ${ }^{81}$.

Das Beispiel des Alexander ist in der Tat zweideutig, ein signum amphibolum $^{82}$. Es ist in der jüdischen Tradition, in den Antiquitates des Flavius Josephus überliefert ${ }^{83}$. Da Alexander im Buch des Propheten Daniel (Dan. 7-8,

73 Dazu Quell, Phänomen des Wunders, S. $268 \mathrm{f}$.

74 ANGENENDT, Wunder, S. 99.

75 So sieht auch BRENNECKE, Wunder, S. 74 anhand der Vita Severini aus dem 6. Jahrhundert in der Betonung eines Gottes, der allein in den Wundern handelt, die Popularisierung der Gnadenlehre Augustins.

76 Über die bekannte Erweiterung des Wunderbegriffs bei Augustin siehe VooGHT, Miracles; BoesCH GAJANO, Verità e pubblicità; eine kurze Zusammenfassung auch bei MCCREADY, Signs of Sanctity, S. 8-15.

77 DCD 18, 18, 1-3. Dazu die Anmerkungen von Gustave Bardy in DCD (CEuvres de saint Augustin, Bd. 37) S. 795-798, 828.

78 Vooght, Théologie du miracle, S. 216. Dazu siehe auch McCready, Signs of Sanctity, S. 72-75. Die civitas terrena mit FLASCH, Augustin, S. 388-389 verstanden als Gemeinschaft derjenigen »die nach dem Fleische leben«. Flasch bezieht sich auf MaIER, Augustin.

79 DCD (Euvres de saint Augustin, Bd. 37), S. 829 (Anmerkungen von Gustave Bardy).

80 DCD, 21,6, S. 397. Siehe zur Rolle der kirchlichen Autorität, die sich dem Wunderphänomen annimmt Boesch Gajano, Verità e pubblicità, S. 368. Dazu unten, Kap. 2.2.2.

81 Ibid. 22, 10, S. 599-601.

82 GuiberT DE NOGENT, Quo ordine, P, I, Z.147.

83 Blatr, Latin Josephus, 2, 16, S. 216. Kritisch ediert sind von den lateinischen Antiquitates durch Franz Blatt nur die Bücher I-V. Für die weiteren Bücher muß nach wie vor auf 
11) ein, wenn auch unwissendes, Werkzeug Gottes ist, kann er nicht einfach der heidnischen Sphäre zugeordnet werden. Josephus läßt Alexander zudem in einer Vision Gott sehen, der ihm die Zerstörung der Perser weissagt. Alexander erweist Gott darauf die Ehre, hat daher nun nicht mehr die Funktion als unwissendes Werkzeug Gottes. In dieser Tradition ist es daher eindeutig Gott, der dieses Wunder wirkt ${ }^{84}$. Auch Augustinus berichtet in De civitate Dei von der Verehrung Gottes im jüdischen Tempel durch Alexander, qualifiziert dessen Frömmigkeit aber als falsch und ihn als gottlos ${ }^{85}$. Das Exemplum der Teilung der Pamphylischen See berichtet er nicht. Dieses Exemplum ist auch sonst nicht breit überliefert ${ }^{86}$.

Die Verwendung des Beispiels der Teilung des Roten Meeres für das Volk Israel für ein von Gott gewirktes Wunder hingegen ist traditionell und wird von Guibert als unzweifelhaftes Gegenbeispiel erwähnt ${ }^{87}$. Schon bei Gregor dem Großen wurden anhand der Teilung des Roten Meeres Überlegungen zu Wundern angestellt ${ }^{88}$. Wie oben gezeigt, ist dieses Exemplum bei Anselm von $\mathrm{Bec} / \mathrm{Canterbury}$ belegt ${ }^{89}$. In der Geschichtsschreibung wurde es ebenfalls verwendet: Eusebius setzte Konstantins Schlacht an der Milvischen Brücke damit in Parallele ${ }^{90}$. In der verteidigenden Version des Mirakelbuchs von Saint-Médard de Soissons wurde ein Ereignis während einer translatio des hl. Gregor in Parallele gesetzt zur Durchquerung des Roten Meeres der Israeliten, was zeigt, daß dieses Beispiel nicht nur in theologischen Abhandlungen, sondern auch in der Hagiographie verwendet wurde ${ }^{91}$.

die Edition Basel 1524 (Frobenius) zurückgegriffen werden. Die lateinische Übersetzung dieses griechischen Textes ist gemäß Blatt, S. 17-24 im Umkreis von Cassiodor angefertigt worden. Dazu auch CARY, The Medieval Alexander, S. 18. Siehe unten, S. 57, Anm. 111.

84 Siehe dazu CarY, The Medieval Alexander, S. 126.

85 Augustinus. De civitate Dei, 18, 45, S. 644-646. Übrigens brachte Alexander im Tempel Opfer dar, aber nicht als hätte er sich in wahrer Frömmigkeit zum Dienste Gottes bekehrt, sondern weil er in gottlosem Wahn auch ihn neben seinen falschen Göttern glaubte verehren zu sollen. Zur Charakterisierung Alexanders siehe auch ein weiteres Exemplum in: Augustinus, De civitate Dei, 4, 4, S.540. Zu diesem Exemplum und dessen Umdeutung durch Johannes von Salisbury siehe Moos, Geschichte, S. 209 u. Anm. 481.

86 Die Episode ist bei ANDREAS von SAINT-VICTOR ( $\dagger 1175)$ in seiner Expositio super heptateuchum, S. 118 überliefert. Andreas verfaßte dieses Werk vor 1147 in Saint-Victor/Paris. Darüber hinaus ist das Exemplum erst in der zweiten Hälfte des 12. Jahrhunderts überliefert, beispielsweise bei Petrus Comestor in der Historia Scolastica, Sp. 1158C oder bei Gottraied von Viterbo, Pantheon (1187-1190), zit. bei CAry, The Medieval Alexander, Anm. 45, S. 293.

87 So werden die Wunder, die Gott beim Auszug aus Ägypten für das Volk Israel wirkte, innerhalb der biblischen Bücher immer wieder erwähnt, so im Psalter (z. B. Ps. 76) oder auch im Neuen Testament (z. B. Act. 7, 36).

88 MCCready, Signs of Sanctity, S. 58, 187, 223f.

89 Siehe oben, Anm. 41.

90 Siehe dazu Heinzelmann, Funktion, S. 34.

91 Miracula S. Gregorii, HS Douai 854, fol. 95r: [...] iter facientes ei qui portabatur, adeo ut qui reliquias Gregorii deferbant minime indigerent aut virga Moysi in Rubro Mari, aut pallio Helyse in divisione Iordanis, in aquis mediis et ipsi quasi sicco pede pertranseuntes, in 
Danach nennt Guibert ein Heilungswunder des römischen Kaisers Vespasian, der einen Krüppel durch die Berührung mit seinem großen Zeh heilt. Dabei gibt er Sueton als Quelle der Erzählung an. Das Heilungswunder wird nicht explizit in Parallele zu biblischen Wundern gesetzt, läßt aber in der Logik der Argumentation an die neutestamentarischen Heilungswunder Jesu denken ${ }^{92}$. Die Erzählung über die Wunderheilung durch Vespasian wurde während des frühen und hohen Mittelalters nicht oft als Beispiel verwendet. Sie wird als Beispiel im Policraticus des Johannes von Salisbury (1150er-1160er Jahre) genannt, scheint in früheren Texten jedoch nicht erwähnt worden zu $\operatorname{sein}^{93}$. Weiter zählt Guibert Wunderzeichen auf, die anläßlich von Geburten heidnischer Regenten erwähnt wurden. Diese leiten über zu Wunderzeichen rund um Könige und Kaiser christlicher Zeit. Als heidnische Kaiser nennt er wiederum Alexander, Julius Caesar und Octavian. Der letztere spielt bei Orosius in den Historiae adversum paganos eine wichtige heilsgeschichtliche Rolle, indem er durch die Schaffung der pax Augusta den Boden der Ankunft Christi und der Verbreitung des Christentums bereitete. Darauf wiesen nach Orosius verschiedene Prodigien und Zeichen hin ${ }^{94}$.

Autorisierte Wunder aus der Schrift werden mit dem Erlebten oder zu Besprechenden in Parallelität gesetzt. Im Marienlob geht Guibert auf ähnliche Weise vor. Er versucht die wunderbaren Ereignisse der biblischen Geschichte, die in dieser Schrift im Zentrum stehen, so die jungfräuliche Geburt Jesu und der Umstand, daß Maria Jesus in ihrem Leib trug, auf die gleiche Art zu erklären wie die zeitgenössischen Wunder im Reliquientraktat: mit Analogien. Er zieht bei der Erklärung der Ereignisse die gleichen Beispiele heran wie im Reliquientraktat: Moses als speziellen Mittler zwischen Gott und Mensch ${ }^{95}$,

nomine eius qui convertebat aquas in aridam, meritis sui sanctissimi sacerdotis. Auch John OTT, Educating the Bishop, zeigt, daß Moses als Beispiel in der Hagiographie oft verwendet wurde. Zur Einordnung dieser Handschrift und möglichen Beziehungen zu Guiberts Reliquientraktat siehe unten, Kap. 5.1.3.

92 Quelle des vespasianischen Heilungswunders: C. Sueton, Vesp. 7, 2f. Guibert spricht die Wunder Jesu direkt in seinen Schriften nicht an. Zu den neutestamentarischen Wundern VAN DER LOOS, Miracles.

93 Iohannes SAReSberiensis, Policraticus, II, 10, S. 83f. Für Johannes von Salisbury wird dieses Wunder eindeutig durch Gott gewirkt. Siehe dazu WARD, Miracles, S. 12. Zum Policraticus siehe Moos, Geschichte, hier S. 288. Eine Suche in der Patrologia Latina und in der Library of Latin Texts (CLCLT) brachte außer den Erwähnungen bei Guibert und Johannes von Salisbury keine Resultate.

94 Orose, Histoires, VI, 20, 5-8, Bd. 2, S. 227-229; Heinzelmann, Funktion, S. 40f. mit weiteren Literaturangaben. Diese sog. "Augustustheologie» hatte im Mittelalter große Nachwirkung. Daß Zitate von Orosius' Kirchengeschichte in Guiberts Werken weder von Robert B. C. Huygens noch von Edmond-René Labande ausgewiesen sind, heißt nicht, daß Guibert dieses Werk nicht gekannt haben kann, ist dieses doch sehr breit überliefert. So besitzt beispielsweise die Kathedrale von Laon (Laon BM 137) eine Handschrift des Orosius aus dem 7. Jahrhundert, siehe dazu LESNE, Scriptoria, S. 607.

95 Guibert de Nogent, De laude, Sp. 538; Guibert de Nogent, Quo ordine, S. 90. 
die Stelle vom Esel des Bileam ${ }^{96}$ und auch die Heilung des Vespasian ${ }^{97}$. Im Marienlob geht es Guibert um deren moralische Eigenschaften wie Bescheidenheit und Bewußtsein, um auszuloten, wie bewußt Maria die Ankündigung des Engels empfangen hat.

Diese Methode der Parallelsetzung historischer Situationen mit biblischen Passagen ist seit den frühen christlichen Geschichtsschreibern üblich ${ }^{98}$. Anders als in den Dialogi Gregors des Großen, der explizite Parallelisierungen vornimmt, ist die Referenz auf die Bibel bei den genannten Wundern zumeist implizit vorhanden ${ }^{99}$. Ein Wunder ist ein Wirken Gottes, für dessen Beurteilung die autoritative Schrift, die Bibel, herangezogen werden muß. Gottes Wirken in der Welt ist in der Bibel festgehalten, deshalb müssen auch historische und zeitgenössische Ereignisse, die als Wunder gedeutet werden, in Parallele zu biblischen Ereignissen gesetzt werden können ${ }^{100}$. Die Auswahl der Beispiele zeigt aber Zweifel Guiberts an einem schematischen Parallelismus, den er auflöst, indem er den Fokus der Betrachtung auf die Intervenienten und Begünstigten der Wunder und deren moralische Disposition lenkt.

\section{Deutungsprobleme}

Ist schon die Beurteilung von Wundern aus der schriftlichen Tradition immer wieder problematisch, bietet auch die Deutung aktueller Zeichen und deren Charakterisierung als Wunder vielfältige Probleme. Diese Deutungsprobleme werden an den Erklärungsversuchen oder an den geäußerten Zweifeln ersichtlich. Probleme bei der Beurteilung von Heiligen oder Begünstigten von Wundern werden unten im Kapitel 2.1.3. thematisiert. Guibert muß jedoch auch Ereignisse einordnen, die auf irgendeine Art zeichenhaften Charakter haben, aber nicht unmittelbar mit Heiligen oder Heiligenkult in Zusammenhang stehen. So berichtet Guibert beispielsweise in den Monodiae, daß im Kloster Saint-Germer-de-Fly das Begräbnis eines Mönchs vorbereitet wur-

96 Guibert de Nogent, De laude, Sp. 547; Guibert de Nogent, Quo ordine, S. 91.

97 Guibert de Nogent, De laude, Sp. 547; Guibert De Nogent, Quo ordine, S. 90.

98 Heinzelmann, Funktion, S. 34.

99 Wie z. B. in Grégoire LE Grand, Dialogues, II, 22, 4-5, S. 204. Dazu McCready, Signs of Sanctity, S.241f. Es muß für einzelne Wundererzählungen nachvollzogen werden, ob diese Referenzen auf abstrakter Ebene oder in der konkreten Ausgestaltung von Erzählungen zu fassen sind. Siehe Flusin, Miracle et Histoire, S. 157, der diese Referenzen postuliert.

100 Verschiedene Beispiele aus der Kreuzzugschronik lassen den Verdacht aufkommen, daß Guibert über die Parallelsetzung der Unternehmung der Franken zu biblischen Ereignissen ironisch Distanz nimmt zum Berichteten. Er vergleicht das Teilen des Roten Meeres mit dem Meer der Feinde, dessen dichtgedrängte Fluten von Soldaten durch die Kreuzfahrer getrennt wurden, die Gottesfurcht der Kreuzfahrer mit der Wolke, die sie des Tages, und mit dem Licht der göttlichen Hoffnung, die sie des Nachts führte, GulBERT DE NoGENT, Dei Gesta, VII, 22, S. 308. Siehe zu den Funktionen von Wundererzählungen in der Kreuzzugschronik auch Kap. 4.4.2. 
de ${ }^{101}$. Da der verantwortliche Mönch nicht mehr sicher war, wo sich noch Platz zwischen den alten Gräbern befand, stieß er während des Grabens auf ein altes Grab. Als die Mönche dies öffneten, fanden sie darin nur die Kapuze mit dem Kopf des Verstorbenen und seine Sandalen. Dazwischen fehlte der Körper. Guibert kommentiert dieses Ereignis, das er von Augenzeugen vernommen hat: "Wir wundern uns über das unbegreifliche Urteil Gottes! Was sehen wir für geheimnisvolle und scharfsinnig gewirkte Dinge! An diesem Wunder ist dies würdevoll, daß der Kopf im Grab blieb, während der Körper, wohin es Gott gefiel, weggetragen wurde «102. Guibert wurde ein Ereignis zugetragen, das schwierig zu beurteilen war, erstaunte und deshalb von ihm als miraculum beurteilt wurde. $\mathrm{Da} B$ hier auch Ironie in der Charakterisierung des Ereignisses im Spiel ist, ist zumindest nicht ganz von der Hand zu weisen, prangerte doch Guibert schon einige Jahre vorher in der Kreuzzugschronik und später im Reliquientraktat Mißbräuche rund um Gräber im Zusammenhang mit dem Heiligenkult an. Die anschließende Erzählung handelt von einem ähnlichen Vorfall: In Reims mußte wegen Bauarbeiten das Grab des Erzbischofs Artaldus ( $† 961)$, das in der Nähe desjenigen des heiligen Remigius lag, geöffnet werden. Vom Körper des Bischofs wurde nichts mehr gefunden, nur ein Mantel lag noch unversehrt im Grab. Guibert schloß die natürliche Ursache des Verschwindens, das Verwesen, aus, da sonst der Mantel auch Spuren der Fäulnis getragen hätte. Im Gegensatz zum vorherigen Ereignis verfügte er in diesem Fall über ein Deutungsschema, mit Hilfe dessen er die Begebenheit einordnen und deuten konnte. So erklärte er dieses Ereignis als iudicium Dei, analog zu solchen, die bei Gregor dem Großen berichtet würden ${ }^{103}$. Im vierten Buch der Dialogi erklärt Gregor anhand eines Beispiels, daß nur Menschen, die keine schweren Sünden begangen hätten, in Kirchen begraben werden sollten, sündhafte von diesem Begräbnisort nur noch größere Strafen davontragen würden ${ }^{104}$. Dieses zweite Beispiel zeigt, daß die Deutungsarbeit zweifach ist: Ereignisse müssen als zeichenhaft gedeutet werden, diese Zeichen müssen dann aber in ihrer Aussage für die Gemeinschaft ausgelegt werden.

101 Guibert DE Nogent, Autobiographie, I, 24, S. 192-194.

102 Ibid. I, 24, S. 194: Quod cum aliqui vidissent, nobisque retulissent, Dei incomprehensibile judicium mirati sumus. Quae tam occulte ac subtiliter fieri pervidemus! In quo illud dignum est miraculo, quod caput ibi dimissum, corpus autem quo Deo placuit a suo loco exportatum est. Der Editor Edmonde-René Labande übersetzt den letzten Satz: »En l'occurence c'était bien un objet d'étonnement que, la tête étant demeurée en place, le corps eût été emporté Dieu seul sait où. « Er vermeidet in der Übersetzung den Begriff »miracle « mit Wunder und betont den Aspekt des Staunens, was zeigt, daß dieses Beispiel am Rand dessen steht, was auch in der modernen Forschung unter miraculum verstanden wird.

103 Ibid. I, 24, S. 194: Videmus his temporibus, quae apud beatum Gregorium referuntur super noxiorum cadaveribus Dei judicia innovari, quos per sacra loca constat indebite tumulari.

104 Grégotre le Grand, Dialogues, IV, 52f., Bd. III, S. 176-178. 
In der Kreuzzugschronik ist wiederholt von Vorzeichen und deren Deutung die Rede. Zum Beispiel erwähnt Guibert eine Beratung der Großen des kapetingischen Reichs in der Sache des Kreuzzugs, die er auf den 11. Februar 1096 datiert. $\mathrm{Zu}$ dieser Gelegenheit erwähnt er eine Mondfinsternis und fügt die Beschreibung einer weiteren Himmelserscheinung an. Dabei handelt es sich um Sternschnuppen, die kurz danach während einer regnerischen Nacht gesehen worden sein sollen ${ }^{105}$. Aufgrund der Interpretation dieser Zeichen habe man das Beten von Litaneien angeordnet, um so das zu erwartende Unglück abzuweisen. Die Himmelserscheinungen selbst sollen mit ihrem Datum aufgeschrieben worden sein. Nach der Beschreibung einer weiteren Mondfinsternis bemerkt Guibert, daß diese Erscheinungen zwar natürlich, aber trotzdem manchmal Zeichen seien, weshalb man sie in den gestae von Bischöfen oder Königen zu verzeichnen pflege ${ }^{106}$. Wiederum ist nicht von vornherein klar, wann außergewöhnliche Naturerscheinungen innerhalb einer Gemeinschaft mit welchen Bedeutungen versehen werden können. In diesem Fall nahmen kirchliche Würdenträger durch das Anordnen von Litaneien die Deutungshoheit an sich. Guibert stellt dann das Festhalten solcher Zeichen in Zusammenhang mit den Konventionen historiographischer Werke.

\subsubsection{Rahmenbedingungen für Wunder}

Im Laufe des Exkurses über Wunder wird klar, daß Guibert das Wesen des Wunders nicht hauptsächlich interessiert. Weder steht für ihn im Mittelpunkt des Interesses, Wunderzeichen heilsgeschichtlich einzuordnen, noch die Beziehung von direkten oder indirekten Eingriffen Gottes zur Natur zu erkennen. Im Gegenteil stellt sich heraus, daß Guibert viel mehr an den Rahmenbedingungen des Wunders als an der wunderwirkenden Kraft interessiert ist. Wichtig ist in diesem Zusammenhang Guiberts Bemerkung, daß er die Wunder nicht wegen ihrer Neuheit aufschreibe, sondern um den Sinn ihrer unterschiedlichen Ursachen zu zeigen ${ }^{107}$. Diese Bemerkung folgt auf die Aufzählung von vier Exempla, die Merkmale von Personen zeigen sollen, durch welche Wunder geschehen.

Zweifel an den Wundern selbst sind nicht festzustellen. Vielleicht deshalb wird in den theoretischen Erörterungen nicht versucht, das Phänomen Wunder zu definieren. Vielmehr handelt es sich darum, die Rahmenbedingungen zu klären, unter denen ein Wunder als richtig oder konform akzeptiert werden kann. Unter diesen Rahmenbedingungen sind die Einstellungen der Mittler

105 Guibert de Nogent, Dei Gesta, II, 17, S. $133 \mathrm{f}$.

106 Ibid. II, 17, S. 134: Ubi dicendum quod, licet luna in pleniluniis naturaliter patiatur defectiones, sunt tamen aliquae in ipsis colorum eius mutationibus portensiones, unde et in pontificalibus et regum Gestis exinde solent fieri annotationes.

107 Guibert DE NoGENT, Quo ordine, P, I, Z. 368: At quia haec signa non tam pro sui novitate quam pro causarum ipsarum reddenda diversitatis ratione rettulimus [...]. 
als Personen, durch welche Wunder geschehen, für die Beurteilung des Geschehens wichtig.

\section{Vorbilder aus der Tradition}

Die wunderbaren Teilungen von Wasser für Alexander und Moses als Beispiele aus der schriftlichen Überlieferung sind auch in bezug auf die Rahmenbedingungen für Wunder signa amphibola, die Protagonisten Alexander und Moses als Modelle aussagekräftig. Diese sind in ihrer Beziehung zur wunderwirkenden Kraft, Gott, antitypisch ${ }^{108}$.

In der biblischen Tradition wird Alexander der Große in den Makkabäerbüchern (1. Macc. 1, 1-8) und im Buch Daniel (Dan. 7-8, 11) als mächtiger, aber schlechter Tyrann dargestellt, der unwissentlich das Instrument Gottes zur Vernichtung der Perser ist. Das Wunder der Teilung der Pamphylischen See ist in der jüdischen Tradition, in den Antiquitates des Flavius Josephus, überliefert. Dort kündigt Gott Alexander im Traum das Wunder an, worauf der Herrscher Gott Verehrung erweist ${ }^{109}$. Die biblische und die jüdische Tradition sind in der Einschätzung des Alexander nicht übereinstimmend, die Einschätzung des Wunders, das Gott an der Pamphylischen See gewirkt hat, erweist sich denn auch als schwierig ${ }^{110}$. Wie sich im Verlauf von Guiberts Argumentation im Exkurs zeigt, sind für Guibert sowohl Wunder möglich, die Gott in Folge tugendhaften Lebenswandels, Buße oder Reue geschehen läßt, als auch solche, die ohne Verdienst der Person geschehen, an der sie gewirkt werden. Alexander der Große ist in christlicher Tradition das Modell des unwissenden Werkzeuges

108 Die Begrifflichkeit »antitypisch, Antityp« soll hier im Sinne von »Gegenfigur, der anderen entgegengesetzt « verwendet werden, nicht im Zusammenhang der Typologie als Methode der Schriftdeutung, die von Typos und Antitypos als Figur des Alten bzw. des Neuen Testamentes spricht. Siehe dazu HaLl, Art. »Typologie«.

109 Josephus latinus, Antiquitates 11, 8, ed. Basel, Frobenius 1524, S. 328: Parmenio vero solus eum interrogavit, cur omnibus eum adorantibus ipse adorasset principem sacerdotum gentis Judaeae. Cui ille: non hunc, inquit, adoravi, sed deum cuius principatu sacerdotii functus est. Nam per somnium in huiusmodi eum habitu conspexi, adhuc in Dio civitate Macedoniae constitutus. Dumque mecum cogitassem, posse Asiam vincere, incitavit me ut nequaquam negligerem, sed confidenter transirem. Nam se perducturum meum dicebat exercitum, et Persarum traditurum potentiam: ideoque neminem alium in tali stola videns, cum hunc advertissem, habens visionis et probationis nocturnae memoriam, salutavi. Exinde arbitror divino iuvamine me directum, Dariumque vicisse, virtutemque solvisse Persarum. Propterea et omnia quae meo corde sperantur, proventura confido. Postquam Parmenioni locutus est principem sacerdotem honorans, occurrentibus reliquis sacerdotibus, ad civitatem usque pervenit: et ad templum ascendens, sacrificavit deo, secundum sacerdotis ostensionem. Ipse autem sacerdotum principi, et reliquis sacerdotibus munificenter multa donavit. Allato vero ei volumine Danielis, in quo scriptum erat, quendam Graecorum devicturum Persarum potentiam, arbitratus seipsum esse quem scriptura significabat, gavisus est: tunc quidem multitudinem dimisit.

110 Cary, The Medieval Alexander, S. 125-127. Auch in der Exempla-Literatur und bei Johannes von Salisbury finden sich widersprüchliche Urteile über Alexander als Herrscher. Siehe dazu Moos, Geschichte, S. 348 u. Anm. 682. 
Gottes. Ob Guibert nur die Geschichte der Teilung der Pamphylischen See als isoliertes Exemplum kannte oder ob er den bei Flavius Josephus dargestellten Traum des Alexander kannte und daher das Beispiel auch in diesem Sinne zweideutig ist, entzieht sich unserer Kenntnis ${ }^{111}$.

Moses hingegen ist ein spezieller Mittler zwischen Gott und Mensch, da er Gott von Angesicht zu Angesicht schauen kann ${ }^{112}$. Er hat von Gott direkt Zeichenkraft erhalten ${ }^{113}$. Moses ist zudem vor allem in monastischer Tradition das Beispiel für vollkommenes oder kontemplatives Leben ${ }^{114}$.

Gerade Moses und Alexander sind als Werkzeuge Gottes Antitypen: Moses als einziger, der Gott direkt schauen kann, Alexander als unwissendes Instrument Gottes. Für unwissende Instrumente Gottes werden als weitere Modelle der sprechende Esel des Bileam und die Prophetien des Bileam und des Hohepriesters Kaiphas genannt, die beide unbewuBte Werkzeuge Gottes, beziehungsweise Verkünder seines Heilsplans sind ${ }^{115}$. Die Prophetien des Bileam und des Kaiphas werden in verschiedenen exegetischen Schriften, so in Kommentaren zu den Paulusbriefen und dem Matthäusevangelium, immer wieder erwähnt. Dies unter zwei Aspekten: Zum einen sind sie wie bei Guibert Beispiele von unwissenden Instrumenten Gottes, die Prophezeiungen machen; der Esel, dem Gott den Mund öffnet, der Prophet Bileam, dem Gott die Augen öffnet und der Hohepriester Kaiphas, der kraft seines Amtes den Erlösungstod Jesu verkündet ${ }^{116}$. Zum anderen werden die gleichen biblischen

111 Die lateinische Version der Antiquitates wurde in Italien und in Frankreich während des früheren Mittelalters immer wieder abgeschrieben. Zur handschriftlichen Überlieferung siehe BlatT, Latin Josephus, S. 27-111. Viele der Handschriften aus dem 12. Jahrhundert wurden in Nordfrankreich, Belgien oder in der Rheingegend abgeschrieben. BLATT, Latin Josephus, S. 16 setzt dies mit den Kreuzzügen in Zusammenhang, da in den Antiquitates viele geographische Informationen enthalten sind.

112 GuiberT DE NoGENr, De laude, Sp. 538: [...] qui dum Deo facie ad faciem quasi homo ad proximum loquebatur [...]. Moses galt als besonderer Mittler zwischen Gott und den Menschen. Bezug genommen wird auf Num. 12, 7-8: at non talis servus meus Moses qui in omni domo mea fidelissimus estore enim ad os loquor ei et palam non per enigmata et figuras Dominum videt quare igitur non timuistis detrahere servo meo Mosi. Das Zitat im Marienlob ist parallel zu Deut. 34, 10f., wo Moses ebenfalls beschrieben wird: et non surrexit propheta ultra in Israhel sicut Moses quem nosset Dominus facie ad faciem. In omnibus signis atque portentis quae misit per eum ut faceret in terra Aegypti Pharaoni et omnibus servis eius universaeque terrae illius.

113 In Exod. 4, 1-9 verwandelt Gott den Stab des Moses erstmals in eine Schlange. Durch diesen werden danach die Wunder gewirkt.

114 Peppermüller, Art. »Moses (B. Christentum)«. Diese Gedanken entwickelt auch Guibert in seiner frühen Schrift De virginitate. Siehe dazu Runenstein, Guibert of Nogent, S. 24-26.

$115 \mathrm{Zu}$ Bileam siehe auch oben, S. 44.

116 Wie zum Beispiel in einem Kommentar des Hieronymus über das Matthäus-Evangelium zu Vers 7, 22 oder in einem Kommentar zum Prophetenbuch des Jona. Guibert erwähnt in seinem Vorwort zu den Tropologiae in prophetis den Hieronymus-Kommentar zu den kleinen Propheten. Huygens, Tradition manuscrite, App. 20, S.110. Neben den Beispielen scheint Guibert in seiner Reliquienkritik auch den Gedanken, daß Wunder 
Modelle auch in Argumentationen von Streitschriften der Kirchenreform erwähnt, wie von Petrus Damiani im Liber Gratissimus. In dieser Streitschrift wird sowohl Bileam als Typus des simonistischen Priesters dargestellt als auch anhand der Prophetie des Kaiphas gezeigt, daß die Sakramente, die durch simonistische Priester erteilt wurden, gleichwohl gültig sein können ${ }^{117}$. Obwohl Guibert im zweiten Buch des Reliquientraktats das Problem des Empfangs der Eucharistie durch unwürdige Priester ebenfalls anspricht, ist diese Deutungsebene aus dem Kreis der Kirchenreform in seiner Verwendung dieser Exempla nicht zu fassen ${ }^{118}$. Guibert interessiert sich vielmehr für die Eigenschaften von Menschen als unbewußte oder bewußte Mittler - er bezeichnet sie als Kanäle -, durch die Gott Wunder wirkt ${ }^{119}$. Dies wird im Verlauf der Argumentation durch vier zeitgenössisch situierte Beispiele verdeutlicht.

zum Nutzen der Gläubigen geschehen (formuliert am Beispiel des Eucharistiewunders in Soissons), zu übernehmen. Hieronymus, Commentariorum in Matheum, S. 45f.: Multi dicent mihi in illa die: Domine, Domine, nonne in nomine tuo prophetavimus et in nomine tuo daemonia ejecimus et in nomine tuo virtutes multas fecimus? Et tunc confitebor illis: Quia numquam novi vos; discedite a me qui operamini iniquitatem. Prophetare et virtutes facere, et daemonia ejicere interdum non ejus est meriti qui operatur, sed vel invocatio nominis Christi hoc agit, vel ob condemnationem eorum qui invocant vel utilitatem eorum qui vident et audiunt conceditur, ut licet homines despiciant signa facientes, tamen Deum honorent ad cuius invocationem fiant tanta miracula. Nam et Saul et Balaam et Caiphas prophetaverunt nescientes quid dicerent [...]; oder auch in einem Kommentar über das Buch Jona: Commentarii in Ionam prophetam, 1, 7, S. 387: Sicut enim in condemnationem Balaam asina loquitur, et Pharao et Nabuchodonosor in iudicium sui, somniis futura cognoscunt, et tamen Deum non intellegunt revelantem. Caiphas quoque prophetat ignorans, quod expediret unum perire pro cunctis. Augustinus erwähnt mehrmals Kaiphas, der den Tod Jesu prophezeite, da er der Hohepriester des Jahres war, so z. B. in: Augustinus, De consensu Evangelistarum libri IV, II, 70, 136, S. 239: [...] per eos veritas ipsa locuta est, sive per nescientes, si mali erant, sicut per Caiphan, qui nesciens quid dixerit, cum esset pontifex, prophetavit, sive per scientes ac iam intelligentes adque credentes. AmbrosIASTER, Commentarius in XIII epistulas Paulinas. Ad Corinthios prima 13, 2, S. 145: Nam et Balam profetavit, cum profeta non esset, sed ariolus: et Caifas profetavit non merito, sed dignitate ordinis sacerdotale [...].

117 Petrus Damiani, Brief Nr. 40, in: Briefe des Petrus Damiani, S. 405-408, 413-416. Zur Überlieferung ibid. S. 13-31. Petrus Damiani stellte diese Streitschrift 1052 zusammen. $\mathrm{Da} \beta$ in Streitschriften des Investiturstreites Interpretationskonflikte bzgl. Exempla ausgetragen wurden, zeigt Moos, Geschichte, S. 334. Siehe dazu auch GoETz, Geschichte als Argument.

118 Guibert de Nogent, Quo ordine, P, II, S. 120f. Das Problem ist zu Anfang des 12. Jahrhunderts nicht mehr virulent, da es schon 1061 durch einen Konzilsbeschluß gelöst wird. Siehe Briefe des Petrus Damiani, S. 386, Anm. 3. Guibert geht im Reliquientraktat auch nicht auf Wunder durch simonistische Priester ein, wie sie bei Petrus Damiani im Liber Gratissimus genannt sind. Briefe des Petrus Damiani, S. 439-446, 477-480. Rubenstein, Guibert of Nogent, S. 148 hat gezeigt, daß Guibert nicht oft kirchenreformerische Positionen einnimmt. Zu Guiberts Stellung zu kirchlicher Führung, wie sie vor allem in den Monodiae thematisiert wird, siehe Lemmers, Crisis of Episcopal Authority.

119 Der Gedanke, daß Gott die Gabe seiner Gnade wie durch Kanäle leitet, ist schon in der Predigtanleitung zu finden. GuiberT De Nogent, Quo ordine, S. 50. 
Unbewußte Mittler versus verdiente Gläubige

Mit den ersten beiden Beispielen seines Exkurses nennt Guibert Wunder, die ohne Zutun oder Verdienst der Person, an der sie gewirkt worden waren, geschehen sein sollen. Diese seien in neuester Zeit in seiner Region geschehen, so das erste Wunder in Soissons ${ }^{120}$. Im Zentrum der Erzählung steht eine Jesus-Vision eines unwissenden Kindes. Ein adeliger Knabe sah beim erstmaligen Besuch der Messe, daß der Priester anstelle der Hostie ein wunderschönes Kind in die Höhe hob. Durch das unschuldige Kind, dem seine Rolle als Verkünder der Präsenz Christi ohne Verdienste zugewiesen wurde, tat Gott wie durch einen Kanal ein Zeichen. Daß nach diesem Ereignis der Knabe in der Welt aufwachse und sich kaum an das Wunder erinnern könne, sei ein Zeichen, daß dieses Wunder nicht zum Verdienst des Knaben, sondern zur Stärkung des Glaubens der Anwesenden geschehen sei ${ }^{121}$.

Dieses gängige Eucharistiewunder paßt thematisch in den Gesamtkontext der Abhandlung - die Auseinandersetzung um den Auferstehungsleib und der Ablehnung von Reliquien Jesu. Ähnliche Wundererzählungen wurden oft verwendet, um die Realpräsenz Christi in der Hostie zu beweisen ${ }^{122}$. Ein solches Verwandlungswunder wurde 1025 auf dem Konzil von Arras gegen Häretiker als Beweis für die Wandlung der Opfergaben erwähnt ${ }^{123}$. Diese Erzählung kann über den Traktat De corpore et sanguine Domini, den Paschasius Ratpertus zwischen 831 und 833 verfaßt hatte, bis zu einer karolingischen Mirakelsammlung zurückverfolgt werden ${ }^{124}$. Für diese Erzählung in den genannten Quellen darf aber, im Gegensatz zu Guiberts Version, eine schriftliche

120 Ibid. P, I, Z. 178-210.

121 Ibid. P, I, Z. 196-200.

122 Browe, Eucharistische Wunder, S. 101. Dazu auch Snoek, Medieval Piety, S. 48.

123 Konzil von Arras, ed. PL 142, Sp 1283: Quidam vir virtute venerabilis Plexis nomine, Monachorum gregem cura pervigili servabat: cujus de virtutibus et miraculis esset satis ad loquendum. Sed quod ad praesens negotium attinens utiliter occurrit, unum audite. Hic dum quadam die ex more sacrosancto altari humili devotione adstaret, et missarum solemnia celebrans Dominici corporis et sanguinis veneranda mysteria consecraret: ut ventum est ad horam fractionis, vidit subito quod et fideliter credendum, et creduliter sit admirandum, id est, sanctificati panis portionem in infantem transformari, et Angelum Domini particulatim ipsum dividere: manifesto veritatis indicio, quia verum Christi Corpus est, quod sub Sacramento communicandae carnis et sanguinis de altari sumimus. Zum Konzil in Arras siehe unten, S. 83.

124 Paschasius Radbertus, De corpore et sanguine domini, c. 14, S. 89f. Die Erzählung steht bei Paschasius Radbertus im Kapitel 14 (S. 85-92), worin Beispiele solcher Verwandlungs- und Erscheinungswunder zusammengestellt werden. Da dieser erwähnt, daß das Ereignis in Zusammenhang zu einer Messe für den heiligen Ninian gestellt werden kann, konnte eine versifizierte Mirakelsammlung des heiligen Ninian als Quelle des Radbertus eruiert werden, die gemäß Karl Strecker im 8 . Jahrhundert im angelsächsischen Kloster Candida Casa verfaßt und von Alkuin in sein Florilegium aufgenommen wurde. Siehe BHL 6240, a-c. Miracula Nynie Episcopi, in: MGH Poetae latini aevi carolini, IV, 2, 2, ed. v. Karl Strecker, Hannover 1914, S. 943-962, hier S. 957-959. Dazu STrecker, Quellen. Unter den Beispielen findet sich auch eine Erzählung aus der Vita Gregors des Großen von Paulus Diaconus. 
Übernahme vorausgesetzt werden, da der Zusammenhang zur Version der karolingischen Mirakelsammlung immer hergestellt werden kann. In Guiberts Traktat wird das bekannte Motiv - das Christuskind erscheint während der Wandlung - in lokalem Kontext und von der vielfach bezeugten Version deutlich abweichend erzählt ${ }^{125}$.

Diese Episode unterstreicht so aber neben ihrer Funktion als Beispiel gleichzeitig Guiberts theologische Ansicht der Präsenz des sakramentalen Leibes Christi in der Eucharistie ${ }^{26}$. Ein weiteres eucharistisches Beweiswunder führt Guibert im zweiten Buch der Reliquienkritik an: Unter Bezug auf Cyprian, De lapsis, erzählt er eine Begebenheit, wonach Ungläubige, die am Sakrament teilgenommen hatten, die Hostien aus der Messe nach Hause nahmen. Dort fanden sie diese in Asche verwandelt ${ }^{127}$.

Das zweite Wunder der Beispielserie in Guiberts Wunderexkurs hat sich gemäß den Zeugenangaben in Saint-Quentin ereignet. Eingeleitet wird die Erzählung mit dem Hinweis auf die unschuldigen Kinder und auf drei Zitate aus dem Matthäus-Evangelium und dem Römerbrief. Diese Hinweise sollen zusätzlich zur ersten Botschaft belegen, daß der Wille Gottes unergründlich ist ${ }^{128}$. Ein Knabe wollte als Meßdiener einer Jesus-Statue die Kommunion erteilen, worauf diese den Jungen auf seinen baldigen Tod ansprach. Dieser traf wenige Tage später ein ${ }^{129}$. Diese zweite Erzählung ist wie die erste ebenfalls mehrfach überliefert, wird von Guibert aber analog zum Eucharistiewunder aus Soissons in lokalem Zusammenhang berichtet ${ }^{130}$. Das Wunder wird als weiteres Argument angeführt, daß Gott Wunder an Unschuldigen vollbringt. Der Tod des Knaben muß vom irdischen Standpunkt aus als ungerecht und unergründlich eingeschätzt werden, wird aber mit der viel größeren Gabe des ewigen Lebens ausgeglichen. Das Beispiel steht im Zusammenhang mit Wundern, die an Unbeteiligten geschehen, läßt aber Guibert, wie die Bibelzitate ausdrücken, in seiner Deutung etwas ratlos.

Mit den anschließenden zwei Exempla illustriert Guibert in seinem Traktat Wunder, die Reue oder Bußwillen von Gläubigen belohnen.

Die erste Erzählung handelt, literarisch sorgfältig ausgestaltet, von einem Mädchen, das aufgrund inzestuösen Verkehrs schwanger wurde und mit dem

125 In den anderen Quellen ist ein Priester am Grab des heiligen Ninian die Hauptperson, die immer wieder bittet, das Jesuskind zu sehen. Dieser Wunsch wird ihm während einer Messe erfültt. Siehe MarCHal, Meisterli von Emmenbrücke, für die Analyse eines ähnlichen Falles, wo sich ein Wandermotiv mit einer Erzählung in lokalem Kontext vermischt und in diesem lokalen Kontext Bestandteil der Erinnerung einer Gemeinschaft wird.

126 GeiselmanN, Eucharistielehre, S. 70, spricht für den Beginn des 12. Jahrhunderts von einem neu auflebenden Berengarismus; GüNTER, Psychologie der Legende, S. 259f.

127 Guibert DE Nogent, Quo ordine, P, II, Z.455-466. Guibert verwendet seine Vorlage nur ungenau. Bei Cyprian stand die entwendete Hostie in Flammen, so daß sie nicht mehr berührt werden konnte, siehe RUBENSTEIN, Guibert of Nogent, S. 149.

128 Matth. 20, 15 und Rom. 9, 18.

129 Guibert DE NoGENT, Quo ordine, P, I, Z. 210-233.

130 Auch dieses Wunder ist weit verbreitet, siehe dazu Fuchs, Collections. 
jungen Vater des Kindes beschloß, ihre Heimat im Artois zu verlassen ${ }^{131}$. Dieser wollte das Mädchen loswerden und warf sie auf offenem Felde in einen alten Brunnen. Dann schleuderte er Steine hinterher, um das Mädchen zu töten. Sie konnte sich jedoch retten und harrte symbolische vierzig Tage im Brunnen aus, genährt nur von Tropfen, die sich von einem Grasbüschel lösten ${ }^{132}$. Als Parallele der reichlichen Ernährung durch diese Tropfen macht Guibert einen Hinweis auf die Vorräte des Sardanapalus, der als Typus des im Luxus versunkenen Menschen in klassischen Texten, wie auch solchen von Kirchenvätern und mittelalterlichen Verfassern genannt wird ${ }^{133}$. Gerettet wurde das Mädchen durch Bauern, die auf die Schreie aus der Tiefe aufmerksam wurden und es unter Beteiligung einer großen Volksmenge aus dem Brunnen zogen. Entscheidend für die Rettung war die Beichte, die das Mädchen vor der Abreise noch ablegte. So schließt Guibert die Geschichte ab mit dem Satz: Ecce quid valuit fides in paenitentia, quid valuit in intentione corrigendi perseverantia ${ }^{134}$. Wichtig ist der Glaube an Gott, der Rettung und Vergebung nach sich zieht. Schon in der biblischen Wunderkonzeption ist angelegt, daß der Glaube wichtiger ist als wunderbare Ereignisse ${ }^{135}$.

Den Aspekt der Tugendheiligkeit unterstreicht auch das letzte Exemplum, in dem der Dekan der Kirche von Cambrai, Erlebald, die Hauptrolle spielt ${ }^{136}$. Dieser hatte zeitlebens strenge Buße getan und erschien nach seinem Tod verschiedenen Personen in Visionen, um ihnen von seinen weiteren Qualen zu berichten. Die Geschichte wird auf ungeschickte Art mit einer weiteren Erzählung einer Vision verknüpft, in der eine Nonne von Bourbourg einer anderen erschien, um ihr zu berichten, daß sie und der Dekan Erlebaldus in den Himmel aufgenommen seien. Neben anderen Deutungsaspekten hebt diese Erzählung den guten Christen hervor, der seine Aufnahme in den Himmel erarbeitet hat. So werden sowohl die Visionen als auch die ganze Bußleistung als Wunder bezeichnet.

Mit diesen letzten Beispielen, die Reue, Buße und Tugendheiligkeit in den Vordergrund stellen, reiht sich Guibert wiederum in die augustinisch-gregorianische Traditionslinie ein. In den Schriften Augustins sind Reue und Buße neben den oben aufgeführten biblischen Beispielen als spirituelle Wunder bezeichnet ${ }^{137}$. Das Argument, daß äußere Wunderwirksamkeit ohne tugendhaften

131 Guibert De Nogent, Quo ordine, P, I, Z. 241-291.

132 Die Zahl 40 steht vor allem für irdische Bedrängnis und Entsagung. So bewahrt die Kirche in der 40tägigen Fastenzeit die Erinnerung an die biblischen Fastenzeiten und Aufenthalte in der Einsamkeit. Siehe dazu Lexikon der mittelalterlichen Zahlenbedeutungen, Sp. 709-723.

133 Siehe dazu Nachträge zu A. Otto, S.90. In christlicher Ikonographie ist Sardanapalus oft als Antithese der Tugend dargestellt.

134 Guibert de Nogent, Quo ordine, P, I, Z. $292 \mathrm{f}$.

135 ANGENENDT, Wunder, S. 103.

136 Siehe auch unten, S. 77 .

137 Siehe dazu Aigle, Mayeur-Jaouen, Miracle et karama, S. 19, die auf Boglioni, Miracle et nature, S. 81 verweisen. Zum Gedankengut von Gregor dem Großen auch BoEsCH 
Lebenswandel wertlos sei, wird in hagiographischen Texten des Früh- und Hochmittelalters immer wieder vorgebracht. Gerade im Hinblick auf das Wunderwirken von Häretikern, Magiern oder auch dem Antichrist ist die Tugendheiligkeit und das spirituelle Wunder in christlicher Argumentation wichtig 138 .

Es zeigt sich aber, daß Guibert in den Beispielen seines Exkurses nicht genau zwischen Mittlern und Empfängern von Wundern unterscheidet, sondern diese gemeinsam betrachtet. Mit den vier Beispielen zeigt er, daß Wunder durch unbewußte Mittler (Eucharistie-Wunder in Soissons) oder an unbewußten Empfängern (Wunder in Saint-Quentin), wie auch aufgrund von Reue oder Buße geschehen können. Er will so das Bewußtsein für unterschiedliche Rahmenbedingungen von Wundern schärfen.

\section{Die wundertätigen Könige}

In der Aufzählung doppeldeutiger Wunder kommt Guibert, nachdem er Vorzeichen für Schicksale weltlicher Herrscher wie Karl des Großen oder Ludwig des Frommen genannt hat ${ }^{139}$, auf das Wunder der Skrofelheilung des Königs Ludwig VI. zu sprechen ${ }^{140}$. Dieses Wunder ist in zweierlei Hinsicht speziell. Zum einen betrifft es den Status des Königs. Dies ein Grund, weshalb ihm von der Forschung viel Aufmerksamkeit geschenkt wurde. Zum anderen gibt Guibert an, bei einer solchen Zeremonie selbst anwesend gewesen zu sein. Ob das Wunder unmittelbar stattgefunden hatte oder nicht, läßt er offen. Diese Wundertätigkeit eines weltlichen Herrschers wird von Guibert als problematisch beurteilt ${ }^{141}$. Er gibt an, er habe gesehen, wie die Kranken in Scharen zum Kö-

Gajano, Expériences, S. 55. Dort werden die Taufe, das Lob Gottes und Hilfe an den Nächsten als spirituelle Wunder bezeichnet.

138 VAN UYTFanghe, La controverse biblique et hagiographique, S. 212f., zur Betonung der Tugendheiligheit. Bei Demm, Zur Rolle des Wunders, S. 304 und SchreIner, Discrimen veri ac falsi, S. 20f. sind die Argumente von Augustin und Gregor dem Großen, aber auch weitere Beispiele aus der Hagiographie zusammengestellt. Zur Betonung der Tugendheiligkeit siehe Boesch Gajano, Proposta, S. 639 und 647 und Boglioni, Miracle et nature, S. 80. VAUCHEZ, Miracle, S. 41-43 zeigt den zweigleisigen Umgang des Klerus und der Mönche mit dem Wunder: einerseits die grundsätzliche Zurückhaltung vor allem gegenüber Wunderheilungen, andererseits den bewußten Einsatz dieser Wunder.

139 Das Beispiel von Karl dem Großen ist in ErNhARD, Vita Caroli, cap. 32, S. 88-92, dasjenige von Ludwig dem Frommen bspw. bei Astronomus, Vita Hludovici imperatoris, cap. 6 , S. 544 (die Vita des Astronomus ist in Nordfrankreich breit überliefert, so auch in einer Handschrift aus Saint-Médard de Soissons aus dem 10. Jahrhundert), den Annales Fuldenses, S. 30f. und den Annales Bertiniani, S. 36, zum Jahr 840 überliefert. Siehe GuiBERT DE NogENT, $Q u o$ ordine, S. 90 . Zu Vorzeichen für weltliche Herrscher in der Tradition der Geschichtsschreibung siehe HeinZELmanN, Funktion, S.28f., in der Kirchengeschichtsschreibung S. 34-36, bei Orose, Histoires, S. 41.

140 Guibert de Nogent, Quo ordine, P, I, Z. 157-166. Siehe dazu Bloch, Die wundertätigen Könige, S.66-70; Eulers, Der wundertätige König, S. 15f. und im speziellen Poly, Gloire des rois, der den Zusammenhang mit Saint-Maclou in Corbeny, das sich unweit von Laon befindet, betont.

141 Guibert DE Nogent, Quo ordine, P, I, Z. 158: Quid, quod dominum nostrum Ludovicum regem consuetudinario uti videmus prodigio? 
nig liefen. Er selbst habe beim König gestanden und versucht, die Kranken abzuhalten. Der König habe diese aber herangezogen und demütig gesegnet $^{142}$. Guibert berichtet als erster von dieser später eng mit dem französischen Königtum verbundenen wunderbaren Skrofelheilung, legt aber die Probleme, welche diese Wundertätigkeit aufwirft, nicht offen. Die Fragen der modernen Forschung, ob es sich bei diesem Wunder in Guibert Verständnis um eine erbliche Wundertätigkeit infolge der königlichen Sakralität oder um eine individuelle Heiligkeit handle, sind aus seiner Darstellung nicht eindeutig zu beantworten ${ }^{143}$. Dieses Problem wirft explizit erst William von Malmesbury in seinen Gesta regum Anglorum für den englischen König auf, als er ein Wunder des letzten angelsächsischen Königs Eduard des Bekenners (1042-66) berichtet. Er verwirft die Idee, daß das Wunder aufgrund einer königlichen erblichen Geblütsheiligkeit geschah und ordnet die Wunderkraft vielmehr der individuellen Heiligkeit des Königs zu ${ }^{144}$. William hat diese Wundererzählung, die Heilung einer Frau von ihren Geschwulsten, der Vita des Königs entnommen ${ }^{145}$. Auch für Robert II., kapetingischer König von 987/996-1031, werden Heilungswunder berichtet, wenn auch für ihn keine Spezialisierung auf die Skrofeln festzustellen ist. Die Wunder, die König Robert gewirkt hat, werden ebenfalls in seiner Vita berichtet, verbunden mit der Darstellung seines tugendhaften, heiligenmäßigen Lebens ${ }^{146}$.

Guibert hingegen entnimmt das Wunder nicht einer Vita, die von der Heiligkeit ihres Protagonisten zeugen soll, sondern beobachtet es als Augenzeuge. Seinen König Ludwig, den er in seinen Schriften oft erwähnt, schätzt er nicht als heilig ein. Daß Guibert die Wundergabe der Skrofelheilung im Gegenteil mit dem Königtum verbindet, geht aus der Erwähnung hervor, da $\beta$ auch schon Ludwigs Vater, Philipp I., diese besaß. Philipp hätte sie aber nescio quibus incidentibus culpis, durch seine Sündhaftigkeit, wieder verloren ${ }^{147}$.

142 Ibid. P, I, Z. 158-163: Hos plane qui scrophas circa iugulum aut uspiam in corpore patiuntur ad tactum eius, superaddito crucis signo, vidi catervatim, me ei cohaerente et etiam prohibente, concurrere, quos tamen ille ingenita liberalitate serena ad se manu obuncans humillime consignabat. Deutsche Übersetzung in BLOCH, Die wundertätigen Könige, S. 68 .

143 Die wichtigste Darstellung zu diesem Thema ist immer noch BLOCH, Rois thaumaturges, in deutscher Übersetzung von Claudia Märtl: BLOCH, Die wundertätigen Könige. Siehe auch das Vorwort von Jacques Le Goff in der deutschen Ausgabe.

144 William of Malmesbury, Gesta Regum, II, 222, Bd. 1, S. $406-408$ u. Bd. 2, S. 207 (Kommentar). Siehe dazu und zur Diskussion des Ansatzes von Bloch EhLERs, Der wundertätige König. Barlow, King's Evil, S. 37f stellt die These auf, daß William von Malmesbury eine Replik auf Guiberts Äußerung bietet: Unde nostro tempore quidam falsam insumunt operam, qui asseverant istius morbi curationem non ex sanctitate sed ex regalis prosapiae hereditate fluxisse.

145 Vita Edwardi regis, S. $61 \mathrm{f}$.

146 Epitoma vitae regis Rotberti pii, Helgaud de Fleury, Vie de Louis le Pieux, § 11, S. 76. Siehe dazu Ehlers, Der wundertätige König, S. 8.

147 Guibert DE Nogent, Quo ordine, P, I, Z. 164f. Le Goff zeigt in Bloch, Die wundertätigen Könige, S. 23f., daß sowohl für Frankreich als auch für England erst ab dem 13. Jahrhundert von einem ständigen königlichen Brauch der Berührung der Skrofeln auszugehen ist. 
Auch der Vergleich mit dem englischen König zeugt vom Bewußtsein, daß diese Gabe mit dem Königtum verbunden war ${ }^{148}$. Die königliche Wundertätigkeit war für Guibert nicht wie für William und Helgaud der Heiligkeit der Könige zuzuordnen. Der Grund der königlichen Wundertätigkeit wird von Guibert wiederum nicht erörtert, wohl aber der Grund des Verlustes derselben: die moralische Haltung des Königs.

Das Beispiel der Skrofelheilung des französischen Königs zeigt wie die vorhergehenden Beispiele, da $\beta$ die Erörterung über die Rahmenbedingungen von Wundern nicht nur gelehrte Abhandlungen des Problems sind, sondern auch Versuche, aktuelle Vorfälle einzuordnen und zu beurteilen.

\section{Heilige und Reliquien}

Wundererzählungen werden in erster Linie in Zusammenhang mit dem Heiligenkult verschriftlicht. Heilige und Reliquien als Bindeglied zwischen der göttlichen Wunderkraft und den Gläubigen spielen in Guiberts Argumentation eine wichtige Rolle, sie sind der Ausgangspunkt der Schrift De sanctis et eorum pigneribus. Sie sind somit wichtige Rahmenbedingungen für Wunder. Das erste Buch des Traktats, woraus der oben genannte Wunderexkurs nur ein Teil ist, handelt auf breiterer Ebene vom Reliquienkult. Guibert eröffnet die Argumentation mit der Stellung des Reliquienkultes in christlicher Lehre und Praxis. Als erstes beleuchtet er dann die Ebene von Texten, die im Zusammenhang mit Kulten von Heiligen stehen ${ }^{149}$. Anschließend folgen der Exkurs zu den Wundern und ein Definitionsversuch von Heiligen. Zum Schluß des Buches geht Guibert, nachdem er die zweifelhaften Fälle ausgeschieden hat, auf die Mißbräuche des Reliquienkults anerkannter Heiliger ein. Guiberts Argumentation zum Zusammenhang von Wundern und Heiligen ist in gewiBer Weise zirkulär: Einerseits sind Wunder ein Beweis für die Autorität von

148 Ibid. P, I, Z.165f.: Super aliis regibus qualiter se in hac re gerant supersedeo, regem tamen Anglicum neutiquam in talibus audere scio. Bloch folgert aus dieser Stelle, daß Guibert dem englischen König die Heilkraft absprechen würde und erklärt dies mit dem patriotischen Bewußtsein Guiberts. BLосH, Die wundertätigen Könige, S. 83. Die Charakterisierung Guiberts als ersten Patrioten Frankreichs ist in der wissenschaftlichen Beschäftigung von Historikern des 19. Jahrhunderts wie MoNOD, Le moine, grundgelegt. Dieser Auffassung folgt in bezug auf diese Stelle im Grunde auch EHLERS, Der wundertätige König, S. 16. Eine neue Interpretation der Stelle bietet Jay RuBENSTEIN, Guibert of Nogent's Lessons from the Anglo-Norman World, der konstatiert, daß Guibert die Wundertätigkeit der moralisch nicht unanfechtbaren und sicher nicht heiligen Könige Frankreichs nicht positiv konnotiert und deshalb den englischen König, der nicht gewagt (audere) hätte, von diesem Wunder Gebrauch zu machen, dem französischen König als moralisch überlegen darstellt.

149 Guibert stellt das Problem nicht in absoluter Klarheit dar, da er stark auf die Ebene der Texte eingeht, jedoch ein anderes Verhältnis zu Texten als Autoritäten hat als die moderne Historikerin. Diese unterschiedlichen Kategorien und die etwas unklare, immer mehrschichtige Argumentationsweise Guiberts erschweren das Verständnis des Textes. 
Heiligen. Andererseits haben Heilige als Interzessoren wichtige Funktionen für die Glaubwürdigkeit und Anerkennung von Wundern ${ }^{150}$.

Guibert spricht im Reliquientraktat in erster Linie von verstorbenen Heiligen und deren Kult. Reliquien als Objekte der Verbindung der diesseitigen Welt mit der jenseitigen spielen deshalb neben Kriterien für die Anerkennung von Heiligen eine wichtige Rolle. Sie dienen ihm als Zeugnis von Beispiel und Schutz der Heiligen ${ }^{151}$. Ein Problem Guiberts ist daher, zu zuverlässigen Informationen über die Lebensführung und den Tod dieser Heiligen zu kommen. Hierbei zeigt er ein großes Bewußtsein für die Ebene der Texte, die über Leben und Tod von Heiligen berichten. Guibert pocht dabei im Verlauf des ersten Kapitels mehrmals auf Sicherheit ${ }^{152}$. Sicherheit, daß jemand $z u$ Recht heilig genannt werde. Probleme bieten sich schon bei der Beurteilung von Texten, die über Heilige berichten. Relativ unproblematisch sei dies bei den Aposteln. Schon Märtyrer seien anfällig für Mißbräuche, noch problematischer sei dann aber die Beurteilung von Bekennern ${ }^{153}$. Die Beispiele, die Guibert im Verlauf seiner Argumentation erwähnt, zeigen, daß die Umstände des Todes als wichtig erachtet wurden, wenn es darum ging, eine Person als heilig einzuschätzen. Ob ein Mensch in Sünden starb, ob er eines guten oder schlechten Todes starb, sind wichtige Fragen in diesem Zusammenhang154. So führt Guibert am Ende des Abschnitts über die Texte drei Fälle aus neuerer Zeit an, alle aus dem angelsächsischen Bereich. Zuerst erwähnt er den Körper eines Heiligen, von dem niemand wußte, ob er ein confessor oder ein Märtyrer gewesen sei. Darauf erwähnt er das Beispiel des heiligen Piro. Von diesem hatte

150 GuIBERT DE NOGENT, Quo ordine, P, I, Z. 143-145: [...] quid de illis sperare licebit, quorum claritudini neque visus neque auditus neque scripta neque miracula concurrerunt? Et certe difficillime credendum signis erat preter illa, quae bono continuatus initio finis ediderat. "[...] was wird man von jenen (Heiligen) erhoffen können, zu deren Ruhm weder Gesehenes noch Gehörtes, weder Schriften noch Wunder beigetragen haben? Und sicherlich war es sehr schwierig, an Zeichen zu glauben, außer an jene, die ein Ende hervorgebracht hatte, das mit einem guten Anfang verknüpft war.«

151 Ibid. P, I, Z. 65-67.

152 Guiberts Überlegungen wiederholen sich mit Modifikationen. Gedanken, die zu Anfang des Buches geäußert werden, sind unterbrochen durch den Wunderexkurs und werden im Anschluß daran erneut aufgenommen.

153 Ibid. P, I, Z. 421-426.

154 Ibid. P, I, Z. 118-122. Dieser Passus ist rhythmisch komponiert: Quid dicam de iis sanctis, quorum aut finis est in malo propagatulus aut latet utrum bonus an malus aut inter utrunque fit scrupulus? lesu pie, cuiusmodi sanctus, cuius finis constat ambiguus! Antequam ergo eum deprecer, necesse est ut de veritate sanctitatis eius altercer. "Was soll ich über jene Heilige sagen, von denen auch nur ein klein wenig ein schlimmes Ende überliefert wird oder von denen unbekannt ist, ob es gut oder schlecht war oder ob zwischen beiden ein Zweifel sei. Gütiger Jesus, welcher Art muß ein Heiliger sein, dessen Ende ungewiß bleibt! So ist denn, bevor ich bei ihm Fürbitte einlege, nötig, daß ich erörtere, ob er wahrhaftig ein Heiliger sei.« Die Beachtung der Todesart, die nach mittelalterlicher Vorstellung der Lebensführung entspricht, zeigt sich auch in vielen Wundererzählungen in den Monodiae. Siehe dazu unten, S. 170. 
Guibert in der Vita des hl. Samson gelesen, dort aber bemerkt, daß Piro eines unheiligen Todes gestorben war: Er fiel betrunken in einen Brunnen und starb an den Folgen des Sturzes ${ }^{155}$. Julia Smith bezeichnet dieses Beispiel als »an extreme and unfair one $\ll$, da sie, obwohl in der Vita des hl. Samson auf Piro als Heiligen verwiesen wird, einen Kult bezweifelt ${ }^{156}$. Diesem widerspricht der spätere Brief von Papst Alexander III. an Knut Ericson und an das schwedische Episkopat von 1171-1180, der von signa und miracula spricht, die durch diesen Heiligen gewirkt worden seien ${ }^{157}$. Für Guibert ist die Bezeichnung als sanctus für einen Betrunkenen einer jener Mißbräuche, die er den Produzenten hagiographischer Texte vorwirft: die mangelnde Berücksichtigung der moralischen Integrität der Verehrten. Auch für das dritte Beispiel, Ælfegus, den Vorgänger des Lanfranc und Anselm auf dem erzbischöflichen Stuhl in Canterbury, erwähnt Guibert Unklarheiten bezüglich seines Todes: Er wurde im Gefängnis umgebracht, weil er das Lösegeld nicht bezahlen wollte ${ }^{158}$. Anselm überzeugte Lanfranc auf dessen Anfrage vom Martyrium seines Vorgängers. Daraufhin richtete dieser die Verehrung ein ${ }^{159}$.

Zum Schluß des Wunderexkurses geht Guibert auf die Mißbräuche und demzufolge auf die infecta miracula, verderbte Wunder, ein. In seinem ersten Beispiel werden diese verderbten Wunder hervorgebracht durch einen falschen Heiligen, mißbräuchlich propagiert vom Abt eines nicht genannten Klosters. Dieser falsche Heilige war ein Knappe (puer vulgaris, militis alicuius armigerens) im Beauvaisis: Weil dieser an einem Karfreitag gestorben war, organisierte der Abt des Klosters, zu dessen familia der Knappe gehörte, einen Kult. Bald begaben sich Pilger zu dessen Grab, und der Abt unterstützte, daß dort infecta miracula (verderbte Wunder) geschahen, die dem Kloster Einkünfte bringen sollten. Diese konnten gemäß Guibert nur infecta miracula sein, da sie mißbräuchlich um der Einnahmen willen unterstützt wurden ${ }^{160}$. Im zweiten Beispiel, dem Mißbrauch einer falschen Reliquie, war Guibert selbst involviert. Ein Kleriker nötigte ihn, zu bestätigen, daß das Stück Brot,

155 Der Bezug zur Ebene der Texte ist dadurch gegeben, daß Guibert aus der Vita des Samson vom Tod des Piro erfahren hat. Er berichtet, er hätte diese Passage den Umstehenden vorgelesen: Legi, testor deum, et iis qui michi presto fuerant cum nimia detestatione relegi, scilicet in Vita Sansonis celeberrimi apud Francos et Britones sancti [...], GUIBERT DE Nogent, Quo ordine, S. 88. Guibert stößt sich hier nur im ersten Beispiel an mangelnder Kenntnis, in den anderen beiden vielmehr an den unheiligen Todesumständen.

156 SMITH, Oral and Written, S. 309.

157 Siehe Guibert de Nogent, Quo ordine, S. 88, Anm. zu Z. 109-113. In der BHL ist Piro nicht verzeichnet.

158 Ibid. P, I, Z. 114-117: Nec illud excidit quod Lanfrancus Cantuariae apud Anglos episcopus successori postea suo Anselmo, tunc abbati Beccensi, questionem infert super quodam predecessesore suo, qui, in vincla coniectus, quia pecuniis sese redimere renuit peremptus est. 159 EAdmer, Vita Sancti Anselmi, I, 30; Gibson, Lanfranc, S. 171. Zu Lanfranc und der anglo-normannischen Kirchenreform siehe RuBENSTEIN, Liturgy.

160 Guibert De Nogent, Quo ordine, P, I, Z. 378-391. Rubenstein, Guibert of Nogent, S. 124. 
das er den Gläubigen anläßlich der Reliquienreise der Kleriker von Laon zeigte, von Jesus gekaut worden sei. Er bemerkt in seinem Text, daß er dem Kleriker nur der Gläubigen wegen zugestimmt habe, nicht ohne dabei zu erröten ${ }^{161}$. Seine eigenen Forderungen hatte er allerdings nicht erfüllt, dem Mißbrauch nicht Einhalt geboten.

Anschließend an den Wunderexkurs versucht Guibert eine Definition von Heiligen ${ }^{162}$. Aber schon bei den Märtyrern ist er mit Problemen konfrontiert. In diesem Abschnitt kann sich Guibert auf Schriften des heiligen Augustinus stützen ${ }^{163}$. In bezug auf die Frage, ob ein Martyrium alle vorhergehenden Sünden auswäscht, konnte damit argumentiert werden, daß auch Donatisten im gewaltsamen Tode litten, jedoch starben, ohne heilig zu werden. Im Bereich der confessores verweist Guibert auf noch größere Probleme. Das Volk konnte unautorisierte Legenden erzählen und Heilige konstruieren.

Um zu zeigen, wie große Sorgfalt bei der Verkündung von Heiligkeit walten soll, greift Guibert abschließend auf ein Beispiel aus dem ersten, durch autoritative Schriften abgestützten Bereich zurück, den er zu Beginn des Buches angesprochen hatte. Das Beispiel, Mariä Himmelfahrt, zeigt, wie stark Guibert immer wieder die gleichen zentralen Themen in neue Zusammenhänge stellt. Anhand des diskreten Verhaltens der Kirche gegenüber der öffentlichen Verkündung von Mariä Himmelfahrt zeigt Guibert, daß Vorsicht geboten ist bei der Verehrung von Heiligen, über deren Lebensführung und Tod nichts oder wenig bekannt ist. Wenn Guibert auch versichert, persönlich nicht an der Himmelfahrt Mariens zu zweifeln, äußert er doch Vorbehalte, diese öffentlich zu verkünden, da Zeugnisse fehlten ${ }^{164}$. Ähnlich argumentiert schon vor Guibert Petrus Damiani ${ }^{165}$. In der Tat wurde die Tatsache, daß nur apokryphe Texte über Marias Eintritt ins Himmelreich berichteten, schon lange als problematisch wahrgenommen ${ }^{166}$. Das Beispiel in Guiberts Abhandlung ist etwas schwerfällig, soll aber als Mahnmahl der Vorsicht dienen: Wenn schon die Himmelfahrt Mariens nur mit Vorsicht verkündet wird, um wieviel vorsichtiger soll man bei Personen sein, deren Schicksal nach dem Tod gänzlich unbekannt ist?

Auch Rahmenbedingungen von Kulten müssen geprüft werden. Die Authentizität von Reliquien ist ein wichtiges Thema. Die Wunder des Milchzahns von Saint-Médard, der Ausgangspunkt der Abhandlung, brandmarkt

161 Guibert de Nogent, Quo ordine, P, I, Z. 406-415.

162 Ibid. P, I, Z. $420 f .:$ Sed ut res quae pre manibus est liberius valeat pervideri, de iis qui appellantur sanctic primo tractandum. "Aber damit das, was vor Augen liegt, besser erkannt werden kann, muß zuerst von denen, die >Heilige ‘ genannt werden, gehandelt werden."

163 Ibid. P, I, Z. 431.

164 Ibid. P, I, Z. 518f.

165 Petrus Damianl, sermones, De S. Joanne Apostolo, Sermo 64, S. 380, im Zusammenhang mit der Heimholung des Apostels Johannes: Unde, etsi non audeamus pleniter diffinire, pium tamen est arbitrari, ut sicut de beata Dei Genitrice creditur, ita etiam beatus Johannes iam resurrexisse probabiliter asseratur. Dazu SöLL, Mariologie, S. 163.

166 Siehe dazu Iogna-Prat, Culte de la vierge, S. 90. 
Guibert als zweifelhaft, da er die wunderwirkende Reliquie nicht anerkennt und die Wunder nicht für genügend bezeugt hält ${ }^{167}$. Das oben erwähnte Brot, das Jesus gekaut haben soll, beurteilt Guibert als mißbräuchliche Fälschung ${ }^{168}$.

Aber auch für Reliquien anerkannter Heiliger, die eigentlich unproblematisch wären, kann Guibert vielfache Mißbräuche aufzählen. So im Falle des Johannes des Täufers, dessen einer Kopf sich in Konstantinopel, dessen anderer sich in Saint-Jean-d'Angély befinden soll169. Anschließend werden weitere Beispiele von mißbräuchlichem Umgang mit Reliquien angeführt. So wird der Streit um den Körper des heiligen Firminus von Amiens zwischen dem Bischof von Amiens und der Abtei Saint-Denis erwähnt ${ }^{170}$. Als weiteres Beispiel nennt Guibert den Fall des Odo von Bayeux, der gutgläubig den Knochen eines Bauern namens Exuperius als Reliquie des Heiligen gleichen Namens akzeptiert ${ }^{171}$.

167 Guibert dE NOGENT, Quo ordine, P, III, Z. 535-542: Illic in sacris mediis philacterium ab altari dicitur substitisse suspensum, quod sibi et aliquibus qui viderunt extitisse aiunt argumento. Sed quod, queso, argumentum? Quae superna, queso, vox, quis, precor, angelus detonuit dentem Salvatoris hunc esse, quem tenellus ediderit? Sed quid ad me angelus, quid vox? Si throni et dominationes istud assererent, nulli vere fidelium, sed fidei scientiam habentium, animi assentiri ullo modo deberent! "Dort, wurde gesagt, sei mitten in der Messe das Reliquiar vom Altar weg in der Höhe schwebend stillgestanden, was, wie sie sagten, ihnen und anderen, die dies gesehen hatten, Beweisgrund gewesen sei. Aber bitte, was denn für ein Beweisgrund? Was denn für ein Engel hat mit Donnerstimme verkündet, daß dies der Zahn des Erlösers sei, den er als zarter Junge verloren habe? Und was soll mir ein Engel, was eine Stimme? (nach Gal. 1, 8). Selbst wenn Throne und Mächte dies beteuerten, dürfte der Geist wahrhaft Gläubiger, die aber auch vom Glauben ein Wissen haben, keinesfalls zustimmen.«

168 Ibid. P, I, Z. 406-415.

169 Ibid. P, I, Z. 536-549. Von zwei Kopfreliquien des Johannes des Täufers in Konstantinopel und in Saint-Jean-d'Angély berichtet Guibert auch in der Kreuzzugschronik, ed. GuIBerT DE Nogent, Dei Gesta, I, 5, S. 103f. Als Quelle der Information über die Kopfreliquie aus Konstantinopel zitiert Guibert einen Kreuzzugsbrief des Kaisers Alexander Comnenus an Robert I. von Flandern, siehe ibid. Aus welcher Quelle Guibert die Information über die Verehrung der Kopfreliquie Johannes' des Täufers in Saint-Jean-d'Angély nahm, macht er nicht explizit. Die dortige aufwendige Erhebung der Reliquie fand 1016 auf Betreiben des Grafen William V. von Aquitanien statt. Wie die Reliquie nach Aquitanien kam, berichtet eine Translatio (BHL 4293, ed. AASS Jun. IV, S. 757-759), die, wie REMENSNYDER, Remembering, S. 144 annimmt, anläßlich der Erhebung verfaßt wurde. Über die Verehrung der Kopfreliquie in Saint-Jean-d'Angély berichtet zudem Ademar von Chabannes in seiner Chronik (Ademari Cabannensis, Chronicon, III, 56, S. 175-178), der die Translatio nennt, aber kritisch beurteilt. (Siehe zur Verschärfung der Kritik im Laufe der Überarbeitungen Ademari Cabannensis, Chronicon, Notes critiques, S. 308f. u. LANDES, Relics, S. 166, 175, 219 u. passim.) Zudem wird das Ereignis der Erhebung in den Miracula sancti Leonardi Nobiliacensi (BHL 4868, ed. AASS Nov. III, S. 158) erwähnt. Wilhelm habe gemäß dieser Quelle eine Synode einberufen, um die Authenitzität der Reliquie bestätigen zu lassen.

170 Guibert DE Nogent, Quo ordine, P, I, Z. 550-575. Dazu siehe Rubenstein, Guibert of Nogent, S. 127.

171 GuiberT DE Nogent, Quo ordine, P, I, Z. 575-594. 
Guiberts Lösungsvorschlag des Problems ist die Forderung, den Heiligen ihre Grabesruhe zu belassen ${ }^{172}$. In diesem Abschnitt wird jedoch klar, wer in Guiberts Abhandlung angegriffen wird: Äbte und Bischöfe, die als kirchliche Autoritäten verantwortlich waren für den Heiligenkult. Die Gläubigen, die gutgläubig falsche Reliquien verehrten, nimmt er in Schutz. Für den Fall, daß sie versehentlich Reliquien des einen Heiligen für diejenigen des anderen hielten, ist das Problem minim, da die Heiligen alle vereint zur Rechten Gottes sitzen. Im Falle, daß sie falsche Reliquien verehrten, zählt für Guibert ihre gute Intention ${ }^{173}$.

172 Dies unter Bezug auf Gregor den Großen. Im römischen Liturgiebereich blieben im 6. Jahrhundert die Gräber von Heiligen unberührt, im Gegensatz zum gallikanischen Liturgiebereich, wo sich Erhebungen und Öffnungen von Heiligengräbern früher durchgesetzt hatten. Siehe dazu ANGenendT, Corpus incorruptum, S. 330.

173 Guibert de Nogent, Quo ordine, P, I, Z. 703-739. 


\subsection{Der institutionelle Umgang mit dem Wunder}

Nach der Erörterung von Guiberts Deutungsschemata und Rahmenbedingungen von Wundern ist die Frage nach dem weiteren Zusammenhang von Guiberts Beschäftigung mit Wundern und Wunderberichten zu stellen. Die Einleitung zum Reliquientraktat weist darauf hin, daß Guibert nicht ein isolierter Intellektueller war, der sich mit Fragen zu Wundern und zum Heiligenkult beschäftigte. Als Begründung für die Abfassung des Traktats nennt Guibert Fragen, die in seiner Umgebung gestellt wurden:

„Weil viele Fragen über den Zahn des Erlösers, den die uns benachbarten Sanktmedardenser zu haben behaupten, machtvoll an mein Ohr drangen, und während sie (die Sanktmedardenser) einige in der Volkssprache beantwortet haben, beschlo $\beta$ ich, dieses Thema kurz in schriftlicher Form abzuhandeln und unter Verschweigen der Meinungen anderer, das, was ich darüber denke, auszusprechen $\ll^{174}$.

Guibert erwähnt zudem, daß die Mönche von Saint-Médard zu diesen Fragen über ihren Zahn ebenfalls Stellung genommen hätten, wenn auch nur vulgariter, was in diesem Fall wohl als Hinweis auf Mündlichkeit zu deuten ist. Dies stellt er in Gegensatz zu litteris perstringere, schriftlich ausdrücken ${ }^{175}$. Diese Passage zeigt, daß sich der Reliquientraktat in eine aktuelle Diskussion einschrieb, die sowohl mündlich als auch schriftlich geführt wurde, und daß sich die Mönche von Saint-Médard auch schon zu ihrer problematischen Reliquie geäußert hatten. Im folgenden soll versucht werden, dieses Sprechen und Schreiben über Wunder und Heiligkeit genauer zu situieren. Es soll gezeigt werden, daß Guibert Deutungsschemata und Hilfen zur Beurteilung von Wundern nicht nur aus der schriftlichen Tradition, sondern auch aus weiteren Diskussionen schöpfte, die in seiner Umgebung geführt wurden. Im Gegensatz zu hagiographischen oder weiteren institutionell verankerten Schriften zeigt sich in Guiberts Werken dessen Vorliebe für problematische Fälle. Hinweise auf die üblichen Abläufe der Anerkennung von Heiligen finden sich in größerer Ausführlichkeit in hagiographischen Texten und Briefen aus Guiberts sozialem Umfeld.

Monika Otter hat in ihrer Untersuchung über inventiones von Heiligenleibern darauf hingewiesen, da $\beta$ die Bestätigung der Authentizität von Reliquien keine einmalige Sache war, sondern einer dauernden rituellen und narrativen

174 Ibid. S. 79: Cum plurimae questiones super dente Salvatoris, quem nobis contigui Sanctimedardenses habere se asserunt, apud me perstreperent, cum vulgariter aliquibus sategissent, censui litteris pauca super capitulo isto perstringere et tacitis aliorum sensibus quid animus meus inde sentiret edicere.

175 Dies hat schon STOCK, Implications, S. 244 gesehen, wenn auch seine Interpretation des Satzes nicht korrekt ist: Die Mönche von Saint-Médard argumentierten auf mündliche Weise, nicht »einige« im Sinne von mehreren nicht genannten Personen. Guibert scheint hier also nicht auf den Gegensatz von Volkskultur und gelehrter Kultur anzusprechen, wohl aber die verschiedenen Medien der Kommunikation unterschieden zu haben. 
Ausarbeitung bedurfte ${ }^{176}$. Zur rituellen Ausarbeitung zählen Prozessionen, Ostensionen und Translationen von Reliquien, die in regelmäßigen Abständen wiederholt wurden. Zur narrativen Ausarbeitung ist die hagiographische Schriftproduktion zu zählen. Diese hagiographische Produktion wurde ebenfalls immer wieder erneuert, Heiligenviten neu geschrieben oder neue Wunderbücher zu einem Dossier hinzugefügt ${ }^{177}$.

In Guiberts Texten finden sich immer wieder Hinweise auf einen weiteren Aspekt dieses Beglaubigungsprozesses: Kulte mußten nicht nur rituell und narrativ ausgestattet werden, sie mußten auch institutionell abgesichert werden ${ }^{178}$. Über die Wahrhaftigkeit ihres Mittelpunktes, der Überreste des verehrten Heiligen, mußte ein Konsens in einer beteiligten Gruppe erreicht werden. Die Hinweise in Guiberts Texten sind jedoch zu wenig deutlich, um diesen Prozeß der Zuschreibung und Beglaubigung von Heiligkeit genauer zu situieren. Deshalb müssen im folgenden weitere Zeugnisse aus Guiberts Umfeld beigezogen werden, um diesen Prozeß genauer in die zeitgenössischen Diskussionen um Wunder und Heiligkeit einordnen zu können.

Am Beispiel Amiens und der Lokalisierung von Heiligenkulten und deren "Inszenierung« zeigt John Ott, wie die Bischöfe von Amiens den Heiligenkult in und um ihre Stadt monopolisierten und vor allem in problematischen Zeiten instrumentalisierten oder, in weniger moderner Denkweise, die Intervention Gottes zu aktivieren suchten ${ }^{179}$.

$\mathrm{Da}$ sich kirchliche Würdenträger auch mit Wundern beschäftigten, wenn sie nicht an der Authentifizierung eines bestimmten Heiligen beteiligt waren, zeigt ein Brief des Bischofs Lambert von Arras (1093-1115) ${ }^{180}$. Nachdem Lambert von einer wunderbaren Erscheinung gehört hatte, die einem lombardischen Geistlichen widerfahren war, erfragte er vom Leiter der Kanonikergemeinschaft, von der dieser Geistliche abhing, genauere Angaben der Erscheinung. Dieser sollte ihm, entsprechend den kanonischen Vorschriften, Angaben liefern

176 OTtER, Inventiones, S. 37.

177 Erst in neuerer Zeit wurde der Überarbeitung hagiographischer Texte vermehrt Aufmerksamkeit geschenkt. Zu dem Forschungsprojekt Réécriture hagiographique ist der erste Band 2003 erschienen: Récriture hagiographique, der zweite 2006: Miracles, Vies, et réécriture.

178 Boesch GaJano, Expériences, S.60f. erwähnt, daß sich die Kirche als Institution immer wieder um die Kontrolle von Kulten, hier speziell von Wundern bemühte. So nennt sie beispielsweise die Wunderbücher des Bischofs Gregors von Tours, aber auch weitere hagiographische Texte, die zur Fixierung der Zeugnisse von Heiligkeit dienen und Texte, die im Zusammenhang mit der Seelsorge stehen. Darauf nennt sie die Kontrolle der kirchlichen Autoritäten, um schließlich auf die Entwicklung des Kanonisationsverfahrens hinzuweisen. Daß schon vor der Entwicklung des Kanonisationsverfahrens auf der Ebene der Bischofsversammlungen versucht wurde, Kultkontrolle auszuüben, soll im folgenden gezeigt werden.

179 OTT, Bishops of Amiens, S. 68.

180 Brief 107, ed. PL 162. Für den Hinweis auf diesen Brief danke ich Prof. Dr. Laurent Morelle, Paris. 
zum Vorgang der Erscheinung, dem Zeitpunkt und dem Inkarnationsjahr, dem Namen des Papstes und des Ortsbischofs des Ereignisses. Selbst in diesem Fall, der nicht mit Lamberts Funktion als Vorsteher seines Bistums direkt in Verbindung zu bringen ist, wird sein Interesse an der Wahrheitsfindung deutlich. Als Referenzbestimmungen nannte der Prälat kanonische Vorschriften.

Die Diskussion zwischen Lanfranc und Anselm von Bec/Canterbury über die Heiligkeit des Ælfegus ( $† 1012)$, ihres Vorgängers auf dem Bischofsstuhl von Canterbury, ist hingegen in Zusammenhang mit deren Funktion als bischöfliche Amtsträger zu stellen ${ }^{181}$. Die Diskussion wird von Guibert im Reliquientraktat kritisch erwähnt ${ }^{182}$. Jay Rubenstein interpretiert diese Erwähnung als Kritik an der Gutgläubigkeit des Anselm von Bec/Canterbury in Bezug auf die Verehrung des Heiligen ${ }^{183}$. Für Guibert dient die Erwähnung dieser Diskussion aber als Argument dafür, daß es die Pflicht der Bischöfe sei, den Heiligenkult zu überwachen ${ }^{184}$. $\mathrm{Da}$ B Bischöfe sich bemühten, dieser Verpflichtung nachzukommen, zeigt das Beispiel des Gottfried von Amiens. Gottfried wurde als Bischof von Amiens 1110 von Anscherius, dem Abt von SaintRiquier, in dessen Kloster gerufen, um die Wunder des heiligen Angilbert zu sehen und zu bestätigen ${ }^{185}$. Die kirchliche Autoritätsperson wurde also an den Ort des Geschehens gerufen, um einem Kult Anerkennung zu verleihen. Äbte nahmen umgekehrt auch an Kirchenversammlungen teil, an denen über Heilige entschieden wurde.

Die Anerkennung von Wundern und Wunderberichten kann auch in diesen Kontext der Beglaubigung von Reliquien und Anerkennung von Kulten gestellt werden. Der Ort dieser institutionellen Absicherung war zu Anfang des 12. Jahrhunderts noch zu großen Teilen die Versammlung von kirchlichen Autoritätspersonen, Bischöfen und Äbten. Diese versammelten sich auf der Ebene des Metropolitanverbandes oder auf der Ebene der Diözese zu Synoden,

181 EADMER, Vita Sancti Anselmi, I, 30, S. 50-54, hier S. 51: [...] quadam die familiarius cum eo loquens [...]. Dazu KUTrNer, Réserve papale, S.174; AASS Apr. 19, II, S.630. Siehe dazu auch oben, S. 66, Anm. 159.

182 GuIBert De Nogent, Quo ordine, P, I, Z. 114-137.

183 Dazu Rubenstein, Guibert of Nogent, S. 127 und Rubenstein, Osbert of Clare, S. 3537. Ob Guibert durch die Lektüre von Eadmers Vita oder durch Gespräche mit Anselm von dieser Diskussion wußte, ist umstritten. $\mathrm{Daß}$ Guibert aber die Vita gelesen haben kann, ist wahrscheinlich, da sie seit 1112 zirkulierte. BARLow, King's Evil, S. 37.

184 GUIBERT DE NOGENT, Quo ordine, P, I, Z.134-137: Sit itaque videre pontificum, sit dei populi videre custodum, quatinus suis provideant ut, si emulationem dei habent, hanc duntaxat habere sinantur secundum scientiam, ne peccent si recte offerant et recte non dividant. „Es soll deshalb die Pflicht der Bischöfe und der Hüter des Volkes Gottes sein, darauf zu sehen, daß sie für die Ihren Vorsorge tragen, damit diese, wenn sie Eifer für Gott haben, diesen nach Einsicht haben können, damit sie nicht sündigen, wenn sie richtig opfern, aber nicht richtig teilen. «Die Erwähnung von Opferriten könnte in Auslegung alttestamentarischer Opferriten erfolgt sein, siehe z. B. Lev. 1, 12.

185 Miracula S. Angilberti (BHL 471), I, 37, II, 1, S. 137, 139. Siehe dazu auch AASS Nov. III, S. 898, Einleitung zur Vita des Gottfried von Amiens von Albert Poncelet. 
aber auch in unregelmäßigen Abständen, um aktuelle Probleme zu lösen ${ }^{186}$. Das Papsttum begann erst ab dem Ende des 12. Jahrhunderts die Heiligsprechung zu monopolisieren, obwohl es im Laufe des 12. Jahrhunderts eine immer größere Rolle für die Anerkennung von Heiligenkulten spielte ${ }^{187}$. Diese Anerkennung, die schriftlich fixiert und durch einen immer gleich ablaufenden Prozeß gesichert war, setzte sich erst im Laufe des 12. Jahrhunderts durch.

Die Versammlungen der kirchlichen Autoritäten urteilten aber auch über Wunder oder wunderbare Vorfälle außerhalb von Verfahren zur Heiligsprechung. Sie versuchten so, ihre Funktion als Instanz, welche die Ausübung des Kultes in ihren Diözesen regelte, wahrzunehmen. Diese Bemühungen der Kultkontrolle sind auch von den augustinischen Forderungen her abzuleiten ${ }^{188}$.

Kirchliche Amtsträger wie Bischöfe und Äbte sind also sowohl als Promotoren oder Hüter von Kulten als auch als Entscheidungsträger für deren Anerkennung anzusehen. Der Proze $\beta$ der Entscheidungsfindung über Wunder unter den kirchlichen Entscheidungsträgern ist also nie ein unbeteiligter, rationaler, sondern das Wunder ist auch in diesen Kreisen ein Phänomen des Alltags, das auf vielfache Weise beurteilt werden muß.

Die Quellen zu regionalen Kirchenversammlungen ermöglichen nur selten, Diskussionen über Wunder und Heilige genau zu fassen. Zwei Fälle sollen jedoch zeigen, in welchen Zusammenhängen bischöfliche Amtsträger sich mit Wunder und Wundererzählungen befaßten.

Im folgenden wird in einem ersten Schritt anhand einer von Guibert berichteten Wundererzählung aufgezeigt, welche Diskussionen wunderbare Ereignisse im Zusammenhang mit der Kontrolle des rechten Kultes auslösen konnten. In einem Exkurs wird anschließend kurz auf die verschiedenen Versammlungen von kirchlichen Würdenträgern eingegangen, auf denen über Wunder und Kulte diskutiert wurde. In einem zweiten Schritt wird dann der Bogen geschlagen zu Diskussionen, die in Guiberts Umgebung geführt wurden um Wunder, die für die Anerkennung von Heiligen und deren Kult vonnöten waren. Diese Beispiele sollen zeigen, wie wichtig kirchlichen Würdenträgern neben der Kontrolle der Sakramente auch die Kontrolle der Glaubenspraxis war.

\subsubsection{Die bischöfliche Überwachung der Kultpraxis}

Der Fall des Petrus von Grenoble

Guiberts Darstellung eines Marienwunders, des Falls des Petrus von Grenoble, zeigt den regulierenden Zugriff der kirchlichen Autoritäten in Fragen des

186 Auf den Unterschied zwischen synodalen und weiteren Versammlungen von Bischöfen verschiedener Diözesen weist AVRIL, Institution synodale, S. 276f., hin.

187 Siehe dazu unten und Fuchs, Wundererzähler, S. 317f. mit Verweisen auf die Literatur.

188 Siehe dazu Anm. 286. 
Kultes. Dieses Marienwunder wird in der Schrift De laude sanctae Mariae in einer Gruppe von Wundererzählungen berichtet. Es macht deutlich, wie stark Guibert nicht nur in der Reliquienkritik, sondern auch in anderen Texten die Darstellung des Zugriffs der kirchlichen Autorität gewichtet. In den anderen Versionen der Erzählung, so in Marienmirakelsammlungen, werden diejenigen Abschnitte, die das Eingreifen der kirchlichen Autorität zeigen, ganz oder teilweise weggelassen ${ }^{189}$. Im folgenden eine kurze Zusammenfassung der ausführlichen Erzählung ${ }^{190}$.

Im Territorium von Grenoble wurde ein junger Mann, Petrus, an einem Magdalenentag von seinem Stiefvater gezwungen, zu pflügen, obwohl dies eine Mißachtung des Feiertags war. Er wurde deshalb bald vom Blitz getroffen. Dies verbrannte ihm das Bein so, daß nur noch der nackte Knochen davon übrigblieb. Petrus betete zuerst in einer Magdalenenkirche. Als dies nichts nützte, setzte er seine Gebete in einer Marien- und Hippolytkirche fort. Ein Ritter nahm ihn dann aus Mitleid bei sich auf. Eines Nachts hatte Petrus eine Vision, während derer ihm Maria und Hippolyt erschienen und ihm das Bein ersetzten. Da er vor Schmerzen schrie, kamen die Dienerinnen herbei und sahen das Wunder: das Bein war ersetzt. Nach einigen Zweifeln überzeugte sich auch der Ritter vom Wunder. Die Heiligen hatten ihre Arbeit aber nicht ganz vollendet, der junge Mann hinkte deshalb während dem ganzen nachfolgenden Jahr. Zudem unterschied sich die neue Haut deutlich von der alten. Nach einem Jahr erschienen die zwei Heiligen ein zweites Mal und vollendeten ihr Werk.

Dies ist der Zeitpunkt der ersten Intervention des Bischofs Leodegar von Viviers, eines Zeitgenossen Guiberts. Dieser hatte vom Wunder gehört. Als er seine Großen versammelte, um Gericht $z u$ halten, erfragte er auch deren Rat in der Sache dieses Wunders ${ }^{191}$. Der Ritter, in dessen Haus das Wunder stattgefunden hatte, war bei der Versammlung ebenfalls anwesend. Das Wunder spielte also in der Diözese Viviers. Der Bischof begab sich anschließend zu Petrus und überzeugte sich persönlich vom Wunder.

Petrus beschloß darauf, sich zum Dank von der Welt zurückzuziehen und als Rekluse zu leben. Sogleich war der Teufel zur Stelle und begann ihn in Form einer Frau zu bedrohen, die jede Nacht in seine Zelle eindrang. Petrus kämpfte andauernd gegen die Versuchung, so daß seine Erschöpfung bald sichtbar wurde. Der Bischof von Viviers hörte wiederum von den Vorgängen, intervenierte von neuem und ließ die Zelle überwachen ${ }^{192}$. Seine Männer halfen Petrus schließlich, das Monster mit Hilfe einer Stola zu erwürgen.

\footnotetext{
189 Siehe dazu unten, Kap. 5.2.3. und Anhang 2.

190 Für den lateinischen Text siehe Anhang 2.

191 PL 156, col. 570: Episcopus ergo insolito omnimodis rumore percitus, cum die quadam plurima procerum frequentia causas acturi coram eo venissent, adfuit et is cujus domo acta res fuerat cum fratre proprio.

192 Ibid. col. 571: Cum igitur multis quod ab eo ferebatur veniret in scrupulum, accidit supervenire castro illi quem praelibavimus Vivariensem episcopum. Ea denique nocte quidam
} 
Guibert hat nun erst in bezug auf die Fortsetzung der Geschichte ein Problem: Er hat von zwei Versionen vom Ende der Geschichte Kenntnis, die sich vor allem dadurch unterschieden, was aus Petrus geworden war. Er erwähnt, $\mathrm{da} \beta$ er erfahren habe, daß dieser, auf Rat der Bischöfe von Viviers und Grenoble, dem Leben als Rekluse entsagt und sich in den sicheren Hafen eines Klosters zurückgezogen habe. Von wem er diese Version gehört hat, erwähnt Guibert nicht. Er beschreibt jedoch detailliert, auf welchem Weg er von der zweiten Version erfahren hat: Er hatte sie gemeinsam mit seinem Bischof, Barthélémy von Laon, von Bischof Wilhelm von Châlons (Wilhelm von Champeaux, Gründer von Saint-Victor in Paris) gehört. Dieser kannte die Geschichte, weil er anwesend war, als Leodegar von Viviers als betroffener Zeuge sie König Ludwig VI. erzählte. Auf Nachfrage Guiberts versicherte ihm Wilhelm von Champeaux, daß Leodegar nicht erwähnt hatte, daß sich Petrus ins Kloster begeben hätte.

Kirchliche Autoritätspersonen intervenieren im Laufe der Erzählung mehrmals. Die erste Intervention des Bischofs Leodegar von Viviers ist für den Zusammenhang Kultkontrolle und bischöfliche Aufsichtspflicht aussagekräftig. Nachdem der Bischof durch das Gerücht des Wunders aufgeschreckt war, berief er eine Versammlung seiner Großen (proceres) ein. Diese wurden aufgerufen, die Angelegenheit zu bezeugen. Der Bischof begab sich anschließend mit seinen Großen zu der Burg, wo sich Petrus aufhielt, befragte und untersuchte ihn. Über den Wahrheitsgehalt des Wunders wurde also im Rahmen der bischöflichen Aufsichtspflicht über den Kult befunden. Die zweite Intervention des Bischofs erfolgte, nachdem dieser von den Schwierigkeiten des Reklusen gehört hatte und dessen Zelle überwachen ließ. Gemäß der zweiten Version berieten die Bischöfe von Viviers und Grenoble über den Status des vom Teufel angefochtenen Eremiten. Sie rieten ihm, den Schutz einer klösterlichen Gemeinschaft zu suchen. Dies kann als Versuch gesehen werden, künftige Schwierigkeiten in ihren Diözesen zu verhindern.

Die Erwähnung von Bischöfen aus verschiedenen Diözesen am Schluß der Erzählung legt die Folgerung nahe, daß der Fall des Petrus von Grenoble während einer Bischofsversammlung, beispielsweise einer Provinzialsynode besprochen worden sein könnte, hier aber nicht mehr im Rahmen einer institutionalisierten Entscheidungsfindung, sondern eher im Rahmen einer informellen Unterredung ${ }^{193}$.

\section{Orte der Überwachung der Kultpraxis}

Die Erzählung "Petrus von Grenoble« zeigt, daß verschiedene Bischöfe wiederholt versuchten, ungewöhnliche Ereignisse in ihren Diözesen zu kontrollieren.

equites cum cereis suis pro reverentia proximae basilicae, cui ille appendicem habebat cellulam, in ipsius vestibulo vigilabant.

193 Leider erlaubt die Quellenlage nicht, diese Unterredung genauer zu situieren. 
In Guiberts Texten finden sich auch andernorts Hinweise darauf, daß die Beurteilung von Wundern in einen institutionalisierten Zusammenhang gestellt werden kann. Dafür sind die Zeugennennungen der Exempla, die Guibert im Reliquientraktat zur Untermauerung seiner Argumentation verwendet, indirekt aussagekräftig. Nachdem er zwei Wunder aus seiner Umgebung erzählt hat, eines aus Soissons und eines aus Saint-Quentin, gibt er die Quellen der Erzählungen an. Die erste Angabe weist in den lokalen Rahmen einer Kirche: Guibert besuchte die Kirche, wo ihm das Wunder von einem Geistlichen der Kirche erzählt wurde. Nach der Besichtigung des Grabes hielt er die Geschichte für glaubwürdig ${ }^{194}$. Das Wunder in Soissons hingegen wurde gemäß Guiberts Zeugenangaben in einem öffentlichen Kontext kommuniziert. Guibert führt nicht einen Geistlicher der Kirche, in der das Wunder stattgefunden hatte, als Zeugen an, sondern betont, daß das Ereignis ihm vom Erzbischof Radulf von Reims berichtet worden sei, und zudem bezeuge es ganz Soissons und Klerus und Volk von Laon ${ }^{195}$. Als Gewährsmann wird der Erzbischof als Vorsteher der Kirchenprovinz genannt, der zuvor von diesem wunderbaren Ereignis Kenntnis erhalten haben mußte. Da das Wunder an Ostern in der Kirche stattgefunden hatte, könnte mit Suessio quoque testatur die Öffentlichkeit gemeint sein, die den Ostergottesdienst in der Stadtkirche verfolgt hatte. Die Begrifflichkeit für die Erwähnung der Bezeugung durch die Öffentlichkeit in Soissons (Suessio quoque testatur) und von Klerus und Volk von Laon (clerus populusque Lauduni) lehnt sich an die Begrifflichkeit der Urkunden an, die aus der bischöflichen Rechtssprechung und Verwaltungstätigkeit hervorgegangen waren. Die Öffentlichkeit hatte wie im Bereich der Rechtssprechung für die Anerkennung von Wundern eine wichtige Funktion ${ }^{196}$. Diese rechtssprachenahe Begrifflichkeit findet sich in bezug auf Wunder nicht nur bei Guibert de Nogent, sondern auch in vielen Wundersammlungen ${ }^{197}$.

Annegret Wenz-Haubfleisch hat in ihrer Untersuchung von Mirakelsammlungen des ostfränkisch-deutschen Raumes sprachliche Elemente dieser Sammlungen mit denjenigen anderer Schriftstücke verglichen. Sie hat in Urkunden vielfache Parallelen für die Nennung von Zeugen zu ihren Quellen festgestellt, deutet die Verwendung von Elementen allerdings eher als Stilfrage und bleibt somit auf der sprachlichen Ebene. Schliesslich wagt sie den vorsichtigen

194 GUIBERT DE NOGENT, Quo ordine, P, I, Z. 225f.: Haec clero ecclesiae ipsius referente edidici et tumulo astipulante rem vidi et credidi [...].

195 Ibid. P, I, Z. 227f.: [...] sicut primum quod rettuli a domino archiepiscopo Remensi Radulfo audivi, Suessio quoque testatur, clerus populusque Lauduni.

196 Zur Bedeutung der Öffentlichkeit in Mirakelsammlungen siehe WENZ-HaubfLEISCH, Miracula post mortem, S. 128-131. Über die Rolle von Publizität bei Gerichtsverfahren siehe Cordes, Art. »Publizität«, Ogris, Art. »Publizität«.

197 Siehe Wenz-Haubfleisch, Miracula post mortem, S. 129. Vgl. hierzu die Überlegung zu den Wunderbüchern von Gregor von Tours, Heinzelmann, Source de base, S. 240, wo auf den forensischen Charakter der Episoden hingewiesen wird. Dieser Aspekt wurde auch schon in der Zeit Augustins betont. 
Schluß, daß diese Begrifflichkeit eventuell einer auf »Amtlichkeit « und »Wahrheitsgehalt « bedachten Tätigkeit entsprungen sein könnte ${ }^{198}$. Die von WenzHaubfleisch untersuchten Mirakelsammlungen stammen vorwiegend von den Kultstätten, an denen die Heiligen verehrt wurden. Im Unterschied dazu haben sich die erwähnten Wunder bei Guibert de Nogent nicht im Kontext einer Kultstätte ereignet, sondern sind als Einzelereignisse zu situieren, deren Beurteilung im Rahmen der Kultkontrolle erfolgte. Aber auch in Guiberts Umgebung lassen sich Parallelen der Zeugennennung beobachten. Im Formular der Urkunden des Bischofs von Laon werden ähnliche Hinweise auf Zeugen wie bei den Wundererzählungen gemacht ${ }^{199}$. Die Verwendung von Elementen aus der Rechtssprache für Wunder weist nicht allein auf rechtlich geprägte Erörterungen um die Wahrhaftigkeit des Ereignisses hin, sondern ist sicher auch Konvention zur Erhöhung der Glaubwürdigkeit von Wundern'200. Wenn mittels dieser Hinweise im Text aber Glaubwürdigkeit hergestellt werden soll, können sie nicht völlig unabhängig von den Gepflogenheiten in Guiberts Umfeld gesetzt werden. Sie können so Anhaltspunkte für den rechtlichen Zusammenhang sein, in dem die Wunder diskutiert wurden.

Ein weiteres Beispiel im Reliquientraktat ist aus zwei Geschichten zusammengesetzt. Die erste Geschichte ist diejenige des Büßers Erlebald, eines Dekans und Küsters der Kirche von Cambrai ${ }^{201}$. Dieser hatte äußerst strenge Buße geübt und wurde, als er das Ende seines Lebens erreichte, von Dämonen geplagt. Nach seinem Tod erschien Erlebald verschiedenen Personen in Visionen. Ausführlich dargelegt ist die Vision eines Bischofs, dem Erlebald erschien, um ihm zu raten, von seinen Sünden abzulassen. Die Visionen wurden anschließend publik gemacht und allgemein geglaubt ${ }^{202}$. In der zweiten Geschichte handelt es sich um die Vision einer Nonne aus Bourbourg (Diözese Saint-Omer), in der ihr ihre kürzlich verstorbene Mitschwester erschien und ihr verkündete, daß sie zusammen mit Erlebaldus in den Himmel aufgenommen sei. Guibert beruft sich am Ende dieser Geschichte auf eine Auskunft des Bischofs Barthélémy von Laon, daß unter den Einwohnern der Provinz, aus welcher der Büßer stammte, eine Zeugenbefragung durchgeführt worden sei $^{203}$. Die Zeugen hätten über die Ereignisse übereinstimmend ausgesagt. In

198 WenZ-Haubfleisch, Miracula post mortem, S. 150-157.

199 So z. B. in der Urk. 111, in: Actes Laon, S. $191 \mathrm{f}$.: [...] in morte vero culpam recognovisse, absolutionem ab ipso abbate Gaufrido petisse, et omnia que abstulerant coram testibus idoneis aecclesiae restituisse. Testes etiam ipsi presentes aderant pauci de multis, scilicet [...].

200 Zur Einordnung der Zeugenangaben siehe unten, Kap. 3.1.

201 Siehe zu Erlebald oben, S. 61. Dieser ist in Cambrai $1112 / 1117$ belegt. Nachweise bei Platelle, De pignotibus, S. 117.

202 Guibert DE NogENT, Quo ordine, P, I, Z. 337-339: Hac deinde visione et aliorum aliis publicatis cum iam secundum seriem earum et vitae ipsius pietatem sub spe bona de eo omnia crederentur [...].

203 Ibid. P, I, Z. 363: Haec ab episcopo Laudunensi domino meo Bartholomeo cum audissem, tot propemodum postea de provincialibus huius beati hominis testes secuti sunt qui super hac re indissimilia sonuerunt, quot iam in mea memoria recenseri non potuerunt. 
diesem Beispiel zeigt sich der Zusammenhang mit dem Zugriff der kirchlichen Autorität auf die Ereignisse der Geschichte noch deutlicher als in den obenstehenden Beispielen. Die Erwähnung von Zeugen aus der Provinz ${ }^{204}$ und wiederum die Begrifflichkeit weisen darauf hin, daß diese Zeugenbefragung irgendwie im Rahmen der bischöflichen Aufsichtspflicht durchgeführt worden war.

Ein wichtiger Ort für die Überwachung der Kultpraxis in den Diözesen scheint die Synode zu sein. Auf den ersten Blick ist diese Kontrolle des Kultes eher auf der Ebene der Diözesansynoden anzusetzen. Inwieweit sie auch auf den Versammlungen von Bischöfen der Kirchenprovinz praktiziert wurde, wird festzustellen sein.

Somerville hat konstatiert, daß Synoden auch als Gerichtsorte funktionierten, speziell bei Anwesenheit des Papstes ${ }^{205}$. Von dieser gerichtlichen Funktion zeugen auch Konzilsordines, die Vorschriften für Richter enthalten $^{206}$. Es ist aber schwierig zu beurteilen, ob alle Fälle vor der gesamten Synode beraten wurden oder ob sie am Rande der Versammlungen oder gar an weiteren Versammlungen von Bischöfen geregelt wurden. Daß vor allem auch die Diözesansynode gerichtliche Funktionen hatte, ergibt sich aus ihrem Auftrag, das geistige Leben in der Diözese zu regeln. Der folgende Exkurs soll einen kurzen Überblick über die institutionalisierten Zusammenkünfte von kirchlichen Würdenträgern in der Kirchenprovinz Reims liefern.

\section{Exkurs: Bischofsversammlungen in der Kirchenprovinz Reims}

Sowohl die Diözese Beauvais, zu der Saint-Germer-de-Fly gehört, wie auch die Diözese Laon, in der Nogent liegt, gehören zur Kirchenprovinz Reims. Bischöfe und Äbte als kirchliche Autoritätspersonen trafen sich regelmäßig zu Bischofsversammlungen, zumeist wohl zu Synoden. Die Begriffe synodus und concilium wurden im frühen und hohen Mittelalter nicht systematisch verwendet ${ }^{207}$. Von Bedeutung waren die Versammlungen auf der Ebene der Kirchenprovinz, wie beispielsweise die Provinzialsynoden oder die von

204 Provincialis ist nach Niermeyer, Lexicon, S. 868 die Bezeichnung für die Einwohner einer Kirchenprovinz als auch einer Gerichtsbarkeit. Das Verb sequi, Folge leisten, hat wiederum nach NIERMEYER, Lexicon, S. 960 verschiedene Bedeutungen im Zusammenhang mit der Versammlung um eine zentrale Instanz, so auch »an einer Versammlung teilnehmen «, »an der Gerichtsversammlung teilnehmen«.

205 Somerville, Urban II, S. 82 und Somerville, Prolegomena.

206 So Ordo Nr. 15, in: Konzilsordines, Nr. 42, S. 446: Iudices non nisi ieiuni leges et iudicia discernant. Quisquis ex laicis habet querelam, iudicibus proferat. Dieser Ordo weist enge Verwandtschaft zu Ordo Nr. 19 auf, der gemäß Schneider, S. 90-92 in Reimser Handschriften überliefert und dort wohl auch spätestens Anfang des 12. Jahrhunderts entstanden ist. 207 Ibid. S. 2, stellt fest, daß in Konzilsordines keine oder nur ansatzweise eine strenge begriffliche Systematik zu erkennen ist. AvRIL, Institution synodale, S. 275, geht davon aus, $\mathrm{da} ß$ die Bezeichnungen bis ins 12. Jahrhundert synonym verwendet wurden. 
päpstlichen Legaten einberufenen Konzilien. Auf der Ebene der Diözese versammelte der Bischof seinen Klerus in mehr oder weniger regelmäßigen Abständen. Formen und Inhalte, wie auch Teilnehmende dieser Versammlungen sind in vielen Fällen nur schwierig zu rekonstruieren. Ein Synodalordo aus einem Pontifikalbuch aus Reims, datiert zu Anfang des 12. Jahrhunderts, ist nur sehr knapp gehalten ${ }^{208}$. Konzilsordines weisen jedoch vielfältige Abhängigkeiten voneinander auf. Trotzdem soll nachfolgend kurz auf die verschiedenen Versammlungen kirchlicher Würdenträger eingegangen werden.

\section{Versammlungen auf der Ebene der Kirchenprovinz}

Die Provinzialsynoden nahmen im kirchlichen Leben Nordfrankreichs seit den Anfängen der Kirchenreform einen wichtigen Platz ein. Das Reformpapsttum spielte bei diesen Synoden eine große Rolle, waren doch die päpstlichen Legaten oder die Päpste selbst auf den meisten Konzilien anwesend oder beriefen diese gar ein ${ }^{209}$. Die Prälaten versammelten sich in der Regel mindestens ein Mal im Jahr. Anwesend waren je nach Größe der Kirchenversammlung Bischöfe, Äbte und Vertreter des Weltklerus der Kirchenprovinz, weitere Bischöfe und zum Teil auch der König210. Anfangs stand die Umsetzung der Kirchenreform im Zentrum. Ab ungefähr 1106, dem Zeitpunkt der Frankreichreise des Papstes Paschalis II. (1099-1118), gingen auch die päpstlichen Legaten auf den Synoden nicht mehr in erster Linie auf Konfrontationskurs zum gallischem Episkopat (Absetzungen etc.) und zum Königtum (1104 Absolution des Königs Philipp wegen der Eheangelegenheit), sondern übernahmen jetzt eher Aufgaben der ständigen Überwachung der Kirche des Landes ${ }^{211}$. Bereinigungen von Streitfällen oder Klärung strittiger Fragen wurden immer mehr zu den hauptsächlichen Aufgaben der Synoden.

208 Konzilsordines, S. 90-92 (Einleitung), S. 505-508 (Edition).

209 Pontal, Conciles capétiens, S. 17.

210 Oft werden in den Konzilsakten nur Bischöfe namentlich genannt. Für die Teilnahme von Äbten und Weltklerikern sind wir meist auf andere Quellen angewiesen. So beispielsweise auf die Zufallsmeldung in einer Mirakelsammlung, die den Namen eines Abtes nennt, der auf einem Konzil in Reims anwesend gewesen sei, jedoch weder das Kloster des Abtes noch das Datum der Synode. Der Bericht einer wunderbaren Heilung des Abtes auf dem Rückweg von einer Synode, zu welcher der Erzbischof gerufen hatte, war wohl in einem größeren Text eingefügt. In der Mirakelsammlung wird der Abt, entgegen der Ankündigung des Autors, weiter oben im Text nicht erwähnt. Die Sammlung ist überliefert in BN lat. 14463, fol. 87r, einer Handschrift aus dem 12. Jahrhundert aus Saint-Victor in Paris: Dominus abbas Theodericus de quo superius mentionem fecimus, conpunctus corde michi retulit de se ipso, quod in presenti pagina historialiter narro. Hic ad urber Remensium propter ecclesie negotia cum coabbatibus suis ab archiepiscopo invitatus per aliquot dies moram fecit, peractisque vel terminatis pro quibus venerat, revertendi licentiam vir honestus accepit.

211 SCHIEFFER, Päpstliche Legaten, S. 178. 
Auf diesen Synoden war die Besetzung der Bistümer ein wichtiges Thema. Bischöfe wurden eingesetz $\mathrm{t}^{212}$, abgesetzt $\mathrm{t}^{213}$ oder diszipliniert $\mathrm{t}^{214}$. Die Besetzung von Bistümern war für die Durchsetzung der Kirchenreform, aber auch für politische Zwecke äußerst wichtig.

Auf den Konzilien wurde auch das Verhalten weltlicher Großer beurteilt oder es wurden Exkommunikationen ausgesprochen ${ }^{215}$. Die Konzilien hatten zudem normative Funktionen, indem kirchenrechtliche Satzungen festgelegt wurden $^{216}$. Die Kirchenversammlungen waren zudem für die Verwaltung der Kirchenprovinz zuständig. Differenzen zwischen Abteien wurden bereinigt ${ }^{217}$ oder Schenkungen fanden Bestätigung218.

Aussagekräftig für unseren Zusammenhang ist derjenige Aufgabenbereich der Synode, der sich mit dem Kult und dem Dogma auseinandersetzte. So wurden anläßlich von Konzilien Translationen von Reliquien vorgenommen, wie beispielsweise auf dem Konzil in Reims 1049 diejenigen der Reliquien des heiligen Remigius und des heiligen Cornelius ${ }^{219}$. Auf Konzilien wurden aber auch Heilige anerkannt, über deren Vita und Wunder diskutiert. In Beauvais wurde 1120 die Zustimmung zur elevatio des Arnulf von Soissons gegeben, die

2121081 wurde am Konzil von Meaux, nach Absetzung des Bischofs Ursio, Arnulf, der zuvor vergeblich versucht hatte, die Abtei Saint-Médard de Soissons zu reformieren, als Bischof von Soissons eingesetzt. Siehe dazu MANSI, Sacrorum conciliorum, Bd. XX, Sp. 573 und Saint-Médard, S. 146.

2131100 wurde in Soissons die Wahl des Etienne de Garlande auf Betreiben des Königs angenommen, in Troyes 1107 wurde derselbe Bischof wieder abgesetzt, da ihn der Papst nicht anerkannte und auch Ivo von Chartres gegen ihn war. Pontal, Conciles capétiens, S. 242 und 250.

214 Gottfried von Amiens, Guiberts Vorgänger als Abt in Nogent, hatte sein Bistum im November 1114 in Folge von Problemen mit der Stadtgemeinde verlassen und sich in die Kartause bei Grenoble (Grande Chartreuse) zurückgezogen. Die Kleriker seines Bistums versuchten seine Rückkehr zu erwirken. Sein Fall wurde 1114-1115 an mehreren Konzilien verhandelt, die vom päpstlichen Legaten Kuno von Praeneste einberufen wurden; Gottfried mußte wieder in sein Bistum zurückkehren. Dazu Schieffer, Päpstliche Legaten, S. 198; PonTal, Conciles capétiens, S. 260-262, siehe auch unten, Kap. 5.2.3.

215 So beispielsweise auf dem Konzil von Beauvais 1114 Thomas von Marle. PonTAL, Conciles capétiens, S. 260; ScHIEFFER, Päpstliche Legaten, S. 199 (mit Quellenangaben).

216 So beispielsweise in Beauvais 1114, wo Canones reformatorischen und disziplinarischen Charakters formuliert wurden Pontal, Conciles capétiens, S. 260. Eine genaue Analyse der handschriftlichen Überlieferung bei SomerviLLE, Urban II.

217 Reims 1118: Differenzen zwischen Saint-Lucien und Saint-Quentin in Beauvais werden bereinigt. PonTal, Conciles capétiens, S. 265.

218 Reims 1114: Eine Schenkung an Saint-Bertin und Lessies wird bestätigt. PonTal, Conciles capétiens, S. 260.

219 Pontal, Conciles capétiens, S. 156. Gerade diese Translationen, die durch Leo IX. vorgenommen wurden, wurden auch mit dem päpstlichen Zugriff auf die Heiligsprechung in Zusammenhang gebracht, so bei KLAUSER, Heiligsprechungsverfahren, S. 89; KUTTNER, Réserve papale, S. 181 oder bei Kemp, Canonization and Authority, S. 62-64, der mit Leo IX. die übergeordnete Stellung der päpstlichen Kanonisation beginnen läßt. 
unten genauer besprochen wird ${ }^{220}$. Weitaus häufiger wurden auf Konzilien aber Verstöße gegen den rechten Glauben und Häresien verurteilt ${ }^{221}$.

\section{Versammlungen auf der Ebene der Diözese}

Neben den Provinzial- oder Regionalsynoden stehen die Diözesansynoden als Versammlungsorte des Ortsbischofs mit seinem Klerus und seinen Äbten. Odette Pontal konstatierte, daß im 11. und 12. Jahrhundert Diözesansynoden selten abgehalten worden seien und daß sie wenig Spuren hinterlassen hätten ${ }^{222}$. Wenn auch nur wenige Zeugnisse in Form von Konzilsakten zu diesen Synoden überliefert sind, zeugt die Überlieferung von Konzilsordines davon, daß sehr wohl Diözesansynoden abgehalten wurden ${ }^{223}$. Zudem weisen nordfranzösische Bischofsurkunden, oft in den Datumszeilen, darauf hin, daß Diözesansynoden stattfanden. Die Bischofsurkunden von Laon zeigen, da $B$ in diesem Bistum alljährlich im November eine Diözesansynode stattfand. Aus den Unterschriftenlisten ist ersichtlich, daß auch der Abt von Nogent daran teilnahm ${ }^{224}$. Die Bedeutung der Diözesansynoden um die Wende des 11. zum 12. Jahrhundert ist vor allem in den Urkunden der Bischöfe von Arras sichtbar. Die Diözese Arras wurde Ende des 11. Jahrhunderts von der Diözese Cambrai losgelöst und von Urban II. als Bastion der Reform unterstützt 225. Der erste Bischof, Lambert von Guînes (1093-1115), galt als einer der eifrigsten Reformer in Nordfrankreich. Er stand in Kontakt mit Anselm von Bec/ Canterbury und Ivo von Chartres226. Sein Nachfolger Robert (1115-1131) führte die Reform weiter ${ }^{227}$. So sind Diözesansynoden in den Urkunden dieser Bischöfe wie auch ihrer Nachfolger oft belegt. In der Actumzeile der Bischofsurkunden wird oft die Synode als Ausstellungsort genannt ${ }^{228}$, oder es findet sich im Text der Urkunde der Hinweis, daß der Klerus auf der Synode versammelt war und eine Schenkung bestätigte ${ }^{229}$. Weitaus häufiger zeigen aber

220 Siehe unten, S. 87-91; Pontal, Conciles capétiens, S. 293; SchiefFer, Päpstliche Legaten, S. 210.

221 Bspw. das Reformkonzil des Papstes Leo IX. von 1049 in Reims, PL 142, col. 1430-1440, oder das Konzil gegen Abaelard in Soissons 1121, PonTAL, Conciles capétiens, S. 320. Einen Eindruck des Ablaufes einer solchen Provinzialsynode vermitteln die Konzilsordines, so z. B. der Ordo Nr. 15 der Edition von Herbert Schneider, siehe Konzilsordines, S. 438 452.

222 Pontal, Conciles capétiens, S. 16f.

223 Siehe Konzilsordines.

224 In der neuen Edition der Urkunden der Bischöfe von Laon, die auf einer Thèse der École des chartes der Editorin beruht, bspw. Nr. 53, Nov. 1100, Actes Laon, S. 126 oder Nr. 72, 1115, in synodo, Actes Laon, S. 147f. (auch Nr. 90, 97, 98).

225 Chartes Arras, S. XXXI.

226 Ibid. S. XXXIII, zu den Verbindungen des Lambert von Arras auch Morelle, , Grégorien<, und Morelle, Pratique épistolaire.

227 Chartes Arras, S. XXXIVf.

228 Ibid. Nr. 1, 2-6, 8, Urkunden von 1097-98.

229 Ibid. Nr. 7: Ut autem hoc nostrum constitutum omni tempore inviolatum permaneat, in presentia totius nostre sinodi confirmamus et horum fratrum nostrorum testimonio et auctoritate roboramus. 
die Urkunden, daß der Klerus zur Teilnahme an den Synoden gezwungen werden mußte ${ }^{230}$. Es zeigt sich, daß Diözesansynoden als ein Disziplinierungsinstrument des Bischofs angesehen werden können ${ }^{231}$. Auch die Funktion der Umsetzung von Beschlüssen der allgemeinen und regionalen Konzilien wird am Beispiel Arras deutlich ${ }^{232}$.

Auch für die Diözese Amiens zeigen die Bischofsurkunden, wenn auch weit seltener, daß Diözesansynoden stattfanden ${ }^{233}$. Diese Bischofsurkunden zeugen fast ausschließlich von Gütertransaktionen, beispielsweise von Schenkungen von Altären an Abteien. Sie belegen vor allem die Verwaltung der Diözesen. Der Bischof als eigentlicher Besitzer des Kirchenguts mußte theoretisch jede Handänderung dieses Gutes bestätigen ${ }^{234}$. Zu weiteren Themen, die auf diesen Synoden besprochen wurden, beispielsweise die Umsetzung der Kirchenreform, finden sich in den Urkunden nur äußerst spärliche Hinweise. Annie Dufour kann für die Bischofsurkunden von Laon einzig zwei Präambeln nennen, die Hinweise auf Themen geben, die während der Synoden besprochen wurden, vor allem aber zeigen, daß die Beschlüsse, die auf den Provinzial- und Regionalkonzilien gefaßt wurden, auf der Ebene der lokalen Konzilien wieder verkündet wurden ${ }^{235}$. Josef Avril zeigt aber anhand von Konzilsordines,

230 Die Schenkung von Altären an Abteien oder Stifte inner- und außerhalb der Diözese wurden oft an die Bedingung geknüpft, daß entweder der Abt, die Äbtissin oder der Vorsteher der begünstigten Gemeinschaft oder der Priester des Altars an den Diözesansynoden teilzunehmen hatte. Ibid. Nr. 11, 14, 17-20, 26-29, 37, 38, 47. Die Urkunden zeigen auch, daß zu dieser Gelegenheit die dem Bischof geschuldeten Zinsen und Abgaben eingetrieben wurden. Siehe dazu AvRIL, synode diocésain, S. 315.

231 Siehe dazu allgemein Helmrath, Partikularsynoden und Synodalstatuten, S. $140 \mathrm{f}$.

232 So weist Lambert von Arras bei einer solchen Vorschrift anläßlich der Schenkung eines Altars an Ste-Trinité-du-Mont aus Rouen auf die Bestimmungen des Konzils von Chalcedon, vor allem aber desjenigen von Clermont, das 1095 von Papst Urban II. abgehalten wurde, hin. Chartes Arras, Nr. 18: Et quia de metropoli alienae provinciae, scilicet Rothomagensi, et vos et monasterium vestrum estis, constituendo constituimus, sicut in Chalcedonensi concilio legitur confirmatum et in Claromontensi concilio a dignae memoriae venerabili papa Urbano II. est renovatum, quatenus monachus ille quem apud Ambrisnam priorem esse volueritis mihi futurisque ecclesiae Atrebatensis pontificibus quantum ad nostram diocesim pertinet obedientiam canonicam ei promittat et exhibeat.

233 Actes Amiens, Nr. 49: 1114, 17. April, Amiens: Gottfried von Amiens bestätigt auf Anfrage der Archidiakone Fulco und Ingelrann, des Dekans des Kapitels, des Schatzmeisters Guerinus und des Klerus', der auf der Synode versammelt ist, dem Priorat Lihons den Besitz. Die Urkunde ist nur noch in Abschrift vorhanden in: Luc d'Achéry, Spicilegium, 1. Ed., t. VIII (1668), S. 171, 2. Ed. (1723), S. 464.

${ }^{234}$ Chartes Arras, S. VII.

235 Actes Laon, Nr. 54: Nach dem Konzil von Clermont 1095, das kirchenreformerische Canones verkündet, hatte der Bischof kein Recht mehr auf den Wechsel der Altäre: Emanante autem apostolice sedis sententia de abolitione hujusmodi personarum. Oder auch $\mathrm{Nr} .27,1065$ : Sed secundum institutionem canonicam, per archidiaconorum et decanorum clericorumque nostrorum consilium et convenientiam ut annuatim per vicarios eorum sacerdotes, qui curam animarum susciperent et synodus inde celebrarent, exactionem quam debet ecclesia, id est circadam scilicet solidum unum et dimidium, ad ius ecclesie nostre persolvendo defferrent. 
daß Diözesansynoden neben den juristischen Funktionen auch diejenigen der Unterweisung in doktrinären und moralischen Belangen hatten ${ }^{236}$.

Der Bericht des Ademar von Chabannes von einer Synode in Limoges um die Wende vom 10. zum 11. Jahrhundert beschreibt eine diözesane Kirchenversammlung, die einen Eindruck vom Ablauf einer solchen Synode geben $k_{a n n}{ }^{237}$. An der beschriebenen Versammlung nahmen Priester und Kleriker der Diözese, der Bischof, Äbte, Archidiakone und Archipresbyter teil. Nach der Lektüre eines Textes und der Predigt wurden verschiedene Themen angesprochen: So wurde nach Häresien, Perversionen, Empfang der Sakramente durch Exkommunizierte und Konflikten gefragt. Anschließend wurden Predigten gehalten, Instruktionen über Dogmen erteilt, die Messe zelebriert und der Gesang gepflegt. Dann wurden Vorschriften gemä $\beta$ dem kanonischen Recht und Entscheide des Bischofs wie beispielsweise Exkommunikationen verkündet. Eine wichtige Stelle nahmen an solchen Bischofsversammlungen die Eucharistie und der richtige Umgang mit den Hostien ein, Themen, die für Priester von zentraler Bedeutung waren ${ }^{238}$. Eine wichtige Funktion der Diözesansynoden war die Kontrolle des Kultes in der Diözese, wie die Nachfrage nach Häresien und Mißbräuchen und die Instruktionen über Dogmen zeigen. Diskussionen über Heilige und deren Kult und Festtage, aber auch über Wunder als außergewöhnliche Ereignisse können sehr wohl als Teil der Kontrolle des pastoralen Lebens der Diözese geführt worden sein.

\section{Kultpraxis und Häresie}

Diese Hinweise auf kontrollierende Eingriffe der kirchlichen Autorität in die Kultpraxis führen dazu, die ganze Spannweite der Überwachung von Kulten ins Auge zu fassen. Seit dem Anfang des 11. Jahrhunderts wurden wieder vermehrt kultische Praktiken als häretisch, als nicht konform verurteilt. Für diesen Zusammenhang $z$ wischen anerkanntem und als nicht konform verurteiltem Kult ist gerade die oben genannte Synode von 1025 in Arras aussagekräftig und vielfach kommentiert ${ }^{239}$. Guy Lobrichon schätzt den Text der Akten dieser Synode als authentisch ein, obwohl er nur in einem zisterziensischen Manuskript vom Ende des 12. Jahrhunderts überliefert ist. Er beurteilt dieses Zeugnis weniger als Maßnahme gegen eine reale Dissidenz denn als Versuch

236 AvrIL, Institution synodale, S. 287.

237 Ordo 28, in: Konzilsordines, S. 580-585. Der Ordo ist in einem Autograph des Ademar von Chabannes von ca. 1032 überliefert (Berlin, Phillipps 1664, fol. 123v-124r). Nur in wenigen Teilen, so in den Anfangsbestimmungen und im Schlußabschnitt (Nr. 26), scheint Ademar von anderen Ordines abzuweichen, um aufgrund der Bezugstexte auf die Apostolizität des heiligen Martialis hinzuweisen. Sonst passen die einzelnen Elemente gut zum Zeremoniell anderer Diözesansynoden, S. ibid. S. 115-117.

238 AvrIL, Synode diocésain, S. $308 \mathrm{f}$.

239 LOBRICHON, Culte, rire, triomphe, S. 100-103, mit quellenkritischen Überlegungen. FrassetTo, Reaction, mit vielen Literaturhinweisen; Moore, European Dissent, im speziellen S. 9-18; Srock, Implications, S. 120-139. 
des Bischofs, den orthodoxen Kult in einem Teil seiner Diözese wiederherzustellen, der ihm zu entgleiten drohte ${ }^{240}$. Die Synode wurde als Reaktion auf die Häretiker um Gundulf, die sich in der Diözese aufhielten, abgehalten. Nach der Lehre befragt, die sie befolgten, sollen diese die Anerkennung der Sakramente wie Taufe und Eucharistie verweigert haben ${ }^{241}$. Dies zielt mitten in den Bereich, der von Guibert als durch Autoritäten geregelt definiert wird. Ein großer Problempunkt war gerade die Rolle der Priester als Autoritätspersonen ${ }^{242}$. Als unorthodox beziehungsweise häretisch galt auch die von den Angeklagten vertretene Ansicht, als Heilige könnten wohl Apostel und Märtyrer, nicht aber Bekenner gelten ${ }^{243}$. Im Paragraphen zur Verteidigung der Heiligkeit von Bekennern wird die Aufsichtspflicht des Metropoliten (provincialis episcopus) über Heiligsprechungen formuliert. Die nicht-konforme Ausübung des Heiligenkultes kann, auch wenn dieser gemäß Guibert nicht zum Bereich gehört, der durch Autoritäten geregelt ist, von kirchlichen Autoritätspersonen als häretisch wahrgenommen werden.

Häresie führt zur verstärkten Ausformulierung dessen, was als Orthodoxie zu gelten hat, zu stärker kontrollierendem Zugriff der kirchlichen Autorität. Da Häresien sowohl den durch Autoritäten geregelten Bereich als auch denjenigen, der nicht durch Autoritäten geregelt war, berührten, versuchten die kirchlichen Autoritäten in beiden Bereichen regulierend einzugreifen.

Von dieser Regulierung in beiden Bereichen zeugt wiederum Guibert de Nogent. In den Monodiae ist der Fall der Häretiker aus Soissons, Clement und Evrard von Bucy beschrieben ${ }^{244}$. Um deren abweichende Praktiken zu beurteilen, beruft sich Guibert auf autoritative Texte, in diesem Falle auf Schriften des heiligen Augustinus ${ }^{245}$. Anschließend berichtet Guibert vom Einschreiten der kirchlichen Autorität: Hier griff Lisiard von Soissons, der auch bei der Heiligsprechung des Arnulf von Soissons involviert war, ins Geschehen ein ${ }^{246}$. In einem ersten Schritt wurde der Fall der Häretiker vor dem Bischof behandelt, es wurden Befragungen durchgeführt und eine Wasserprobe als Mittel sakraler Rechtsfindung angeordnet. Gemäß seinem Bericht war Guibert als

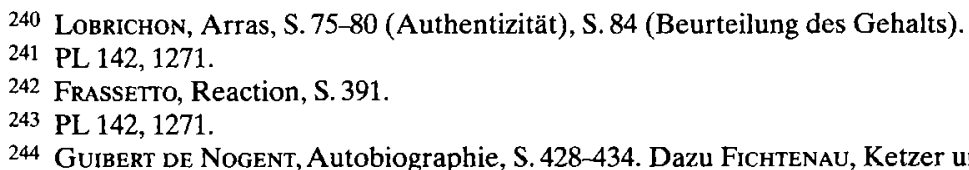

244 Guibert de Nogent, Autobiographie, S. 428-434. Dazu Fichtenau, Ketzer und Professoren, S. 76f. RubEnstein, Guibert of Nogent, S. 115 zeigt die wachsende Aufmerksamkeit Guiberts gegenüber der Häresie und zeigt, daß in Soissons drei Konzile in dieser Richtung stattgefunden haben: 1092 die Verurteilung des Roscelinus, das von Guibert beschriebene Konzil gegen Clement und Evrard von Bucy und 1121 die Verurteilung des Abaelard.

245 Guibert De Nogent, Autobiographic, S. 430: Si relegas haereses ab Augustino digestas, nulli magis quam manicheorum reperies convenire. Zur Häresie und deren Zusammenhang mit Schriftlichkeit: Moore, Literacy, S. 365, dort auch Beispiele von Häresieprozessen, auch S.367. Dort auch seine Bemerkung, daß die Distanz zwischen anerkannt und häretisch nicht so groß ist, wie gemeinhin angenommen, siehe S. 375 .

246 Siehe unten, S. 89. Hier: GuIBERT DE NoGENT, Autobiographie, III, 17, S. 432. 
Abt von Nogent bei der Wasserprobe anwesend. Diese fand in einer ungenannten Kirche, wohl in der Kathedrale, als öffentliche Veranstaltung statt. In einem zweiten Schritt begaben sich der Abt und der Bischof nach Beauvais, um auf einer Synode den Rat der Bischöfe zu erfragen ${ }^{247}$. Der Zugriff der kirchlichen Autorität ist auch hier sowohl auf der Ebene der Diözese als auch auf derjenigen der Kirchenprovinz sichtbar.

\subsubsection{Anerkennung von Heiligenkulten vor dem päpstlichen Kanonisationsverfahren}

Die Kontrolle von Heiligenkulten durch die Bischöfe ist in kirchenrechtlichen Bestimmungen seit spätantiker Zeit ausführlich reguliert. Seit dem Konzil von Karthago im Jahr 401 war kirchenrechtlich festgelegt, daß die Entscheidungsgewalt über die Verehrung von Heiligen beim Bischof liege, dieser also die Autorität zur Kontrolle der Kulte in seiner Diözese inne habe. In der Literatur zum päpstlichen Kanonisationsverfahren wird die Anerkennung von Heiligenkulten in der Zeit vor der Monopolisierung des Heiligsprechungsverfahrens durch das Papsttum relativ einheitlich beschrieben. Der spontanen Verehrung von Heiligen im Volk folgt die Anerkennung des Kultes durch die lokalen kirchlichen Autoritäten mittels einer translatio oder elevatio. Den Bischöfen wurde weniger eine aktive Rolle zugestanden als vielmehr die Funktion der nachträglichen Anerkennung von Kulten ${ }^{248}$. Die normativen Texte der Karolingerzeit zeugen ab dem 8. Jahrhundert von verstärkter Anstrengung zur Kultregelung durch die Bischöfe ${ }^{249}$.

Im 10. und 11. Jahrhundert erhielten diese Anstrengungen in Gallien durch die Erhebung neuer Heiliger und den Zustrom neuer Reliquien hohe Aktualität. $\mathrm{Da} ß$ die älteren Bestimmungen, die den Heiligenkult betreffen, noch präsent waren, zeigen die kirchenrechtlichen Sammlungen: Sowohl im Dekret des Burchard von Worms von 1012 wie auch in den Sammlungen des Ivo von

247 Ibid. III, 17, S. 434: Interea perreximus ad Belvacense concilium, consulturi episcopos, quid facto opus esset.

248 So bei Klauser, Heiligsprechungsverfahren, S. 86-88 oder KutTNER, Réserve papale, S. $173 \mathrm{f}$.

249 KLAUSER, Heiligsprechungsverfahren, S. 88: So die Admonitio generalis 789, can. 42, ed. v. Georg Heinrich Pertz, MGH Capit. I, Hannover 1835, S. 56: Episcopis. Item in eodem, ut falsa nomina martyrum et incertae sanctorum memoriae non venerentur, die Frankfurter Synode 794, can. 42, ed. ibid. S. 77: Ut nulli novi sancti colantur aut invocentur, nec memoria eorum per vias erigantur; sed hii soli in ecclesia venerandi sint qui ex auctoritate passionum aut vitae merito electi sint und das Kapitular von Diedenhofen 805, can. 17, ed. ibid. S. 125: De ecclesiis seu sanctis noviter sine auctoritate inventis, nisi episcopo probante minime venerentur: salva etiam de hoc et de omnibus ecclesiis canonica auctoritate. Auch der can. 51 des Konzils von Mainz 813, ed. Albert Werminghoff, MGH Conc. II, Hannover 1906-1908, S. 272: Deinceps vero corpora sanctorum de loco ad locum nullus transferre praesumat, sine consilio principis, vel episcoporum sanctaeque synodi licentia zielt in diese Richtung. Siehe HermanN-Mascard, Reliques des saints, S. 84. 
Chartres, des Anselm von Lucca und auch im Decretum Gratiani erscheinen die Bestimmungen des Konzils von Karthago und der Kanon 51 des Konzils von Mainz von $813^{250}$. Für die Kirchenprovinz Reims sind vor allem die Sammlungen des Ivo von Chartres zu beachten, da dieser auf vielen Regionalkonzilien eine wichtige Rolle spielte ${ }^{251}$. Auch in England sind nach der normannischen Eroberung Anstrengungen zur Regulierung des Heiligenkultes angelsächsischer Heiliger zu beobachten. Dazu zählt das schon mehrfach erwähnte Beispiel der Diskussionen über den Märtyrertod des Ælfegus durch Lanfranc und Anselm, aber auch die Synode von Westminster von 1102, die ebenfalls von Anselm einberufen wurde. Ein Dekret dieser Synode verkündete in traditioneller Weise, daß niemand Körper von Toten oder Quellen ohne bischöfliche Erlaubnis verehren solle 252 . William von Malmesbury berichtet von Warin, Abt des Klosters Malmesbury, der an Lanfranc als Erzbischof gelangte, um den Confessor Aldhelm als Heiligen bestätigen zu lassen. Dieser soll die Wunder anerkannt haben und verkündet haben, daß Aldhelm verehrt werden soll253.

In diese Zeit fallen auch die ersten päpstlichen Kanonisationen, als erste diejenige des Ulrich von Augsburg durch Johannes XV. im Jahre 993254. In der Folge wird die päpstliche Kurie immer häufiger um die Anerkennung von Heiligen angegangen ${ }^{255}$. Kuttner beschreibt den Gegensatz zwischen bischöflicher und päpstlicher Anerkennung als Gegensatz zwischen lokalem und universalem Kult ${ }^{256}$.

Den Darstellungen der Heiligsprechungen des 10. bis 12. Jahrhunderts bei Kemp, Kuttner und Klauser ist gemeinsam, daß sie aus kirchenrechtlicher Perspektive argumentieren und die Heiligsprechungen auf Bischofsversammlungen als Vorstufe des päpstlichen Kanonisationsprozesses beschreiben. Hermann-Mascard schenkt der Zeit vor dem päpstlichen Kanonisationsprozeß mehr Aufmerksamkeit257.

250 Hermann-Mascard, Reliques des saints, S. 88; Kemp, Canonization and Authority, S. 42.

251 Ivo von Chartres, Decretum und Panormia. Decretum, III, 57, 58, PL 161, Sp. 209f.; III, 270, PL 161, Sp. 260; III, 273, PL 161, Sp. 261; Panormia, II, 28, PL 161, Sp. 1087f.; II, 34, 36, PL 161, Sp. 1090. Zur Überlieferung siehe KéRY, Canonical Collections, S. 250-260 mit Literaturhinweisen.

252 William of Malmesbury, Gesta Pontificum, I, 64, S. 120. Diese Bestimmung wird sowohl von Foreville, Canterbury, S. 64 als auch von KemP, Canonization and Authority, S. 53 als indirekter Versuch interpretiert, die Verehrung von Helden angelsächsischen Widerstands zu unterbinden. HermanN-MasCarD, Reliques des saints, S. 88, welche die Synode aus MAnsI, Sacrorum conciliorum, Bd. XX, Sp. 1152 zu London zitiert, stellt sie in Zusammenhang zu Konflikten zwischen der Volksverehrung, den Ambitionen lokaler Gewalten und der Durchsetzung bischöflicher Autorität. Siehe zur Situation in England oben, S. 39f.

253 Rubenstein, Liturgy, S. 296.

254 KLAUSER, Heiligsprechungsverfahren, S. 90-94.

255 Darstellung der Fälle bei Kemp, Canonization and Authority, S. 56-81.

256 KuTTNer, Réserve papale, S. 175.

257 Siehe zum Heiligsprechungsverfahren auf Diözesanebene auch den Fall des hl. Otmar von Sankt Gallen aus dem 9. Jahrhundert (MGH SS II, S. 48-50) oder den Fall des Anselm 
Im päpstlichen Kanonisationsprozeß spielen die Wunder eines Heiligen eine große Rolle für dessen Anerkennung. Zeugenaussagen über diese Wunder werden festgehalten und auf Widersprüche überprüft ${ }^{258}$. Diese wichtige Funktion von bezeugten Wundern für die Anerkennung von Heiligen zeigt sich schon in frühen Fällen päpstlicher Kanonisation um die Wende vom 11. zum 12. Jahrhundert. In der Bulle Urbans II. für Guorlescius von Quimperlé 1088/99 wird betont, daß der Ort der Anerkennung dieser Wunder die Plenarsynode ist ${ }^{259}$. Auch für die Anerkennung der Heiligkeit des Hugo, Abt von Cluny von 1049-1109, durch Papst Calixt II. im Jahr 1120 spielen bezeugte Wunder eine entscheidende Rolle. Ein Brief des Mönches Hugo an den Abt Pons von Cluny berichtet über diese Anerkennung. Daß Calixt II. für die Bezeugung von Wundern die Augenzeugen höher gewichtete als eine ungewiße schriftliche Tradition, mag mit seiner Nähe zu Cluny zusammenhängen ${ }^{260}$. Der Brief zeigt aber auch, daß dem Papst sowohl Augenzeugen als auch schriftliche Belege für die Wunder präsentiert wurden ${ }^{261}$. Die Bedeutung der Wunder in den frühen päpstlichen Heiligsprechungen kann daher als sehr hoch eingeschätzt werden.

\section{Der Fall des Arnulf von Soissons}

Die Synode von Beauvais vom 17. Oktober 1120 ist ein gut belegtes Beispiel einer institutionalisierten Heiligsprechung auf einer Regionalsynode, die während Guiberts Amtszeit als Abt in Nogent vorgenommen wurde. Anzunehmen ist, daß Guibert, der gute Beziehungen zu seiner Nachbardiözese hatte,

von Canterbury 1163, in dem die Geistlichen der Kirchenprovinz, diesmal mit päpstlicher Autorisation, über Kanonisation entscheiden soliten. PeTERSON, Kanonisationsdelegationen, S. 177. Dazu auch Hermann-MasCard, Reliques des saints, S. 74-105.

258 Siehe beispielsweise den bei VAUCHEZ, Sainteté, S. 563-565 genannten Kanonisationsprozeß des Heiligen Ludwig, wo die Kommentare der Kardinäle verzeichnet sind.

259 Non enim Sanctorum quisque debet canonibus admisceri, nisi testes adsint, qui eius visa miracula suis oculis attestentur et plenarie synodi communi firmetur assensu. AASS Aug. V, S. 274, aus Mabillon AASS OSB sec. VI, nach einem Fragment eines Briefs des Urban II. Dazu Klauser, Heiligsprechungsverfahren, S. 93f. Gemäß HinschuUs, Kirchenrecht, Bd. 3, S. 327f. ist die Plenarsynode zwischen den allgemeinen Konzilien und der Provinzialsynode anzusiedeln. Foreville, Canterbury, S. 65 diskutiert die Bedeutung des Ausdrucks plenarie synodus für die Rolle des Papsttums bei der Heiligsprechung.

260 Guido von Vienne war 1119 in Cluny zum Papst Calixt II. geweiht worden und weilte Anfang 1120 wieder dort, bevor er nach Italien zurückkehrte und inthronisiert wurde.

261 Qui dum inter caetera saepius ageret de vita et miraculis B. Hugonis, non quorumlibet chartulas super his profusius exaratas attendit, sed personas authenticas in medio Cluniacensis capituli praesentatas, de Sancto quae viderant et audierant validius attestatas, gratanter accepit. Episcopis vero et cardinalibus pariter assentientibus, ad laudem et gloriam Domini nostri Jesu Christi natalem tanti Confessoris, tot et tantis virtutibus approbati, festivum fieri Papa decrevit. Diese Passage aus AASS Oct. VII, S. 1125. Siehe dazu Barlow, Hugh I, S. 299-301. Zu Hugo von Cluny siehe BHL 4011. Verzeichnis der Editionen bei BarLow, Hugh I, S. 302. KLAuSER, Heiligsprechungsverfahren, S. 93f. bezeichnet diesen Brief zu Unrecht als Kanonisationsurkunde. 
von dieser Heiligsprechung Kenntnis hatte. Arnulf von Soissons kann im Gegensatz zu Petrus von Grenoble als erfolgreicher Rekluse bezeichnet werden, der dank seiner Herkunft und seiner institutionellen Verankerung die besten Voraussetzungen zur Heiligsprechung hatte. Neben der Vita des Arnulf, in welcher die Vorgänge auf der Synode beschrieben werden, zeigen drei vorangestellte Briefe die Umstände der Heiligsprechung262: Arnulf von Soissons entstammte einer flandrischen Adelsfamilie. Er trat in die klösterliche Gemeinschaft von Saint-Médard de Soissons ein, lebte dort als Rekluse und wurde dann zum Abt des Klosters Saint-Médard gewählt. Nachdem seine Reformpläne scheiterten und er auch König Philipp I. nicht Folge leistete, wurde er abgesetzt. Er zog sich erneut als Rekluse zurück. Während dieser Zeit wurde er wiederholt um Rat angegangen und schuf sich so den Ruf der Heiligkeit ${ }^{263}$. Auf dem Konzil von Meaux 1081, geleitet von den Legaten Hugo von Die und Amatus von Oloron, wurde Arnulf anstelle des abgesetzten Ursio als Bischof von Soissons eingesetzt ${ }^{264}$. Er konnte allerdings in Soissons sein Amt nicht antreten, da er von seinem Vorgänger und dessen Leuten daran gehindert wurde. So wurde er von Papst Gregor VII. nach Flandern geschickt. Dort gründete Arnulf 1084 die Abtei Oudenburg in der Diözese Tournai, verzichtete auf sein Episkopat und starb 1087. Die Mönche von Saint-Médard versuchten anschließend, Reliquien des schon im Rufe der Heiligkeit stehenden Reklusen zu bekommen, was ihnen aber gemäß der Vita nicht gelang 265 .

1114 verfaßte Hariulf, seit 1105 Abt von Oudenburg, eine Vita des heiligen Arnulf, wie Kemp vermutet, schon im Hinblick auf die Anerkennung des Heiligen ${ }^{266}$. Diese Vita bestand in einer ersten Fassung nur aus einem Buch ${ }^{267}$. In der zweiten Fassung war der Inhalt der ersten Fassung in zwei Bücher unterteilt, später wurde ein drittes hinzugefügt. Dieses berichtet von den Wundern nach Arnulfs Tod, von den Ereignissen auf der Synode von Beauvais und von der elevatio des Heiligen ${ }^{268}$. Der Vita vorangestellt sind drei Briefe Hariulfs, der eine an Lambert von Tournai/Noyon als Vorsteher der Diözese, in der

262 MGH SS XV, S. 875-877, 902 (Kap. 15: Konzil von Beauvais). Daß der Fall des heiligen Arnulf von speziellem Interesse für die Kanonisation auf Diözesanebene ist, hat schon KEMP, Canonization and Authority bemerkt, der auf S. 71-74 die Ereignisse zusammenfaßt. Dieses Konzil erwähnt auch Clarius von Sens ad. a. 1120, ed. in: Chronique de SaintPierre-le-Vif de Sens, S. 184, 188, der die Prälaten von Rouen, Sens und Reims als Teilnehmer erwähnt, ohne jedoch zu präzisieren, was auf dieser Versammlung verhandelt wurde.

263 Saint-Médard, S. $145 f$.

264 Pontal, Conciles capétiens, S. 186.

265 Saint-Médard, S. 146.

266 KeMP, Canonization and Authority, S. $71 \mathrm{f}$.

267 Hariulfus Aldenburgensis, Vita Arnulfi, S. 872.

268 Es ist unklar, ob das ganze dritte Buch nach der elevatio verfaßt wurde oder aber die Kapitel 1-14, die von Wundern vor der Synode von 1120 handeln, schon 1119, nach dem Konzil von Reims, in Hinblick auf Anerkennung am Konzil von 1120 zu den ersten zwei Büchern hinzugefügt wurden. Siehe dazu Hariulfus AldenBurgensis, Vita Arnulfi, S. 873, Anm. 12. 
Oudenburg lag, der zweite an Lisiard von Soissons als Nachfolger Arnulfs als Bischof und der dritte an Erzbischof Radulf von Reims als Metropoliten. Der Brief an Erzbischof Radulf ist auch mit Bischof Lisiard als Absender als praefatio der Vita vorangestellt ${ }^{269}$.

Im ersten Brief an Lambert von Tournai/Noyon bat Hariulf die bischöfliche Autorität um Anerkennung des schriftlichen Berichts von Leben und Wunder des Heiligen, damit er zum Nutzen der Kirche verwendet werden könne, indem er gelesen, bekanntgemacht und nachgeahmt werde ${ }^{270}$. Im gleichen Brief bat Hariulf seinen Bischof Lambert, das Werk an Lisiard von Soissons zu schicken, damit er es dem erzbischöflichen Stuhl in Reims unterbreite ${ }^{271}$.

Im zweiten Brief an Lisiard von Soissons wurden die Gründe dargelegt, wieso Hariulf sich an ihn wandte. Genannt wurden dessen eigene Kenntnis seines Vorgängers und dessen Verpflichtung, die Taten des Heiligen zu bezeu-

269 Die Briefe sind handschriftlich nicht mehr faßbar. Oswald Holder-Egger kopierte sie von Mabillon, AA SS OSB, saec. VI, II, S. 502, der sie einem Codex aus Ourscamp entnommen hatte und sie vor seine Edition der zweiten Fassung der Vita einfügte. Siehe Hariulfus Aldenburgensis, Vita Arnulfi, S. 874. Dieser Codex ist verloren, der Autor der Fortsetzung der Chronik des Sigebert von Gembloux aus Ourscamp hat ihn aber für seine Chronik benutzt. Siehe MGH SS VI, ed. Georg Heinrich Pertz, Hannover 1844, S. 471. Die Edition von Mabillon kopiert ebenfalls Migne, PL 174, col. 1371-1376. Die Handschrift der ersten Version der Vita, die Surius für seine Edition (Historia Sanctorum, 15. Aug. IV, S. 689-713) verwendete, ist verloren. Surius kopierte aber nur den Brief des Lisiard von Soissons an Radulf von Reims. Hariulfus Aldendurgensis, Vita Arnulfi, S. 874 f. Mabillon erwähnt in den Vorbemerkungen in PL 174, col. 1367f weitere Handschriften, die einzig den Brief des Lisiard von Soissons überliefern, ohne sie allerdings genauer zu zitieren. Das Fehlen der drei Briefe Hariulfs in einem Teil der Handschriften und Editionen und auch einige Hinweise im Text waren ein Grund, die Vita Lisiard von Soissons zuzuschreiben. Dazu Hariulfus Aldenburgensis, Vita Arnulfi, S. 873. Der andere Grund war, daß Lisiard von Soissons dem ersten Teil der Vita den Bericht der Kanonisation, der translatio und einiger Wunder mit einem separaten Brief an Radulf von Reims anfügte.

270 Hariulfus Aldenburgensis, Vita Arnulfi, S. 875. [...] tibi, o presul venerande, o pater hilarissime Lamberte, presentis opusculi offero xenium, tibi ceu fido pastori ingenioli mei fructigenum committo vellusculum, ut vestra pontificalis auctoritas det robur et fiduciam his ad utilitatem sanctae aecclesiae legendis, cognoscendis et imitandis [...]. „[...] Dir, o verehrenswürdiger Bischof, o erlauchter Vater Lambert, bringe ich das vorliegende Werk zum Geschenk, Dir als Beschützer meines bescheidenen Talentes übergebe ich das kleine, Früchte hervorbringende Pergament (metonym. Gebrauch von vellus für den Beschreibstoff, siehe als Vergleich den Gebrauch von pellis, pilus in Prolog. in liber regum, Vulgata ed. Fischer, Weber 21975, S. 365) damit Eure bischöfliche Autorität dem Kraft und Vertrauenswürdigkeit gebe, damit es zum Nutzen der heiligen Kirche gelesen, dem Sinn nach erfaßt und in die Tat umgesetzt werde."

271 Hariulfus Aldenburgensis, Vita Arnulfi, S. 875. Quod (opusculum) dum clementi iudicio duxeritis laude dignum, obsecramus, ut domino nostro, fratri et coepiscopo vestro Lisardo Suessonico antistiti prorogare non pigretimini, quatenus vestro et illius officio nobilibus arcis Remorum visibus propagetur. "Wenn Ihr es (das Werk) in mildem Urteil des Lobes würdig haltet, bitten wir Euch, daß Ihr nicht versäumt, es unserem Herren, Eurem Bruder und Mitbischof Lisiard, dem Bischof von Soissons, weiterzuschicken, damit es in Eurem und seinem Auftrag vor den vornehmen Blicken der Stadt der Remenser ausgebreitet werde.* 
gen $^{272}$. Darauf folgte die Bitte, sich gemeinsam mit dem Bischof von Tournai/ Noyon an den Metropoliten, Radulf von Reims zu wenden.

Der bischöflichen Versammlung 1120 in Beauvais scheint am Konzil von Reims, im Jahre 1119 durch Papst Calixt II. einberufen, eine Absprache in der Sache Arnulfs von Soissons vorangegangen zu sein. Der Bischof von Tournai/ Noyon, Lambert, setzte sich dafür ein, daß eine translatio des Körpers des heiligen Arnulf bestätigt werde. $\mathrm{Zu}$ diesem Zweck führte er verschiedene Zeugen an, die zum Teil persönlich anwesend waren. Gemäß dem Prolog soll Radulf der Beglaubigung der Heiligkeit durch bezeugte Wunder die eigene Erfahrung und Augenzeugenschaft von Wundern entgegengesetzt haben 273.

Auf dem Konzil wurde dann das Wunderbuch vorgelegt, und während die Bischöfe erörterten, ob dieses denn nötig sei, um den Heiligen zu erheben, lasen einige magistri scholarum das Buch schnell durch (cursim perlegerunt) und räumten dann die letzten Zweifel aus. Darauf setzte Lambert von Noyon und Tournai den Tag der elevatio fest ${ }^{274}$. Die elevatio war in diesem Fall also nicht der Ausgangspunkt, sondern die Folge der Anerkennung der miracula in vita und derjenigen post mortem des Heiligen ${ }^{275}$. Auch in diesem Fall war sowohl das schriftliche Wunderbuch als auch die Nennung von Zeugen für die Anerkennung der Heiligkeit wichtig. Es zeigt sich aber auch, daß über die Vorgehensweise der Authentifizierung von Heiligen keine Einigkeit herrschte ${ }^{276}$. Der Ausspruch des Joffredus von Chartres, diesem vermutlich aus stilistischen Gründen in den Mund gelegt, sollte zeigen, daß an der Heiligkeit des Arnulf nicht ernsthaft gezweifelt wurde. Er ist aber auch Ausdruck, daß die Anerkennung von Heiligen auf verschiedenen Ebenen vorgenommen werden konnten:

Domne Tornacensis, dico vobis in veritate: Si Dominus talia vel semel fecisset circa aliquem predecessorem meorum, ego nec papam nec legatum nec vel archiepiscopum consulerem, sed tota constantia sanctum Dei, ut dignus est, exaltarem ${ }^{277}$.

272 Ibid. S. 875: [...] bina nos congruae rationis causa permovit. Una quidem, quia presentis negotii noticia vos non modica fulcit, vitae scilicet et virtutis meritorum domini nostri, predecessoris vestri, Arnulfi episcopi; altera vero, quia, etsi vobis numquam notus fuisset, tamen quia illum Deus mirabilem cultu iusticiae fecit, quicquid de illo sanctum autenticumque potest dici vel describi, vestro debet testimonio roborari. $» Z$ Wei Gründe ähnlicher Art haben uns dazu veranlaßt: Der eine ist der, daß Euch eine nicht unbedeutende Kenntnis von diesem Gegenstand, das heißt: des Lebens und der Tugenden und Verdienste unseres Herren, Eures Vorgängers, des Bischofs Arnulf, zu Gebote steht; der andere, daß alles, was über ihn Heiligenmäßiges und Verbürgtes gesagt oder geschrieben werden kann, selbst dann wenn er Euch niemals bekannt geworden wäre, dennoch, weil Gott ihn kraft dessen Pflege der Gerechtigkeit verherrlicht hat, durch Euer Zeugnis bestätigt werden muß.«

273 Ibid. S. 254. Dazu KeMP, Canonization and Authority, S. 72.

274 Hariulfus Aldendurgensis, Vita Arnulfi, S. 902.

275 Die translatio oder elevatio war also im 12. Jahrhundert nicht mehr der Ausgangspunkt der posthumen Wunder des Heiligen, wie dies HeinzelmanN, Source de base, S. 246 für die Zeit bis zum 9. Jahrhundert festgestellt hatte.

276 So wurde im Fall der Wunder des heiligen Angilbert der Bischof Gottfried von Amiens ins Kloster gerufen, um die Wunder zu bestätigen, siehe oben, S. 72.

277 Hariulfus Aldenburgensis, Vita Arnulfi, S. 902. 
Im Fall des Arnulf von Soissons handelt es sich um die Heiligsprechung eines Bischofs, Abtes und Reklusen durch Zeitgenossen. Sowohl die Abfassung der Vita wie auch die Bezeugung von Wundern ist weit weniger problematisch als im Fall einer längst verstorbenen und wenig bekannten Person. Parallel dazu kann ein knappes Jahrhundert zuvor die Erhebung des Symeon von Trier erwähnt werden, der auf Betreiben seines Freunds und Bischofs Poppo von Trier 1042 nur sieben Jahre nach seinem Tod von Papst Benedikt IX. heiliggesprochen wurde ${ }^{278}$. Schwieriger war es, mit dem Problem der Heiligkeit längst verstorbener Personen umzugehen. So weigerte sich Guibert, deren Vita zu schreiben ${ }^{279}$. Auch zu diesem Problem sind Beratungen auf Synoden belegt, wie zum Beispiel in Trier, als nach der Auffindung des Leibes des Celsus in Trier (nach 997) erst auf der Synode beraten wurde, was mit diesem Leib geschehen sollte. Die Beratung führte schließlich zur elevatio des Leibes ${ }^{280}$.

Der Fall des Arnulf wurde auf einer Synode der drei Kirchenprovinzen Sens, Rouen und Reims, nach Clarius von Sens einberufen vom päpstlichen Legaten Kuno von Praeneste, verhandelt ${ }^{281}$. Von dieser Synode sind außer der Angelegenheit der Heiligsprechung Arnulfs keine weiteren Geschäfte überliefert. $\mathrm{Da}$ sie auf einer Regionalsynode verhandelt wurde und nicht wie üblich auf der Ebene der Diözese oder aber auf derjenigen des Papsttums, mag mit dem Wirken des Heiligen in Soissons und in Oudenburg zusammenhängen. In der Literatur wird kein anderes Beispiel einer Anerkennung eines Heiligen auf dieser Ebene genannt.

Die Forderung nach Anerkennung von Heiligen durch den Metropoliten, die auf der Synode von Arras 1025 anläßlich der Verurteilung von Häretikern geäußert wurde, scheint keine große Wirkung gehabt zu haben ${ }^{282}$. Ersichtlich

278 Wenz-Haubfleisch, Miracula post mortem, S. 225; Kemp, Canonization and Authority, S. 60 .

279 GuIBERT DE NoGENT, Quo ordine, P, I, Z. 525: Certe cum plures sanctis suis summas antiquitates attribuant, moderno tempore eorum scribi Vitas expostulant. Quod a me profecto sepe petitum est, ego autem in his quae obtutibus subiacent fallor, et de iis, quae nemo unquam viderit, quid veri profiteor? Si dicerem quae dici audivi - et etiam sum rogatus ut super laude horum tam ignobilium dicerem, quin etiam ad populum declamarem - et ego si quesita dicerem, et illi qui talia suggerebant dicere, publico pariter cauterio digni essent. "Außerdem, da viele ihren Heiligen höchstes Alter zuerkennen, fordern sie, daB in der heutigen Zeit ihre Viten geschrieben werden. Dies wurde mir in der Tat oft abverlangt. Aber wenn ich mich schon in Dingen irre, die vor Augen liegen, was kann ich da an Wahrem aussagen über Dinge, die niemand jemals gesehen hat? Wenn ich sagte, was ich vom Hörensagen kannte - und ich wurde auch gefragt, ob ich zum Lob solcher derart Unwürdiger etwas sage, ja sogar dem Volk verkünde - und wenn ich das Erfragte sagte, wären auch jene, die solches vorschlugen zu sagen, ebenso wert, öffentlich an den Pranger gestellt zu werden.«

280 WenZ-HaubfLeISCH, Miracula post mortem, S. 176.

281 Siehe dazu Anm. 262. Zu dieser Synode Schiefrer, Päpstliche Legaten, S. 210.

282 Zur Synode von Arras siehe oben, Anm. 240. Die Synode von Arras wird von Pontal, Conciles capétiens, S. 144 als Diözesansynode beschrieben. Hermann-MaSCARD, Reliques des saints, S. 90-92 kann außer dem Fall des Arnulf keine weiteren Beispiele nennen, die sich auf der Ebene der Kirchenprovinz abspielen. 
wird aber, daß diese Anerkennungen von Heiligen im 11. und 12. Jahrhundert auf allen Ebenen von Kirchenversammlungen thematisiert wurden. Die Konsensfindung darüber konnte auf Diözesanebene verbleiben oder aber auf die Ebene der Kirchenprovinz getragen werden, wenn die Bischöfe auf dieser Ebene oft zusammentrafen oder aber der Fall bistumsübergreifende Dimensionen hatte. Im Laufe des 11. und 12. Jahrhunderts wurden Heiligsprechungen immer mehr auch vor den Papst oder seinen Stellvertreter getragen. Vielfach hing der Ort der Anerkennung von personellen Konstellationen ab. Die Überlegungen von Guibert schreiben sich aber in einen breiteren Diskurs ein, der auf allen Ebenen der kirchlichen Hierarchie geführt wurde. Inwieweit dieser Diskurs in Zusammenhang mit der Kirchenreform gestellt werden kann, wird nicht klar. Das Problem der Beglaubigung von Heiligen durch unwürdige Priester, wie er im Liber Gratissimus des Petrus Damiani thematisiert wird, ist bei Guibert nicht genannt ${ }^{283}$. Auf der Ebene der Kirchenprovinz Reims zeigt sich aber, daß der Klerus sich um die Kontrolle des Kultes bemühte ${ }^{284}$. Diese Kultkontrolle kann zweifellos im Zusammenhang mit dem Bestreben gesehen werden, die Autorität der kirchlichen Hierarchie zu stärken.

283 KEMP, Canonization and Authority, S. 66.

$284 \mathrm{Zu}$ den Personenkreisen, die in die Kultkontrolle involviert waren, und deren Position in bezug auf die Reform siehe Kap. 3.2.1. 


\subsection{Gelehrter und institutioneller Umgang mit dem Wunder}

Guibert de Nogent entwickelt in seinem Reliquientraktat allgemeine Überlegungen zum Reliquienkult und, damit verbunden, zum Wunder. Als Ausgangspunkt der Überlegungen nennt er das Wunderbuch der Mönche von SaintMédard de Soissons und vor allem eine ihrer Reliquien: einen Milchzahn Jesu.

Anhand von Guiberts Argumentationen im Reliquientraktat, aber auch in den anderen Schriften kann gezeigt werden, wie er, ausgehend von der biblischen und historischen Tradition, versucht, das Phänomen Wunder intellektuell zu erfassen. Indem der Abt den christlichen Kult in zwei Bereiche, einen durch Autoritäten geregelten und einen ungeregelten einteilt, stellt er gleichzeitig die Forderung nach der Regulierung des zweiten Bereiches durch die kirchlichen Autoritäten. Gerade der Reliquienkult, der in diesen zweiten Bereich gehört, ist anfällig für Mißbräuche aller Art.

Wichtige Beweismittel von Heiligkeit sind Wunder. Damit diese als Beweise für Heiligkeit herangezogen werden können, muß zwischen wahren und falschen Wundern unterschieden werden können. Dabei kommt autoritativen Texten, die Modelle für Wunder liefern, große Bedeutung zu. Damit versucht Guibert nicht nur schriftlich überlieferte Wunder zu deuten, sondern er versucht auch, diese Schemata auf aktuelle, selbst erlebte oder gehörte Ereignisse anzuwenden, so beispielsweise auf die Skrofelheilung des französischen Königs. Dieses erste, die Konformität zu autoritativen Texten anstrebende Deutungssystem ist jedoch für die Beurteilung von Ereignissen nicht ausreichend, da zu viele Unklarheiten bestehen bleiben. Die Interpretation von Ereignissen, mit denen Guibert in seiner Umgebung konfrontiert ist, erweist sich mit diesem Instrumentarium allein als schwierig. Als Ausweg skizziert er drei Systeme der Beurteilung von Wundern. Zuerst stellt er die Rahmenbedingungen wunderbarer Ereignisse ins Zentrum. Die moralische Disposition der Mittler und auch der Gläubigen erweist sich als wichtiges Kriterium zur Beurteilung eines Wunders. Hinzu kommen zwei weitere Systeme der Anerkennung von Wundern, die eher in der Gemeinschaft verankert sind, in der Wunder als sinnhafte Zeichen gedeutet werden.

Die Anerkennung von Kulten und Wundern durch die kirchlichen Autoritäten, denen die Regulierung dieser Kulte obliegt, kann als zweites System der Anerkennung bezeichnet werden. Diese Forderung wird von Guibert im Reliquientraktat wiederholt gestellt ${ }^{285}$. Sie ist traditionell. Schon bei Augustin wurde Wert gelegt auf autorisierte Wunder ${ }^{286}$. Daß Guibert nicht einfach For-

285 So z. B. in GuIbERT DE Nogent, Quo ordine, Z. 134-137, oder in P, 3, Z. 540-542. Dieses System hatte auch schon GUTH, Kritik, erkannt und zweites hagiographisches Postulat genannt, z.B. auf S. 98.

286 Diese Vorschrift, Wunder zu berichten, findet sich in DCD, 22, 8, S. 558. Dazu Heinzelmann, Funktion, S. 45; Boesch Gajano, Expériences, S. 53-59; Boesch Gajano, Verità e pubblicità. Sie bewirkt nach HeinZelmann, Funktion, S. 45, daß sich die kirchliche Hierarchie des Wunderphänomens annehmen wird. 
derungen aufstellte, sondern diese Überlegungen in Zusammenhang standen mit Diskussionen, der in Kreisen kirchlicher Autoritätspersonen geführt wurde, ist im zweiten Teil des Kapitels gezeigt worden. Bischöfe und Äbte befaßten sich auf vielfache Weise mit der Kontrolle des rechten Kultes. Ein wichtiger Ort des institutionellen Umgangs mit Wundern war die Bischofsversammlung, wo Fragen des Kultes beraten wurden. Auf diesen Bischofsversammlungen wurde über Abweichungen von der Orthodoxie, die als Häresien behandelt wurden, beraten. Diese Abweichungen betrafen oft den von Guibert genannten ersten, durch Schriften geregelten Bereich. Probleme des Heiligen- und Reliquienkults als Teil des zweiten, ungeregelten Bereichs wurden ebenfalls auf Bischofsversammlungen thematisiert, als Versuch der Regulierung von Kulten, als Untersuchung von Unregelmäßigkeiten, kurz als regulierender Zugriff der kirchlichen Autorität auf diesen zweiten Bereich, der nicht durch autoritative Schriften geregelt war. Im Verlauf der Argumentation in Guiberts Reliquientraktat zeigt sich, wie ein konkreter Fall Anlaß zu grundsätzlicher Erörterung geben konnte. Dieses Vorgehen kann auch bei Guiberts Lehrer und einem der bedeutendsten Vertreter der Frühscholastik beobachtet werden. Anselm von Bec/Canterbury rechtfertigte 1079 das Martyrium des Elfegus auf Anfrage Lanfrancs mit einer Analogie zwischen Gerechtigkeit und Wahrheit. Ælfegus wurde in Gefangenschaft umgebracht, da er sein Lösegeld nicht bezahlen wollte, das er von seinen Untertanen hätte eintreiben müssen ${ }^{287}$. Indem Anselm einen Tod aufgrund von Gerechtigkeit (Ælfegus) und Wahrheitsliebe (als Beispiel nennt er Johannes den Täufer) parallel setzt, kann er auf die gerechtfertigte Verehrung des $Æ l f e g u s$ als Märtyrer schließen. Im Traktat De veritate entwickelt Anselm 1086 die Analogie zwischen veritas und rectitudo auf allgemeinerer Ebene, folgt aber dem gleichen Gedankengang wie bei der Rechtfertigung des heiligen Ælfegus, einem Einzelfall288.

Das dritte System der Authentifizierung von Wundererzählungen, die Nennung von Zeugen und die Situierung der Ereignisse durch Raum-, Zeit- und Personenangaben, wird im Reliquientraktat nur am Rande thematisiert. Die Wundererzählungen zeigen aber, daß deren Bezeugung durch Angabe mündlicher oder schriftlicher Belege eine wichtige Rolle spielte. Zeugen der Erzählungen sind sorgfältig genannt. Auch dieses System ist traditionell und vielfach beschrieben worden. Diese drei Systeme der Anerkennung und Einordnung von Wundern ergänzen sich, kollidieren jedoch zuweilen, wenn Wunder mit dem einen System konform gehen, dem andern aber zuwiderlaufen. Guiberts Umgang mit diesem dritten System steht im Zentrum des folgenden Kapitels.

287 EADMER, Vita Sancti Anselmi, S. 52.

288 Anselm von Canterbury, De veritate, Kap. 12; Eadmer, Vita Sancti Anselmi, S. 53, Anm. 1. Dazu ForeviLle, Canterbury, S. 64. 